\title{
LES over RANS in building simulation for outdoor and indoor applications: A foregone conclusion?
}

\author{
Bert Blocken $^{1,2}(\square)$ \\ 1. Department of the Built Environment, Eindhoven University of Technology, P.O. box 513, 5600 MB Eindhoven, the Netherlands \\ 2. Department of Civil Engineering, KU Leuven, Kasteelpark Arenberg 40 - bus 2447, 3001 Leuven, Belgium
}

\begin{abstract}
Large Eddy Simulation (LES) undeniably has the potential to provide more accurate and more reliable results than simulations based on the Reynolds-averaged Navier-Stokes (RANS) approach. However, LES entails a higher simulation complexity and a much higher computational cost. In spite of some claims made in the past decades that LES would render RANS obsolete, RANS remains widely used in both research and engineering practice. This paper attempts to answer the questions why this is the case and whether this is justified, from the viewpoint of building simulation, both for outdoor and indoor applications. First, the governing equations and a brief overview of the history of LES and RANS are presented. Next, relevant highlights from some previous position papers on LES versus RANS are provided. Given their importance, the availability or unavailability of best practice guidelines is outlined. Subsequently, why RANS is still frequently used and whether this is justified or not is illustrated by examples for five application areas in building simulation: pedestrian-level wind comfort, near-field pollutant dispersion, urban thermal environment, natural ventilation of buildings and indoor airflow. It is shown that the answers vary depending on the application area but also depending on other-less obvious-parameters such as the building configuration under study. Finally, a discussion and conclusions including perspectives on the future of LES and RANS in building simulation are provided.
\end{abstract}

\section{Keywords}

computational fluid dynamics (CFD), position paper, urban physics, building physics, fluid mechanics

\section{Article History}

Received: 10 June 2018

Revised: 20 June 2018

Accepted: 21 June 2018

(c) The Author(s) 2018. This article is published with open access at link.Springer.com

\section{Introduction}

CFD can be defined as "the art of replacing the integrals or the partial derivatives (as the case may be) in the Navier-Stokes equations by discretized algebraic forms, which in turn are solved to obtain numbers for the flow field values at discrete points in time and/or space" (Anderson 1995).

The application of CFD in the field of building simulation is particularly challenging. For wind flow around buildings, this can be attributed to the specific difficulties associated with the flow field around bluff bodies with sharp edges, many of which are not encountered in CFD computations for simple flows such as channel flow and simple shear flow (e.g. Ferziger 1990; Leschziner 1990, 1993; Stathopoulos 1997; Murakami 1998). Murakami (1998) meticulously outlined the main difficulties in CFD applied to wind flow around buildings: (1) the high Reynolds numbers in these applications, necessitating high grid resolutions, especially in near-wall regions as well as accurate wall functions; (2) the complex nature of the 3D flow field with impingement, separation and vortex shedding; (3) the numerical difficulties associated with flow at sharp corners and consequences for discretization schemes; and (4) the inflow (and outflow) boundary conditions, which are particularly challenging for LES. These difficulties were directly linked to limitations in physical modeling and in computational requirements at those times, but many of those limitations are still to some extent present today. For indoor airflow, the challenges are represented by (1) the potentially large variations in turbulence levels with can include low-Reynolds effects and relaminarization of the flow; (2) the wide range of spatial scales from the length scale of the room to the details of inlet and outlet openings

E-mail: b.j.e.blocken@tue.nl 
necessitating large numbers of cells and (3) the surface boundary conditions for the energy equation which may inhibit the use of wall functions (Sørensen and Nielsen 2003). Additional challenges can be simultaneous heat flows (e.g. heat conduction through the building enclosure, heat gains from heated objects indoors, solar radiation through the building fenestration), phase changes (e.g. water condensation and evaporation), chemical reactions (e.g. combustion in case of a fire), and mechanical movements (e.g. fans and occupant movements) (Chen and Srebric 2001).

While many CFD approaches exist, a view at the vast literature in building simulation indicates that the two most popular approaches by far are Large Eddy Simulation (LES) and Reynolds-averaged Navier-Stokes simulations (RANS). The use of Unsteady RANS (URANS) in building simulation for stationary (statistically steady) problems is rather limited, although valuable achievements have been reported (e.g. Rossi and Iaccarino 2013; Tominaga 2015; Tominaga and Stathopoulos 2017). URANS is being used frequently though for problems in building simulation that are not stationary, e.g. with time-varying boundary conditions (e.g. Toparlar et al. 2015; Gao et al. 2018). Also the use of hybrid LESURANS approaches in building simulation is rather limited. Hybrid LES-URANS consists of combining LES and URANS for reasons of computational economy, where URANS is applied in the near-wall region and LES outside this region. LES and URANS however are fundamentally different approaches with very different requirements in terms of grid topology. While in relatively simple flows such as channel flow and simple shear flow it is feasible to define a clear boundary between the regions where URANS and LES are applied and hence also the boundary between the two different grid topologies, in the very complex flow fields around buildings or inside buildings characterized by impingement, separation and-for outdoor flows-vortex shedding, this is far from straightforward.

LES and RANS are complementary to other, more traditional methods in building engineering, such as full-scale on-site or laboratory experimentation and reduced-scale laboratory testing. The latter includes atmospheric boundary layer wind tunnel testing (e.g. Penwarden and Wise 1975; Cook 1975; Isyumov and Davenport 1975; Wiren 1975; Castro and Robins 1977; Robins and Castro 1977a,b; Tieleman et al. 1978; Isyumov 1978; Murakami et al. 1979; Britter and Hunt 1979; Beranek and van Koten 1979a,b; Irwin 1981; Huber and Snyder 1982; Stathopoulos 1984; Simiu and Scanlan 1986; Stathopoulos and Storms 1986; Schatzmann et al. 1987; Kawamura et al. 1988; Livesey et al. 1990; Surry 1991; Richards and Hoxey 1992; Kato et al. 1992; Lam 1992; Uematsu et al. 1992; Niemann 1993; Wu and Stathopoulos 1994, 1997; Visser and Cleijne 1994; To and Lam 1995; Sasaki et al. 1997; Meroney et al. 1999; Blocken et al. 2008a;
Salizzoni et al. 2009; Tsang et al. 2012; Conan et al. 2012; Tominaga and Blocken 2015, 2016; Ricci et al. 2017a), water channel measurements (e.g. Princevac 2010; Pournazeri et al. 2012; Cruz-Salas et al. 2014; Neophytou et al. 2014; Karra et al. 2017) or water tank experiments (e.g. Linden et al. 1990, 1999; Hunt and Linden 1999; Bolster and Linden 2007; Livermore and Woods 2007; Yu et al. 2007; Tapsoba et al. 2007; Kang and Lee 2008; Morsing et al. 2008; Chen 2009; Etheridge 2011; Thomas et al. 2011; van Hooff et al. 2012a,b; Partridge and Linden 2013; Khayrullina et al. 2017). Each approach has its specific advantages and disadvantages. The main advantages of CFD are that it can provide detailed information on the relevant flow variables in the whole calculation domain ("whole-flow field data"), under wellcontrolled conditions and without similarity constraints. However, the accuracy and reliability of CFD simulations are of concern and solution verification and validation studies are imperative. This requires high-quality full-scale or reduced-scale measurements, which in turn should satisfy important quality criteria. Therefore, experiments remain indispensable. In addition, the results of LES and RANS simulations can be very sensitive to the many computational parameters that have to be set by the user. For a typical simulation, the user has to select the target variables, the computational geometry, the computational domain, the computational grid, the turbulence model, the boundary conditions, the near-wall treatment, the discretization schemes, the convergence criteria, etc. This raises the need for best practice guidelines for CFD applications, both for LES and RANS.

LES undeniably has the potential to provide more accurate and more reliable results than RANS simulations. However, LES entails a higher simulation complexity and a much higher computational cost. In spite of some claims made in the past decades that LES would render RANS obsolete, RANS remains widely used in both research and engineering practice, in building simulation and beyond. This paper attempts to answer the questions why this is the case and whether this is justified, from the viewpoint of building simulation. Throughout the past decades, many valuable position papers on LES versus RANS have been published. Concerning building simulation for outdoor application, a peak of published position papers was reached about 20 years ago. Now, 20 years later and at the occasion of the $10^{\text {th }}$ birthday of the international journal "Building Simulation", the time seems right to provide a retrospective and an update on the status of LES versus RANS in this field.

At the beginning of this paper, I issue a number of important disclaimers. First, this is a position paper, not a review paper, and no attempt is made to be complete. The building simulation community is a very large and very productive community with many researchers and 
practitioners involved in either LES or RANS simulations, or both. Many have provided very important contributions but in the interest of brevity, only a few can be mentioned and cited in this paper. Several of the application examples in the final stages of this paper will be taken from the author's own work, simply because of the availability of all the data and information about all the specifics of the simulations. The author apologizes to all colleagues whose very valuable work is not explicitly mentioned in this paper. Second, this paper focuses mainly on steady RANS and LES, it only briefly addresses URANS and it does not consider hybrid LES-URANS and other approaches for the reasons mentioned above. Third, this paper focuses only on five application areas: pedestrian-level wind comfort around buildings, near-field pollutant dispersion around buildings, urban thermal environment, natural ventilation of buildings and indoor airflow, although some comments concerning other application areas are provided as well. The reason for this focus is the expertise of the author, which is mainly situated in urban physics and environmental wind engineering and-albeit to a much lesser extent-in indoor airflow. Fourth, as an arbitrary choice, natural ventilation will be addressed as part of the outdoor applications, while evidently it would fit equally well with the indoor applications. Fifth, while building simulation in its widest sense encompasses a very wide range of spatial scales (Fig. 1), this paper only focuses on applications at the meteorological microscale and the building scale.

The paper is structured as follows. Section 2 presents the RANS and LES equations and options for closure. In Section 3, a brief history of RANS and LES is provided. Section 4 provides relevant highlights from some previous position papers on RANS and LES. Given their importance, the availability or unavailability of best practice guidelines is outlined in Section 5. In Section 6, the performance of RANS and LES for the five application areas mentioned above is demonstrated by a series of examples. Finally, Section 7 contains discussion and conclusions including some future perspectives.

\section{Governing equations and closure}

"How can it be that mathematics, being after all a product of human thought independent of experience, is so admirably adapted to the objects of reality?" 1

\subsection{Governing equations}

The governing equations are the conversation of mass (continuity) and Newton's second law. While strictly the term Navier-Stokes (NS) equations only covers Newton's second law, in CFD it is generally used to refer to the entire set of conservation equations. The instantaneous threedimensional NS equations for a confined, incompressible, viscous flow of a Newtonian fluid, in Cartesian co-ordinates and in partial differential equation form are:

$$
\begin{aligned}
& \frac{\partial u_{i}}{\partial x_{i}}=0 \\
& \frac{\partial u_{i}}{\partial t}+\frac{\partial}{\partial x_{j}}\left(u_{i} u_{j}\right)=-\frac{1}{\rho} \frac{\partial p}{\partial x_{i}}+\frac{\partial}{\partial x_{j}}\left(2 v s_{i j}\right)
\end{aligned}
$$

These equations can be supplemented with the energy equation. If it is assumed that the fluid has a constant specific heat, this equation is a convection-diffusion equation for the temperature:

$$
\frac{\partial \theta}{\partial t}+\frac{\partial}{\partial x_{j}}\left(\theta u_{j}\right)=\frac{\partial}{\partial x_{j}}\left(\frac{k}{\rho c_{\mathrm{p}}} \frac{\partial \theta}{\partial x_{j}}\right)
$$

The equation for mass transfer (e.g. vapor or pollutants) has the same form:

$$
\frac{\partial c}{\partial t}+\frac{\partial}{\partial x_{j}}\left(c u_{j}\right)=\frac{\partial}{\partial x_{j}}\left(D \frac{\partial c}{\partial x_{j}}\right)
$$

The vectors $u_{i}$ and $x_{i}$ are instantaneous velocity and

\begin{tabular}{|c|c|c|c|c|c|c|}
\hline Spatial scale & Global & Mesoscale & Microscale & Building & Component & Material/Human \\
\hline Distance & $<6500 \mathrm{~km}$ & $<200 \mathrm{~km}$ & $<2 \mathrm{~km}$ & $<100 m$ & $<10 m$ & $<1 \mathrm{~m}$ \\
\hline Model cat. & NWP & NWP / MMM & CFD & $\mathrm{CFD} / \mathrm{BE}$ & BC-HAM & MSM / HTM \\
\hline
\end{tabular}
position, $p$ is the instantaneous pressure, $\theta$ the instantaneous temperature, $c$ the instantaneous concentration, $t$ the time, $\rho$ the density, $v$ the kinematic molecular viscosity, $c_{\mathrm{p}}$ the

Fig. 1 Schematic representation of the spatial scales relevant to building simulation, including their typical maximum horizontal length scales and associated model categories. NWP $=$ Numerical Weather Prediction; MMM = Mesoscale Meteorological Model; CFD = Computational Fluid Dynamics; BES = Building Energy Simulation; BC-HAM = Building Component - Heat, Air, Moisture transfer; MSM = Material Science Model; HTM = Human Thermophysiology Model

\footnotetext{
${ }^{1}$ Albert Einstein (1879-1955).
} 
specific heat capacity, $k$ the thermal conductivity, $D$ the molecular diffusion coefficient or molecular diffusivity and $s_{i j}$ the strain-rate tensor:

$s_{i j}=\frac{1}{2}\left(\frac{\partial u_{i}}{\partial x_{j}}+\frac{\partial u_{j}}{\partial x_{i}}\right)$

Additional terms can be added to these equations, e.g. the gravitational acceleration term and the buoyancy term. Directly solving the NS equations for the flows in building simulation is generally prohibitively expensive. This is attributed to the fact that these flows are generally characterized by complex geometries and boundary conditions, potentially in combination with high Reynolds numbers. Furthermore, direct numerical simulations (DNS) for engineering problems might also be unnecessary, since often only a limited number of average or integral parameters are required (Ferziger 1990). Therefore, approximate forms of the NS equations are solved. Two main categories employed in building simulations are RANS and LES.

\subsection{Approximate forms of the governing equations}

\subsubsection{Reynolds-averaged Navier-Stokes}

The basis of the RANS equations is the application of the Reynolds decomposition, which consists of expressing the solution variables as they appear in the instantaneous NS equations (Eqs. 1a-e) as the sum of a mean (ensembleaveraged or time-averaged) and a fluctuating component:

$u_{i}=\bar{u}_{i}+u_{i}^{\prime} ; p=\bar{p}+p^{\prime} ; \theta=\bar{\theta}+\theta^{\prime} ; c=\bar{c}+c^{\prime}$

where $\bar{u}_{i}, \bar{p}, \bar{\theta}$ and $\bar{c}$ are the mean and $u_{i}^{\prime}, p^{\prime}$, $\theta^{\prime}$ and $c^{\prime}$ the fluctuating components (around the mean). Inserting Eqs. (2) in Eqs. (1a-e) and taking an ensembleaverage or time-average of the resulting equations yields the RANS equations:

$\frac{\partial \bar{u}_{i}}{\partial x_{i}}=0$

$\frac{\partial \bar{u}_{i}}{\partial t}+\frac{\partial}{\partial x_{j}}\left(\bar{u}_{i} \bar{u}_{j}\right)=-\frac{1}{\rho} \frac{\partial \bar{p}}{\partial x_{i}}+\frac{\partial}{\partial x_{j}}\left(2 v \bar{s}_{i j}\right)-\frac{\partial}{\partial x_{j}}\left(\overline{u_{i}^{\prime} u_{j}^{\prime}}\right)$

$\frac{\partial \bar{\theta}}{\partial t}+\frac{\partial}{\partial x_{j}}\left(\bar{\theta} \bar{u}_{j}\right)=\frac{\partial}{\partial x_{j}}\left(\frac{k}{\rho c_{\mathrm{p}}} \frac{\partial \bar{\theta}}{\partial x_{j}}\right)-\frac{\partial}{\partial x_{j}}\left(\overline{\theta^{\prime} u_{j}^{\prime}}\right)$

$\frac{\partial \bar{c}}{\partial t}+\frac{\partial}{\partial x_{j}}\left(\bar{c} \bar{u}_{j}\right)=\frac{\partial}{\partial x_{j}}\left(D \frac{\partial \bar{c}}{\partial x_{j}}\right)-\frac{\partial}{\partial x_{j}}\left(\overline{c^{\prime} u_{j}^{\prime}}\right)$

$\bar{s}_{i j}=\frac{1}{2}\left(\frac{\partial \bar{u}_{i}}{\partial x_{j}}+\frac{\partial \bar{u}_{j}}{\partial x_{i}}\right)$

where $\overline{s_{i j}}$ is the mean strain-rate tensor. With the RANS equations, only the mean flow is solved while all scales of the turbulence are modeled (i.e. approximated). This is schematically depicted in Fig. 2 . The averaging process generates additional independent unknowns. For the momentum equations, these are called the Reynolds stresses and for the temperature and concentration equations, they are called the turbulent heat and mass fluxes. These stresses and fluxes represent the influence of turbulence on the mean flow and on the mean temperature and mean concentration field, respectively. As a result the RANS equations do not form a closed set. Therefore additional information is required and approximations have to be made to achieve closure. This is performed by means of a turbulence model.

A distinction can be made between first-order closure and second-order closure models. For the Reynolds stresses, first-order closure is performed with the Boussinesq or eddy-viscosity hypothesis. This hypothesis is based on the analogy with momentum transfer by the molecular motion in gasses, which is described by a molecular viscosity. Similarly, the Boussinesq hypothesis relates the Reynolds stresses to the gradients in the mean flow by means of a turbulent or eddy viscosity $v_{\mathrm{t}}$ :

$\overline{-u_{i}^{\prime} u_{j}^{\prime}}=2 v_{\mathrm{t}} \bar{s}_{i j}-\frac{2}{3} k \delta_{i j}$

where $k$ is the turbulent kinetic energy, i.e. the kinetic

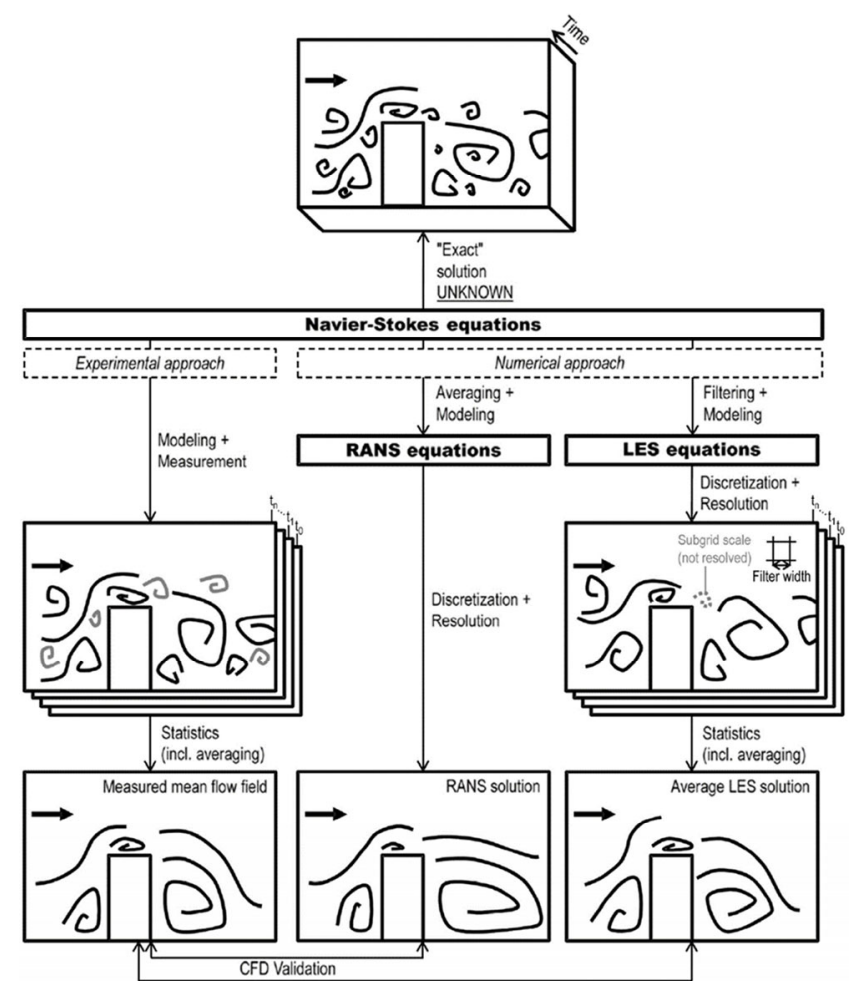

Fig. 2 Schematic representation of flow around a building as captured by experiments, RANS and LES simulations (courtesy of P. Gousseau) 
energy associated with the fluctuations in the flow, and $\delta_{i j}$ is the Kronecker delta:

$k=\frac{1}{2} \overline{u_{i}^{\prime} u_{i}^{\prime}}$

$\delta_{i j}= \begin{cases}1 & \text { for } i=j \\ 0 & \text { for } i \neq j\end{cases}$

As opposed to the laminar or molecular viscosity, the turbulent viscosity is not a property of the fluid but a property of the flow. Turbulence models that are based on the Boussinesq hypothesis are called eddy-viscosity models (EVM). A wide range of EVM turbulence models exist that provide different ways to estimate the turbulent viscosity. Some that are widely used in building simulation are the one-equation Spalart-Allmaras model (Spalart and Allmaras 1992), the standard $k-\varepsilon$ model (Jones and Launder 1972) and its many modified versions, such as the Renormalization Group (RNG) $k-\varepsilon$ model (Yakhot and Orszag 1986) and the realizable $k-\varepsilon$ model (Shih et al. 1995), the standard $k-\omega$ model (Wilcox 2004) and the $k-\omega$ shear stress transport (SST) model (Menter 1997). Second-order closure, also termed second-moment closure or Reynolds stress modeling (RSM), does not employ the Boussinesq hypothesis. Instead, it adopts a more comprehensive approach which consists of computing the Reynolds stresses from their respective transport equations (e.g. Launder et al. 1975). Although RSM is more comprehensive, applications in building simulation have not shown a consistent superior performance of RSM as compared to EVM (e.g. Ferziger 1990; Murakami 1997, 1998; Nielsen et al. 2007). It is generally accepted that no RANS turbulence model is universally valid and verification and validation studies are required to assess the performance of a given turbulence model for a given problem (e.g. Ferziger 1990, 1993; Ferziger and Peric 1996; Shah and Ferziger 1997; Gosman 1999).

Similar to the Boussinesq hypothesis that is based on the analogy with molecular motion, for the temperature and concentration equations, the standard gradient diffusion assumption can be employed. This assumption expresses the turbulent heat flux and the turbulent mass flux as a function of the temperature and concentration gradients in the mean flow by means of a turbulent heat diffusivity $D_{\theta, \mathrm{t}}$ and a turbulent mass diffusivity $D_{c, t}$. These diffusivities are generally related to the turbulent momentum diffusivity by the turbulent Prandtl number $P r_{\mathrm{t}}$ and the turbulent Schmidt number $S c_{t}$, respectively:

$$
\begin{aligned}
& P r_{\mathrm{t}}=\frac{v_{\mathrm{t}}}{D_{\theta, \mathrm{t}}} \\
& S c_{\mathrm{t}}=\frac{v_{\mathrm{t}}}{D_{c, \mathrm{t}}}
\end{aligned}
$$

Like $v_{\mathrm{t}}, D_{\theta, \mathrm{t}}$ and $D_{\mathrm{c}, \mathrm{t}}$ are not properties of the fluid but of the flow. They are generally a function of the type of flow pattern and the location in this flow pattern. The same holds for $P r_{\mathrm{t}}$ and $S c_{\mathrm{t}}$. Nevertheless, often constant values are used for $P r_{\mathrm{t}}$ and $S c_{\mathrm{t}}$ in RANS CFD simulations. This constitutes an important simplification and can give rise to serious errors. Many studies have shown the large impact of the choice of $S \mathcal{C}_{\mathrm{t}}$ on the resulting concentration fields (e.g. Tominaga and Stathopoulos 2007, 2009, 2010, 2013; Gousseau et al. 2011a; Gromke and Blocken 2015; Blocken et al. 2016a; Toja-Silva et al. 2017; Li et al. 2018; Kang et al. 2018). Second-order closure is also possible for the turbulent heat and mass fluxes, but this option is not often used in CFD for building simulation.

\subsubsection{Large Eddy Simulation}

In LES, a distinction is made between the large eddies in the flow that are mainly determined by the geometry of the problem under study and the smaller eddies that tend to be more universal. A filter is applied and scales smaller than the filter size $\Delta$ are removed from the variables. The following notation is used for a filtered variable (denoted by the tilde):

$$
\tilde{\varphi}(x)=\int_{D} \varphi\left(x^{\prime}\right) G\left(x, x^{\prime}\right) \mathrm{d} x^{\prime}
$$

with $D$ the fluid domain and $G$ the filter function determining the scale of the resolved eddies. As a result, the smaller scales are not resolved but their effect on the resolved scales is modeled by means of a turbulence model. This is schematically depicted in Fig. 2. The solution variables can thus be split up into a filtered and a subfiltered component:

$u_{i}=\tilde{u}_{i}+u_{i}^{\prime} ; p=\tilde{p}+p^{\prime} ; \theta=\tilde{\theta}+\theta^{\prime} ; c=\tilde{c}+c^{\prime}$

where $\tilde{u}_{i} \tilde{p}, \tilde{\theta}$ and $\tilde{c}$ represent the resolvable part and $u_{i}^{\prime}$, $p^{\prime}, \theta^{\prime}$ and $c^{\prime}$ the unresolved part. The filtered continuity, momentum equation, temperature and concentration equations are obtained by substituting Eqs. (10) in the instantaneous NS equations and filtering these equations:

$$
\begin{aligned}
& \frac{\partial \tilde{u}_{i}}{\partial x_{i}}=0 \\
& \frac{\partial \tilde{u}_{i}}{\partial t}+\frac{\partial}{\partial x_{j}}\left(\tilde{u}_{i} \tilde{u}_{j}\right)=-\frac{1}{\rho} \frac{\partial \tilde{p}}{\partial x_{i}}+\frac{\partial}{\partial x_{j}}\left(2 v \tilde{s}_{i j}\right)-\frac{\partial \tau_{i j}}{\partial x_{j}} \\
& \frac{\partial \tilde{\theta}}{\partial t}+\frac{\partial}{\partial x_{j}}\left(\tilde{\theta} \tilde{u}_{j}\right)=\frac{\partial}{\partial x_{j}}\left(\frac{k}{\rho c_{\mathrm{p}}} \frac{\partial \tilde{\theta}}{\partial x_{j}}\right)+\frac{\partial q_{\mathrm{t}, i j}}{\partial x_{j}} \\
& \frac{\partial \tilde{c}}{\partial t}+\frac{\partial}{\partial x_{j}}\left(\tilde{c} \tilde{u}_{j}\right)=\frac{\partial}{\partial x_{j}}\left(D \frac{\partial \tilde{c}}{\partial x_{j}}\right)+\frac{\partial q_{c, i j}}{\partial x_{j}}
\end{aligned}
$$

where $\tilde{s}_{i j}$ is the rate of strain tensor. Additional terms appear 
due to the filter operation, i.e. the subgrid-scale Reynolds stresses and the subgrid-scale heat and mass fluxes:

$\tau_{i j}=\widetilde{u_{i} u_{j}}-\tilde{u}_{i} \tilde{u}_{j}$

$q_{\mathrm{t}, i j}=\tilde{\theta} \tilde{u}_{j}-\widetilde{\theta u_{j}}$

$q_{c, i j}=\tilde{c} \tilde{u}_{j}-\widetilde{c u_{j}}$

As in the RANS approach, closure needs to be obtained. As the grid size is often used as the filter, the model used to provide closure is often called a subgrid-scale (SGS) model. SGS models usually adopt the Boussinesq hypothesis:

$\tau_{i j}-\frac{1}{3} \tau_{k k} \delta_{i j}=-2 \mu_{\mathrm{t}} \tilde{s}_{i j}$

with $\mu_{\mathrm{t}}$ the SGS turbulent viscosity. The isotropic part of the SGS stresses $\tau_{k k}$ is not modeled but added to the filtered static pressure term. To obtain $\mu_{\mathrm{t}}$, different SGS models have been devised. The first type of SGS model was developed by Smagorinsky (1963) and is referred to as the Smagorinsky-Lilly SGS model, where the eddy viscosity is modeled as:

$\mu_{\mathrm{t}}=\rho\left(C_{\mathrm{s}} \Delta\right)^{2} \sqrt{2 \tilde{s}_{i j} \tilde{s}_{i j}}$

with $\Delta$ the filter width and $C_{\mathrm{s}}$ the Smagorinsky constant. $C_{\mathrm{s}}$ usually has a value ranging from 0.1 to 0.2 . Afterwards, several other models were developed including the Germano dynamic model (Germano et al. 1991) and its modified version by Lilly (1991).

\section{Brief history of LES and RANS}

"Historia vero testing temporum, lux veritatis, vita memoriae, magistra vitae" 2

\subsection{Early history of RANS}

The concept of the Reynolds decomposition, on which the RANS approach is based, was first proposed by Osborne Reynolds in 1895 (Reynolds 1895). As mentioned in Section 2, application of the Reynolds decomposition and ensemble-averaging or time-averaging of the NS equations yields the RANS equations, in which the instantaneous flow variables have been replaced by the mean flow variables at the expense of adding additional terms to the equations, referred to as Reynolds stresses. These additional terms

\footnotetext{
2 "History is the teacher and witness of times, sheds light upon reality, gives life to recollection and guidance to human existence", from Cicero, De Oratore, II, 36. Marcus Tullius Cicero (106 BC - 43 BC), Roman philosopher, politician, lawyer, orator, political theorist, consul and constitutionalist.
}

render the system of equations unclosed. The first attempt to address this so-called closure problem is attributed to Joseph Valentin Boussinesq (1877). In 1877, he introduced the concept of eddy viscosity and proposed to relate the Reynolds stresses to the gradients in the mean flow; the so-called Boussinesq or eddy-viscosity hypothesis. This hypothesis reduces the turbulence closure problem to calculating the eddy viscosity.

In 1904, when Ludwig Prandtl (Prandtl 1904) introduced the concept of the boundary layer, he additionally devised the concept of the mixing length based on the philosophy that for wall-bounded turbulent flows, the eddy viscosity should vary with distance from the wall. This provided the basis for the Prandtl's one-equation (turbulence) model. Later, many other turbulence models were developed. These can be categorized as linear EVMs, nonlinear EVMs and RSMs. In the linear EVMs, we distinguish between algebraic models, one-equation models such as the Prandtl's oneequation model and the Spalart-Allmaras model, and two-equation models such as the standard $k$ - $\varepsilon$ model, the realizable $k$ - $\varepsilon$ model, the RNG $k-\varepsilon$ model, the $k$ - $\omega$ model and the SST $k-\omega$ model. The adoption of RANS in the field of building simulation will be addressed in subsections 3.3 and 3.5.

\subsection{Early history of LES}

In 1922, long before the first digital computer was introduced, Lewis Fry Richardson (1881-1953) published his book "Weather Prediction by Numerical Process" (Richardson 1922), in which he presented his idea to predict the change of the atmospheric circulation by numerical integration of the NS equations in the rotating frame, the continuity equation and the first law of thermodynamics. With this approach, he attempted to forecast the weather during a single day (20 May 1910) by direct computation using data at a specific time ( $7 \mathrm{AM})$ to calculate the weather six hours later. This was done with nothing more than people performing calculations by hand, aided by slide rules and simple desk calculating machines. It generally took three months to predict the weather for the coming 24 hours. In the last chapter of his book, "The Speed and Organization of Computing", he envisioned the practical organization of this type of forecasting as a "Forecasting Factory", something like a large hall with many "computers", a term he actually used to refer to the people performing the calculations (Fig. 3):

"Imagine a large hall like a theatre, except that the circles and galleries go right round through the space usually occupied by the stage. The walls of this chamber are painted to form a map of the globe. The ceiling represents the north polar regions, England is in the gallery, the tropics in the 
upper circle, Australia on the dress circle and the antarctic in the pit. A myriad computers are at work upon the weather of the part of the map where each sits, but each computer attends only to one equation or part of an equation. The work of each region is coordinated by an official of higher rank. Numerous little 'night signs' display the instantaneous values so that neighboring computers can read them. Each number is thus displayed in three adjacent zones so as to maintain communication to the North and South on the map. From the floor of the pit a tall pillar rises to half the height of the hall. It carries a large pulpit on its top. In this sits the man in charge of the whole theatre; he is surrounded by several assistants and messengers. One of his duties is to maintain a uniform speed of progress in all parts of the globe. In this respect he is like the conductor of an orchestra in which the instruments are slide-rules and calculating machines. But instead of waving a baton he turns abeam of rosy light upon any region that is running ahead of the rest, and a beam of blue light upon those who are behindhand."

He estimated he would need 64,000 people to race "the weather for the whole globe" (Richardson 1922). As stated by Hunt (1998) in his extensive review of Richardson's life, such a hall "would be more like a football stadium"-and actually a rather large one, completely filled with people doing hand calculations.

Although the reviewers of Richardson's book were impressed and seemed to realize the inherent value of this work (Ashford 1985), it also received negative criticism because of the sheer impracticality of the method and the rather catastrophic result of unrealistic pressure rise in the single trial forecast - which later only appeared to be due to insufficiently controlled initial conditions and the failure to apply smoothing techniques to the data to remove unphysical

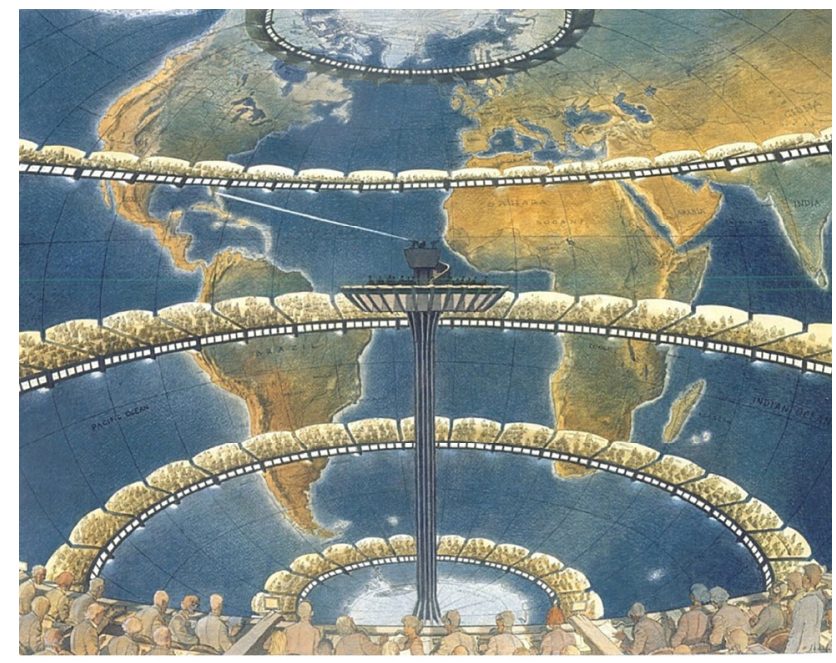

Fig. 3 Artist impression of the Forecast Factory (reproduced with permission ()François Schuiten) surges in pressure. Confronted with the impracticality of his approach, Richardson stated:

"Perhaps some day in the dim future it will be possible to advance the computations faster than the weather advances... But that is a dream."

The intrinsic potential of Richardson's astonishing idea only materialized with the advent of the digital computer. When von Neumann and Charney started to use the electronic digital computer called ENIAC (Electronic Numerical Integrator and Computer; Fig. 4) to calculate the weather, they used equations and methods very close to those described by Richardson in his book. Having obtained the first results of their efforts, Charney sent Richardson a copy of his paper (Charney et al. 1950) describing these results. Richardson replied in writing, congratulating Charney and his team and stating their work was "an enormous scientific advance on the single, and quite wrong result in which the calculations of Richardson (1922) ended" (Ashford 1985). Lynch (2008) states that "since the ENIAC was about five orders of magnitude faster than human computation, the Forecast Factory would have been comparable in processing power to this early machine." Indeed, the first calculations for a 24-hour forecast took about 24 hours on ENIAC (Lynch 2008). As nowadays weather forecasting is done on computers based on algorithms very similar to those by Richardson, one can state that "his dream has come true" (Kimura 2002; Lynch 2008). Since decades, the pioneering work of Richardson is universally recognized as the foundation of modern Numerical Weather Prediction (NWP).

What is now called LES emerged from the early days of NWP by the efforts of Smagorinsky, Lilly, Deardorff and others that followed in Richardson's footsteps (e.g. Smagorinsky 1963; Lilly 1962, 1964; Deardorff 1970a,b,c,d).

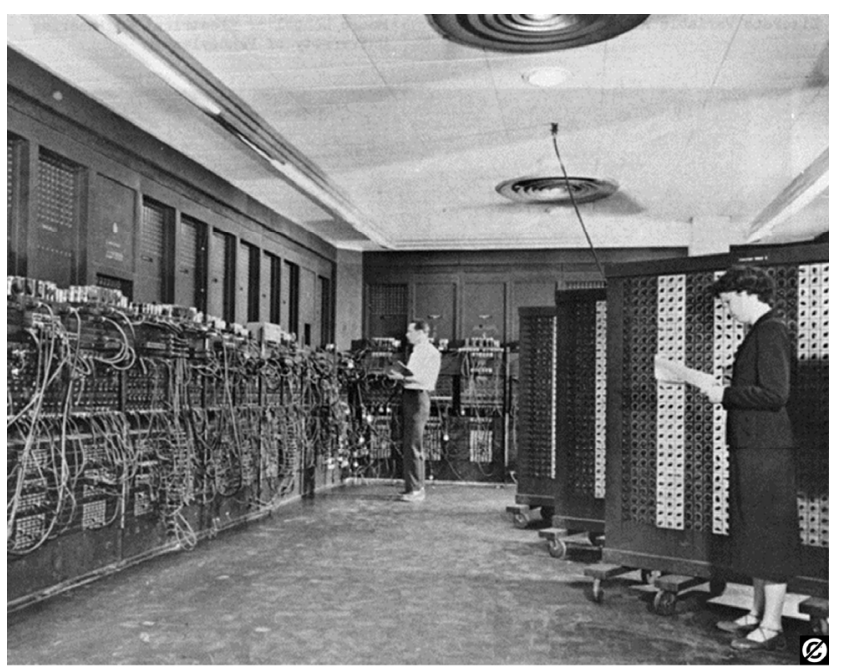

Fig. 4 The Electronic Numerical Integrator and Computer (ENIAC) in building 328 at the Ballistic Research Laboratory (BRL) 
The philosophy of LES also has its roots in Richardson's concepts of eddy structure and eddy diffusion (Richardson $1926,1929)$ and the subsequent development of self-similarity theory by Kolmogorov (1941). This theory implies that the larger eddies in the flow depend to a large extent on the geometry under study while the smaller scales tend to be more universal.

In the 1950s, in the beginning of his career, Smagorinsky worked with Charney and others to solve Charney's simplest equations using the ENIAC computer. In 1953, Smagorinsky was appointed at the U.S. Weather Bureau where in 1955 he became the director of the General Circulation Research Section. His ambition was to proceed to the final step of the von Neumann/Charney computer modeling program: a three-dimensional, global, primitive-equation general circulation model of the atmosphere. Smagorinsky was convinced that the increasing computational power would enable going beyond the simulation of the evolution of the atmosphere for a few days as common in weather forecasting. His ambition was to integrate the equations of motion, thermodynamics and radiative transfer for long enough time periods to simulate not only the weather but its actual statistics, i.e. the climate. In the 1970s, his collaborators provided the first simulations of the impact of increasing $\mathrm{CO}_{2}$ concentrations in the atmosphere on the Earth's climate and they developed the first coupled atmosphere-ocean climate models. These successes laid the foundations for the current awareness and knowledge of global warming.

In his pursuit to extend forecasting past one or two days, Smagorinsky exploited new methods of NWP. In his pioneering paper in 1963 (Smagorinsky 1963), he extended early weather models to include variables such as wind, cloud cover, precipitation, atmospheric pressure and radiation emanating from the earth and sun. This required a method to account for atmospheric turbulence occurring on scales smaller than the model grid size but that are still important in the atmospheric energy cycle. This led to the introduction of one of the first successful approaches to LES, achieved in collaboration with his co-worker Douglas Lilly: the first order subgrid-scale closure called the Smagorinsky-Lilly model. This approach is still being used world-wide and has spread from meteorology to all fields of science and engineering involving fluid dynamics.

Lilly (1962) later employed this technique in 2D simulations of convection. In reviewing the meteorological development of LES, Lilly (2000) attributes the actual development and application of LES to James Deardorff, who initially worked on $2 \mathrm{D}$ direct numerical simulations of buoyant convection. As increasing computational resources became available, Deardorff initiated a series 3D numerical simulations using the Smagorinsky-Lilly eddy-viscosity formulations. In 1970, he published a first simulation of turbulent channel flow in a domain with $24 \times 14$ horizontal and 20 vertical grid points (Deardorff 1970a). Later, he focused on idealized neutral (Deardorff 1970b) and unstable (Deardorff 1970c, 1972) planetary boundary layers. Interestingly and to the best of our knowledge, although Deardorff fundamentally developed Large Eddy Simulation, he never used the term himself. According to Lilly (2000) this term originated in the Stanford-Ames turbulence group in 1973 and was first used in print by Leonard (1974).

Deardorff advocated the combination of LES with laboratory (water tank) experiments and field measurements because of the large potential synergy of these three approaches. This philosophy is strongly reflected in the field of building simulation, where LES and RANS simulations are routinely combined with either field measurements or laboratory tests, or both.

\subsection{RANS in building simulation-outdoor}

The first efforts to evaluate wind flow around buildings with various types of approximations to the NS equations were made in the 1970s. Yamada and Meroney (1972) studied 2D airflow over a square surface-mounted obstacle in a stratified atmosphere, both with CFD and in the wind tunnel. Hirt and Cook (1972) calculated 3D flow around structures and over rough terrain. Frost et al. (1974) numerically analyzed the 2D neutrally stratified wind flow over a semi-elliptical surface obstruction, used to represent an idealized building. These studies provided the basis for the steady RANS investigations that would follow soon after.

Indeed, in outdoor building simulation applications, steady RANS was first employed for the wind flow around generic isolated building configurations, often with a cubical shape, to analyze the mean velocity field and the mean surface pressure (e.g. Vasilic-Melling 1977; Summers et al. 1986; Paterson and Apelt 1986, 1989, 1990; Murakami et al. 1990a, 1992; Murakami and Mochida 1988, 1989; Baskaran and Stathopoulos 1989, 1992; Stathopoulos and Baskaran 1990; Murakami 1990a,b, 1993; Baetke et al. 1990; Fraser et al. 1990; Mochida et al. 1993; Stathopoulos and Zhou 1993) (Fig. 5). A number of these early RANS studies specifically focused on the sensitivity of the results to computational parameters such as the grid resolution (e.g. Murakami and Mochida 1989; Murakami 1990a,b; Fraser et al. 1990; Baskaran and Stathopoulos 1992), the boundary conditions (e.g. Murakami and Mochida 1989; Paterson and Apelt 1990; Baetke et al. 1990; Stathopoulos and Baskaran 1990; Baskaran and Stathopoulos 1992) and the turbulence model (e.g. Baskaran and Stathopoulos 1989; Murakami et al. 1992; Murakami 1993; Mochida et al. 2002). These early parametric studies laid the foundations for the best practice guidelines that would be compiled many years later 


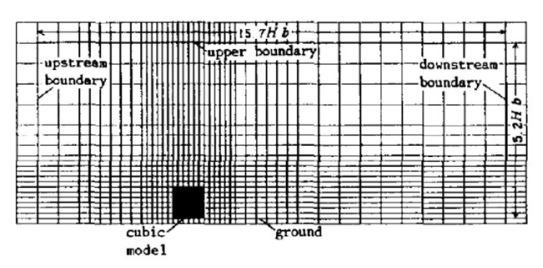

C

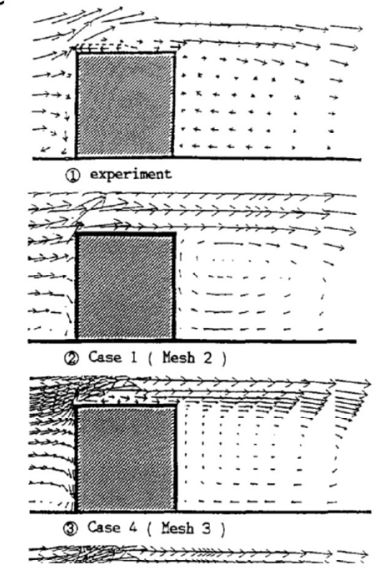

e

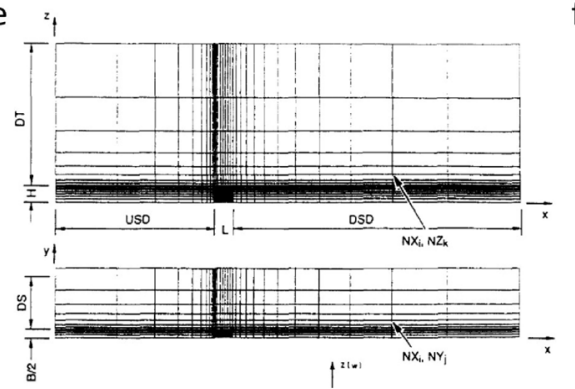

b

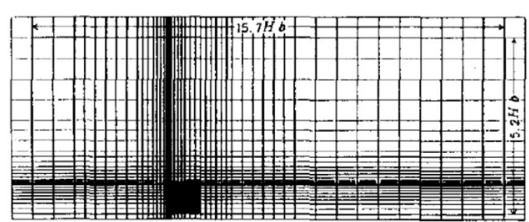

d

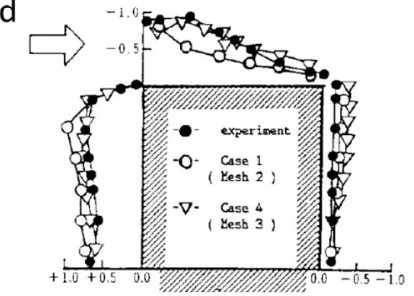

vertical section at center of the mode

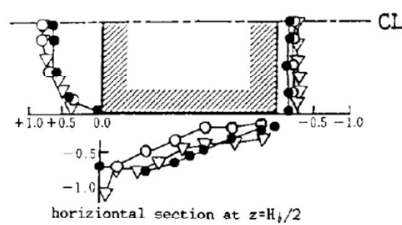

f

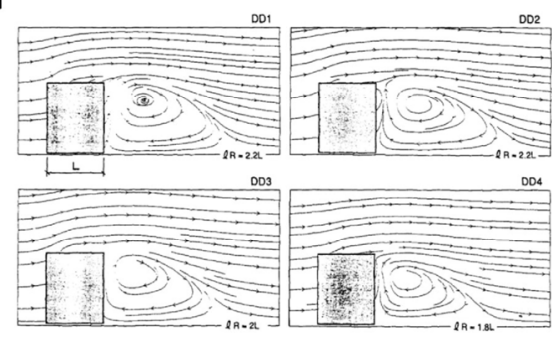

Fig. 5 Early RANS studies for wind flow around an isolated building. (a,b) Two different grid topologies (mesh 2 and mesh 3 ) in vertical centerplane (Murakami and Mochida 1988); (c) velocity vector field and (d) surface pressure coefficient from wind tunnel experiments and as obtained with the two grid topologies (Murakami and Mochida 1988); (e) grid topology in a vertical and a horizontal plane and (f) streamlines as obtained with computational domains of different size (Baskaran and Stathopoulos 1992) (all figures: reproduced with permission (OElsevier)

and are nowadays intensively used in building simulation for outdoor applications.

The studies mentioned above are not all studies that were performed for isolated buildings. But starting from the 1990s, a gradual shift was made to studies for multiple-building configurations, which were supported by the foregoing studies and by the increasing availability of computational power (e.g. Murakami 1990a, 1997, Murakami et al. 1990b, Fraser et al. 1990, Stathopoulos and Baskaran 1996) (Figs. 6a-d). Since that time, more and more case studies-i.e. studies for actual buildings or urban areas-were performed with steady RANS in various application areas such as pedestrian-level wind conditions, wind comfort and wind danger (Figs. 6a-e) (e.g. Murakami and Mochida 1989; Murakami 1990a; Gadilhe et al. 1993; Takakura et al. 1993; Bottema 1993; Stathopoulous and Baskaran 1996; Murakami 1997; Westbury et al. 2002; Richards et al. 2002; Hirsh et al. 2002; Blocken et al. 2004,
2012; Yoshie et al. 2007; Mochida and Lun 2008; Tominaga et al. 2008a; Blocken and Carmeliet 2008; Blocken and Persoon 2009; Janssen et al. 2013; Montazeri et al. 2013; An et al. 2013; Yuan and Ng 2014; Iqbal and Chan 2016; Yasa 2016; Allegrini and Kubilay 2017; Ricci et al. 2017b; Du et al. 2018; Liu et al. 2017; 2018; Dhunny et al. 2018), urban thermal environment (Fig. 6f) (e.g. Ashie and Kono 2011; Tominaga et al. 2015; Toparlar et al. 2015, 2017, 2018; Gromke et al. 2015; Montazeri et al. 2017; Yang et al. 2017; Kang et al. 2017; Gao et al. 2018; Allegrini and Carmeliet 2018), urban ventilation and/or pollutant dispersion (Fig. 6g) (e.g. Hanna et al. 2006; Flaherty et al. 2007; Baik and Park 2009; Lateb et al. 2010, 2011; Gousseau et al. 2011a; Panagiotou et al. 2013; van Hooff and Blocken 2013; Blocken et al. 2016a; Antoniou et al. 2017; Jeanjean et al. 2017; Efthimiou et al. 2017; Juan et al. 2017; Toja-Silva et al. 2017; Garcia-Sánchez et al. 2017; Gao et al. 2018; Peng et al. 2018; Buccolieri et al. 2018) 


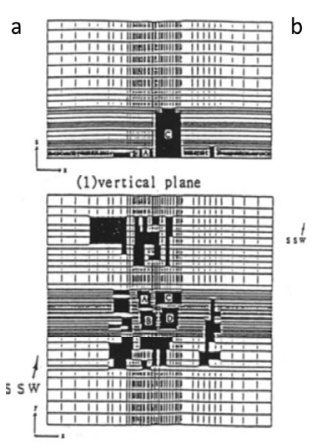

(2)horizontal plane

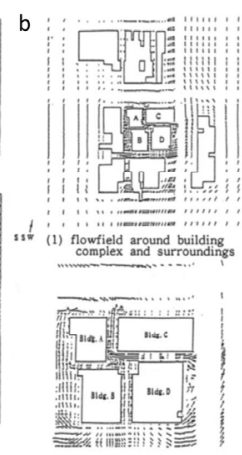

ist (2) flowfield near the bulding complex
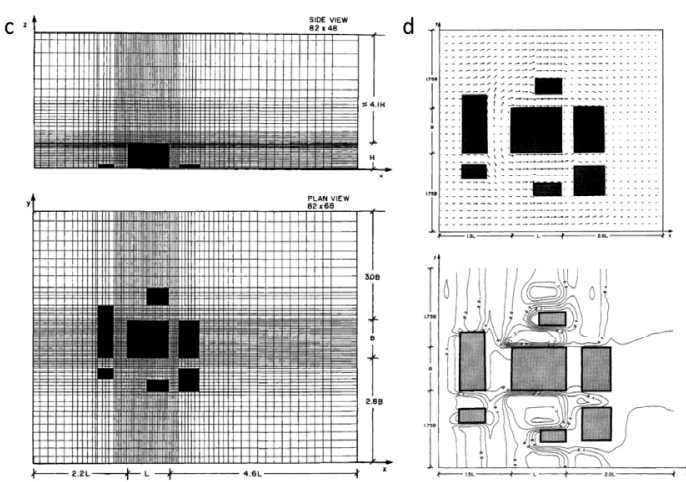
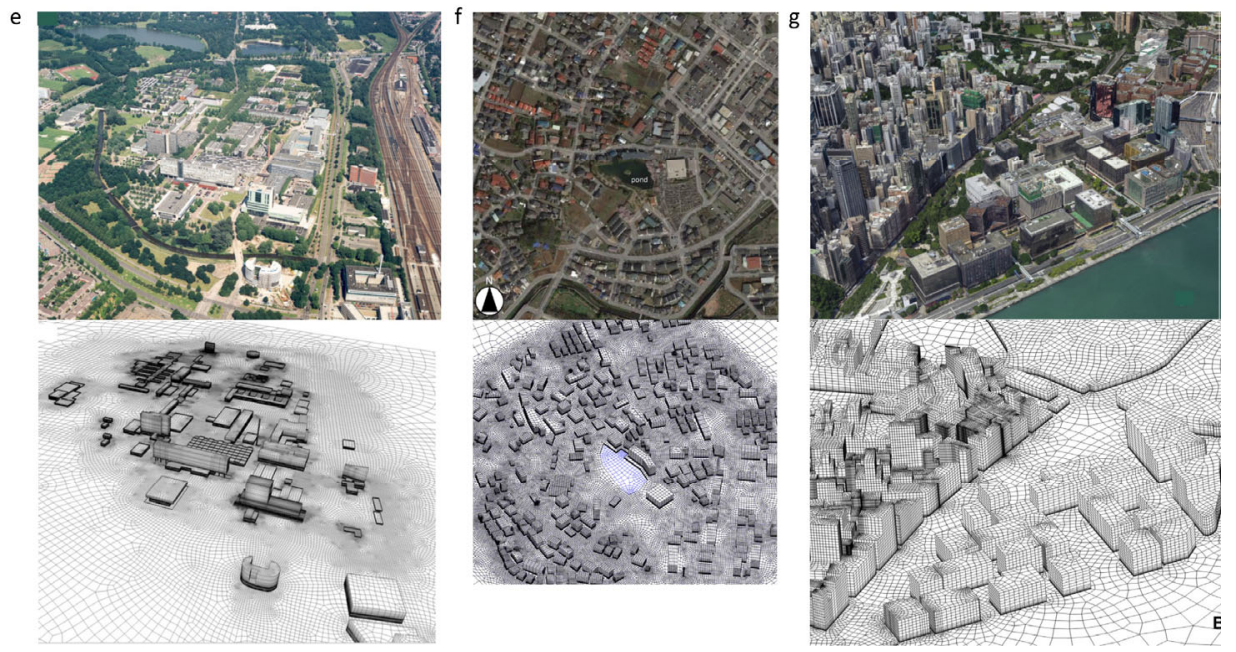

Fig. 6 RANS case studies for (a-d) pedestrian-level wind conditions around buildings; (a,b) by Murakami (1990b) for a building group in Tokyo, Japan; (c,d) by Stathopoulos and Baskaran (1996) for a building group in Montreal, Canada. (e) RANS case study for pedestrian wind comfort by Blocken et al. (2012) for the campus of Eindhoven University of Technology in the Netherlands; (f) RANS case study for urban thermal environment by Tominaga et al. (2015) for a neighborhood in Hadano, Japan; (g) RANS case study for urban ventilation by Peng et al. (2018) for part of Kowloon, Hong Kong (all figures: reproduced with permission (CElsevier)

and natural ventilation of buildings (e.g. Mochida et al. 2005, 2006; Horan and Finn 2008; Norton et al. 2009; van Hooff and Blocken 2010a,b, 2013; Wu et al. 2012; Martins and da Graça 2016; Aydin and Mirzaei 2017).

\subsection{LES in building simulation—outdoor}

Early LES studies for wind flow around buildings were performed by Murakami et al. (1987, 1990a, 1992), Murakami (1990a,b, 1993), Hibi et al. (1993), Song and He (1993), Nicholls et al. (1993), Mochida et al. (1993) and others. In some cases the LES results were compared with wind tunnel measurements and intercomparison of results obtained with different grid systems, boundary conditions and/or Smagorinsky constants were made (e.g. Murakami et al. 1987; Murakami 1990a,b; Mochida et al. 1993; Selvam 1997; Tominaga et al. 1997). In other cases the LES results were used to analyze the deficiencies in the RANS modeling (e.g. Murakami et al. 1990a) (Figs. 7a,b). Kato et al. (1992) applied LES to investigate the mechanism of cross-ventilation of isolated generic building models with open windows (Figs. 7c-e). Hibi et al. (1993) performed LES simulations to determine the fluctuating pressure fields around buildings with wall openings in view of assessing the relation between building shape and wind-induced vibrations. Song and $\mathrm{He}$ (1993) computed the flow pattern around a tall building to analyze the large scale vortex structures and unsteady flow, while Nicholls et al. (1993) simulated microburst winds flowing around a building.

Several comparative LES-RANS studies were focused on demonstrating and explaining the deficiencies of the steady RANS approach, mainly with the standard $k-\varepsilon$ model (Jones and Launder 1972), for wind flow around buildings. These include the stagnation point anomaly with overestimation of turbulent kinetic energy near the frontal corner (see Fig. 7b) and the resulting underestimation of the size of separation and recirculation regions on the roof and the side faces, and the underestimation of turbulent kinetic energy in the wake resulting in an overestimation of the size of the cavity zone and wake. These deficiencies are a direct result of the 
a

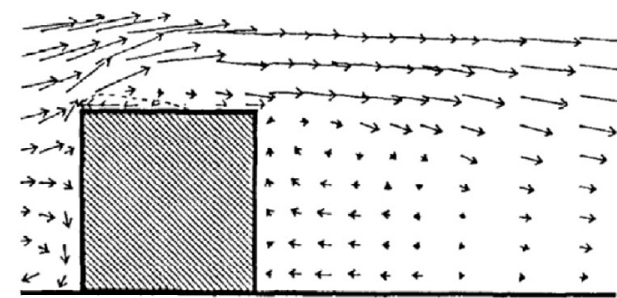

(1) experiment

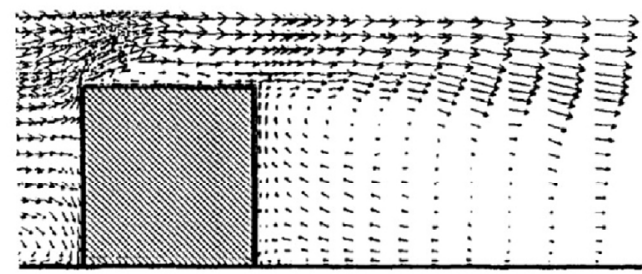

(2) LES

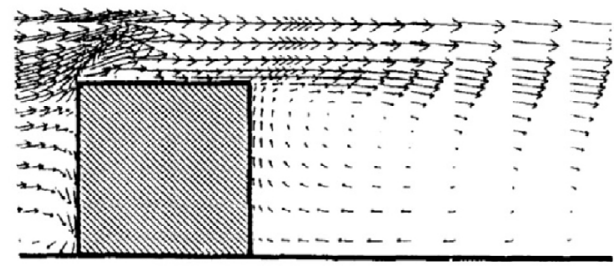

(3) $k-\varepsilon$ model

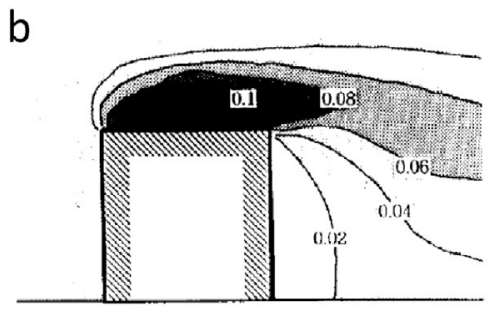

(1) wind tunnel experiment

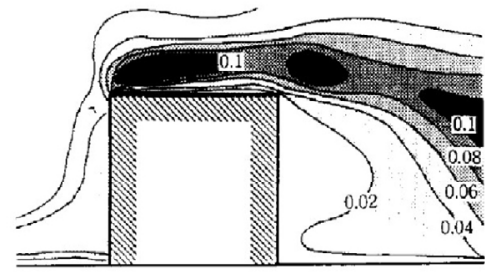

(2) LES

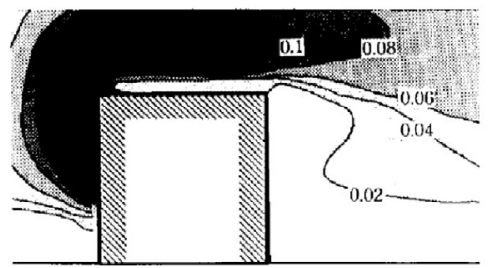

(3) $k-\varepsilon$ model

C

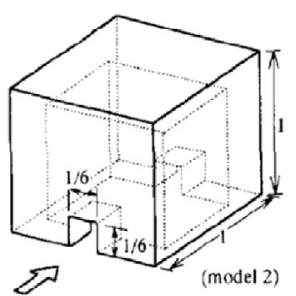

d

\begin{tabular}{|c|c|c|c|c|}
\hline Model 1 & Model 2 & Model 3 & Model 4 & Model 5 \\
\hline \% & 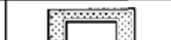 & ……… & in & . \\
\hline $\begin{array}{l}\text { Tunnel type: } \\
\text { windward and } \\
\text { lecward wall is is } \\
\text { connected by a square } \\
\text { duet of } 1 / 6 \times 1 / 6\end{array}$ & $\begin{array}{l}\text { Thick orifice type : } \\
\text { Thickness of the wall } \\
\text { is } 1 / 6\end{array}$ & $\begin{array}{l}\text { Thin orfice type: } \\
\text { thickness of the wall } \\
\text { is } 1160\end{array}$ & $\begin{array}{l}\text { Thick orifice type } \\
\text { with wind roesk: } \\
\text { similar to model } 2 \text { but } \\
\text { with a wind break } \\
\text { panel }\end{array}$ & $\begin{array}{l}\text { Thin orifice type with } \\
\text { wind break : similar } \\
\text { to model } 1 \text { but with a } \\
\text { wind break pane: }\end{array}$ \\
\hline
\end{tabular}

e

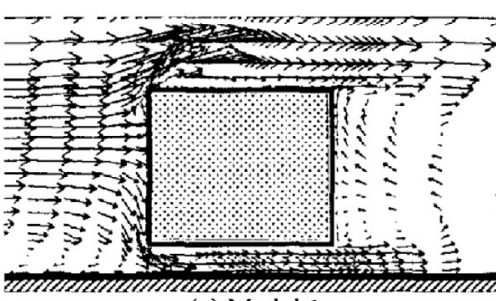

(a) Model 1

(1) Vertical section

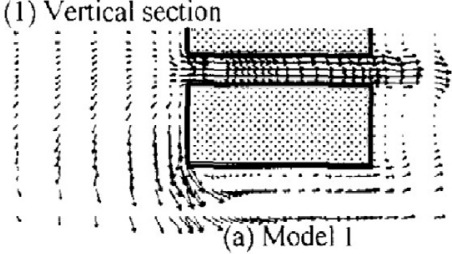

(2) Horizontal section

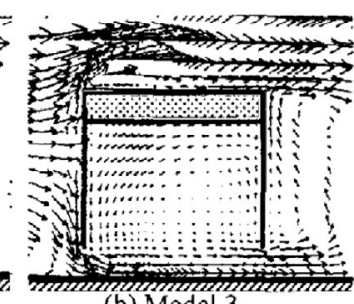

(b) Model 3

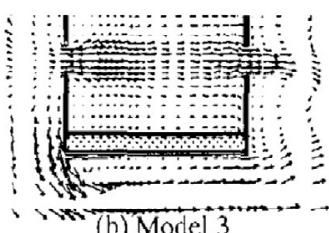

(b) Model 3

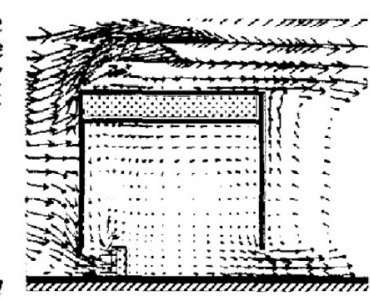

(c) Model S

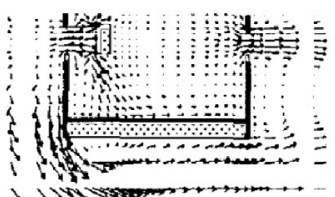

(c) Model 5

Fig. 7 (a,b) Early LES study for wind flow around an isolated cubic building: (a) mean velocity vector field and (b) turbulent kinetic energy in vertical centerplane by wind tunnel tests, LES and RANS with the standard $k-\varepsilon$ model (Murakami et al. 1990a). (c,d,e) Early LES study for natural ventilation of an isolated cubic building by Kato et al. (1992): (c) building geometry; (d) different model opening configurations; (e) mean velocity vector field in vertical and horizontal cross-sections (all figures: reproduced with permission (C)Elsevier) 
RANS averaging and the eddy-viscosity hypothesis-more specifically, the isotropic nature of the eddy viscosity. As a partial solution towards this problem, various revised linear and non-linear $k-\varepsilon$ models and also second-moment closure models were developed and tested. While improved performance for several parts of the flow field could be obtained (e.g. Baskaran and Stathopoulos 1989; Murakami et al. 1992; Murakami 1993; Wright et al. 2001; Mochida et al. 2002), the main limitation of steady RANS modeling remained: its incapability to model the inherently transient features of the flow field such as separation and recirculation downstream of windward edges and vortex shedding in the wake. These large-scale features can be explicitly resolved by LES. From the most early high-quality LES studies on, comparative LES-RANS-wind tunnel studies for wind flow around buildings have systematically illustrated the intrinsically superior performance of LES compared to RANS. Nevertheless, as will be discussed further, LES entails specific disadvantages that are not easy to overcome such as a higher simulation complexity and a much higher computational cost.

Examples of actual case studies with LES are some application studies of pedestrian-level wind conditions (e.g. He and Song 1999; Adamek et al. 2017; Jacob and Sagaut 2018), urban thermal environment (e.g. Liu et al. 2012), pollutant dispersion and/or urban ventilation (e.g. Hanna et al. 2006; Patnaik et al. 2007; Gousseau et al. 2011a, 2015; Liu et al. 2011; Nozu and Tamura 2012; Antoniou et al. 2017; Wang et al. 2018a,b) and natural ventilation of buildings (e.g. Jiang and Chen 2002) (Fig. 8). However, many examples

a
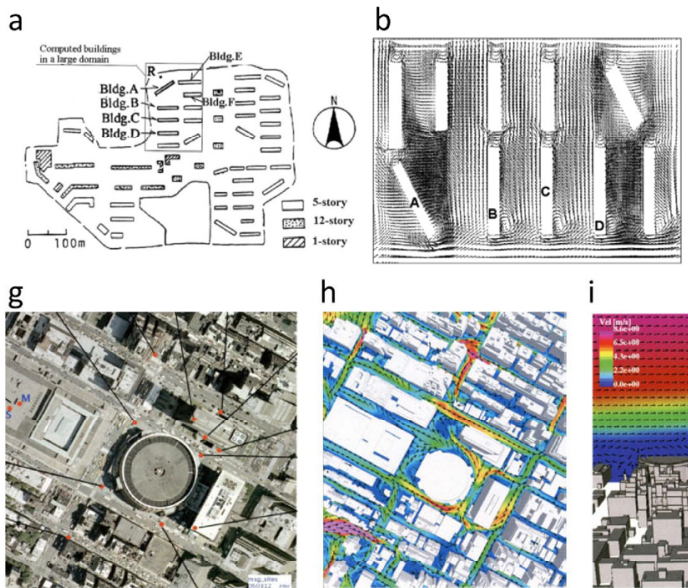

h

i
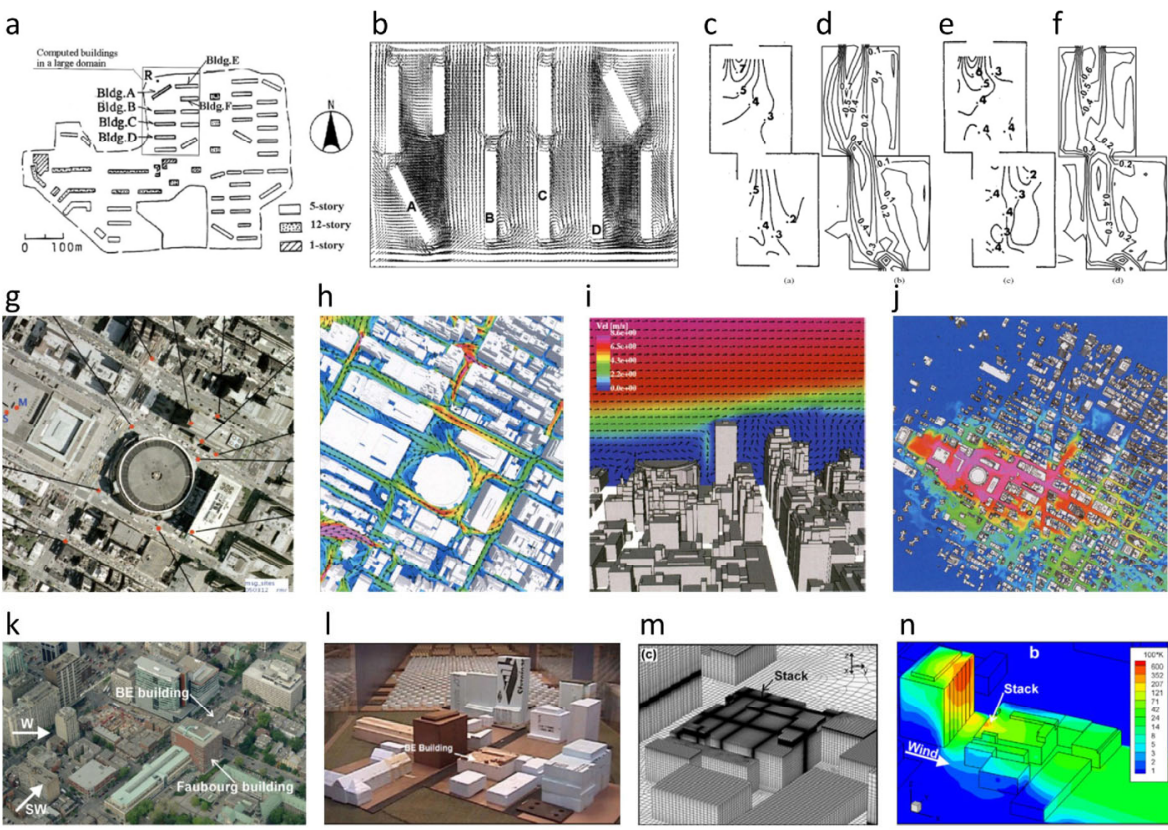

I
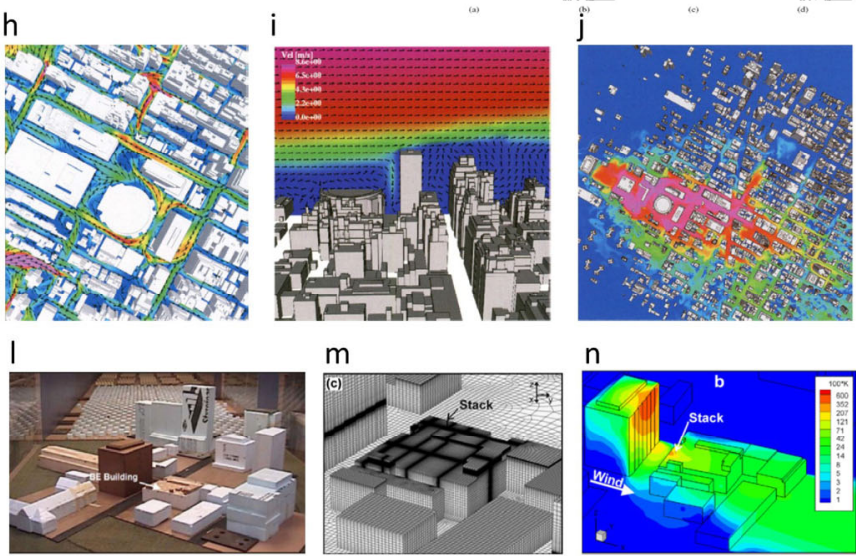

n
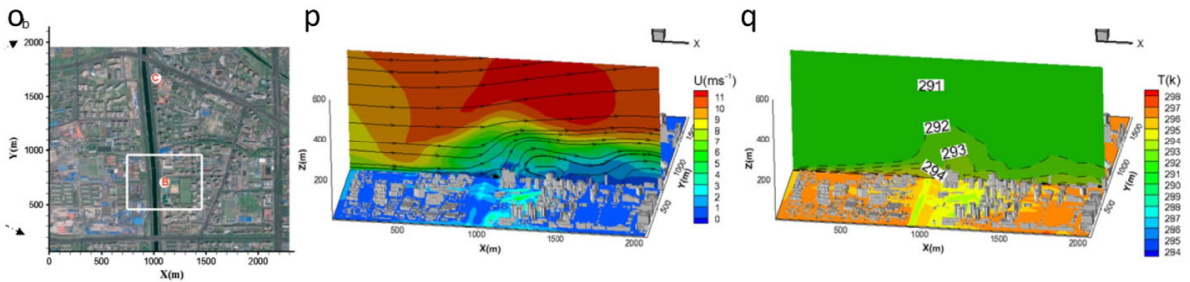

Fig. 8 (a-f) LES case study for natural ventilation of buildings by Jiang and Chen (2002) (reproduced with permission @eElsevier): (a) top view of building site; (b) mean velocity vector field around the buildings at $3 \mathrm{~m}$ from the ground; (c-f) wind speed distribution inside apartment in building A as obtained from (c) wind tunnel test; (d) LES with fixed wind direction; (e) on-site measurement; (f) LES with varied wind direction. (g-j) LES case study for pollutant dispersion in downtown Manhattan by Hanna et al. (2006) (reproduced with permission (CAmerican Meteorological Society (AMS)): (g) top view with position of measurement sensors; (h-j) LES results of (h) horizontal wind velocity vectors at $z=5 \mathrm{~m}$; (i) wind velocity vectors in vertical plane; (j) tracer gas dispersion for WNW wind direction. $(k-n)$ LES case study for pollutant dispersion in downtown Montreal by Gousseau et al. (2011a) (reproduced with permission (OElsevier): (k) view of site; (l) corresponding wind tunnel model; (m) computational grid; ( $\mathrm{n}$ ) contours of dimensionless concentration coefficient on building surfaces. (o-q) LES case study for thermal environment in a district in Beijing, China by Liu et al. (2012) (reproduced with permission @Elsevier): (o) LES computational domain; (p) LES wind field at ground level and in vertical plane; (q) same for LES temperature field 
of RANS case studies mentioned in Section 3.3 versus only relatively few by LES demonstrate that the vast majority of CFD application studies in the past three decades were indeed performed with the steady RANS approach and this continues to be the case. Therefore it seems that in many aspects of building simulation, researchers and practicing engineers have employed the increasingly available computational power to perform RANS simulations for larger and more complex problems, rather than to make the switch from RANS to LES for less extensive problems.

\subsection{RANS in building simulation-indoor}

The first predictions of airflow in rooms were performed in the 1970s. Nielsen $(1973,1974 a)$ was the first to compute air movement in buildings with CFD. Given the computational limitations at that time, he focused on 2D simulations of room airflow and employed a calculation procedure based on a stream function approach. He also performed comparisons of the computed velocity profiles with hot-wire measurements at different positions in the room. Nielsen (1974b) also simulated the humidity concentrations in cold stores using the advection-diffusion equation (see Eq. 3d). Later, Nielsen et al. (1978) solved the 2D RANS equations with the standard $k-\varepsilon$ model for closure and compared the results with new laser-Doppler anemometry measurements (Figs. 9a,b) and with the previously obtained hot-wire data. In 1979, Nielsen et al. (1979) also analyzed buoyancy-assisted room ventilation flow with the 2D RANS equations supplemented with the energy equation (see Eq. 3c). Later, this team also collaborated
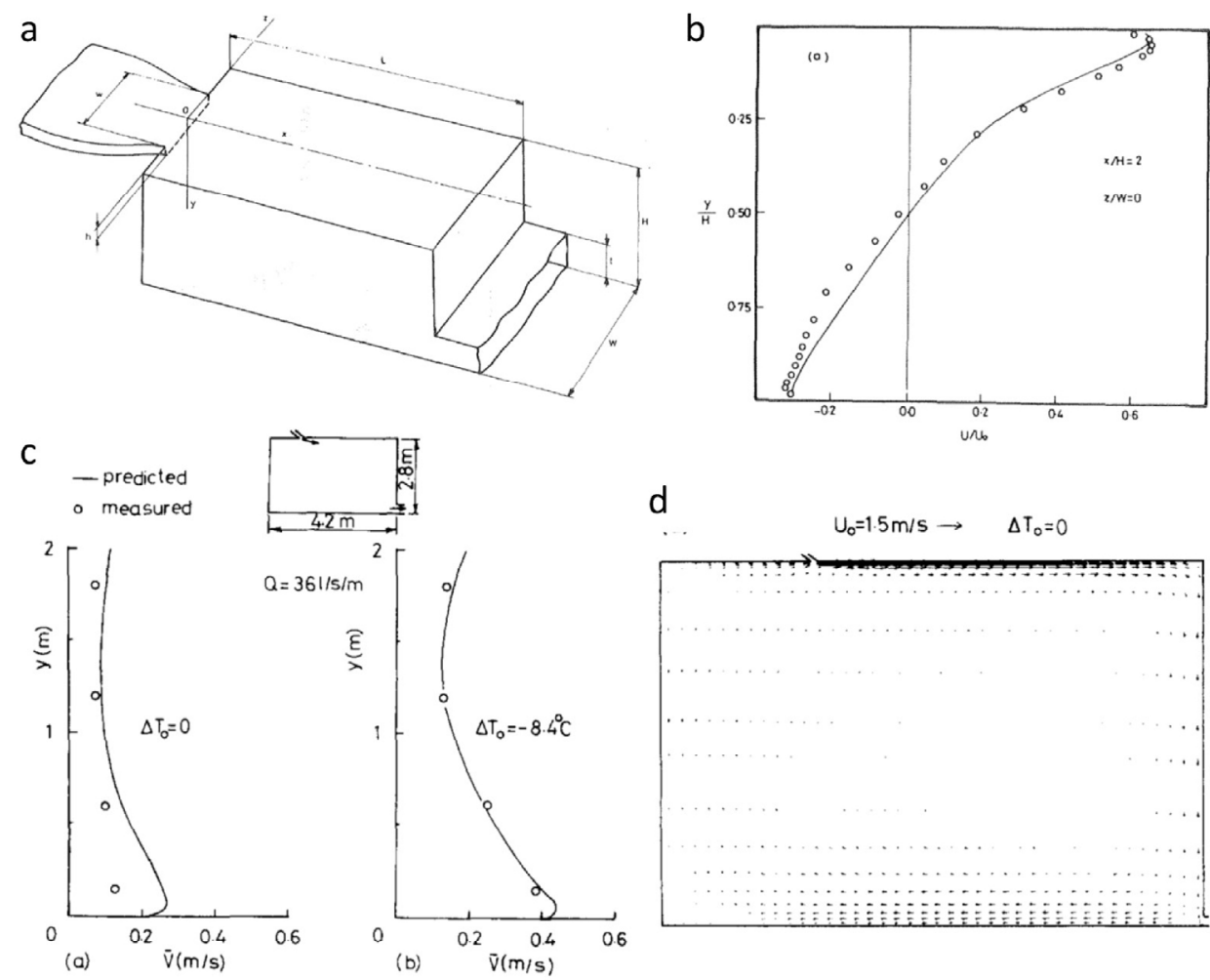

d
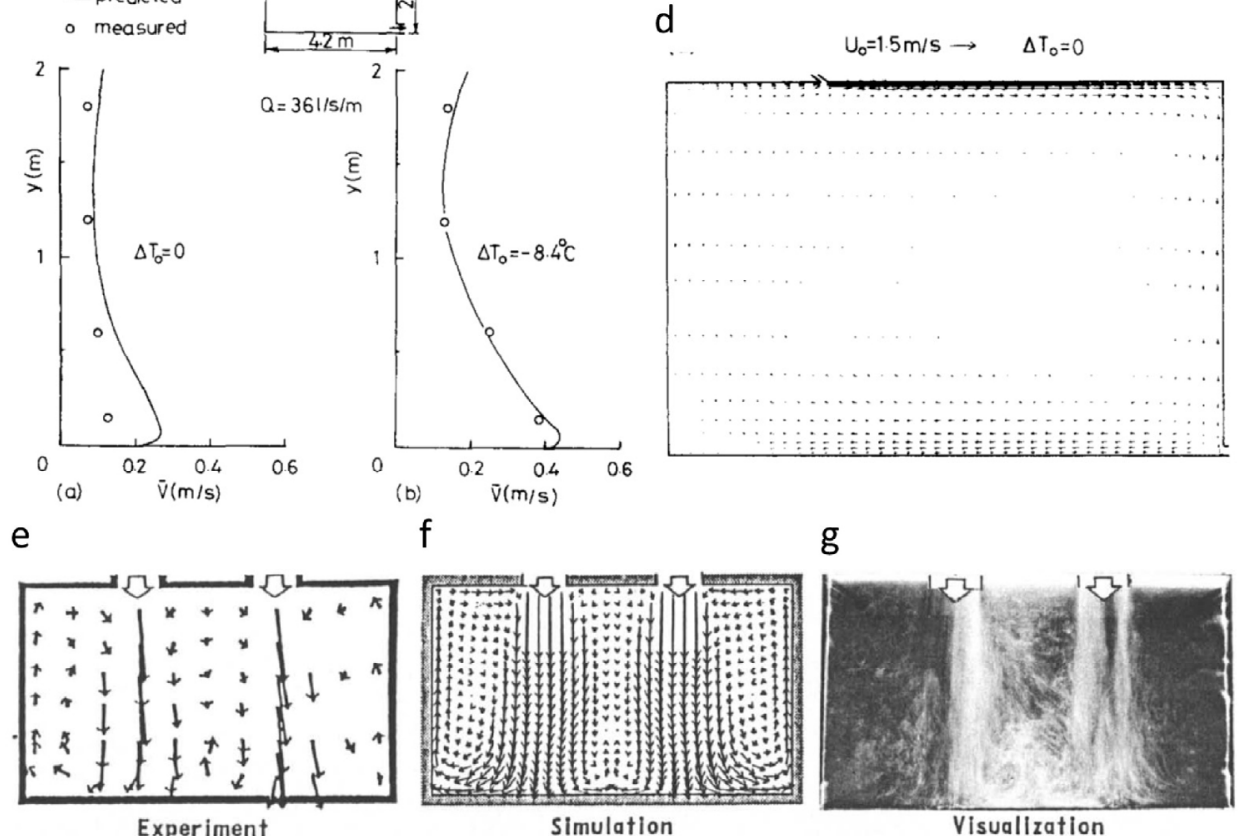

$\mathrm{f}$
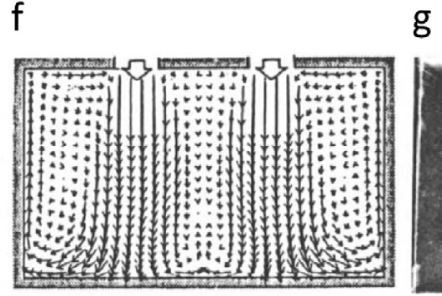

Simulation

g

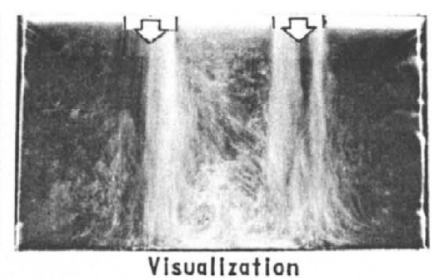

Fig. 9 Early RANS studies of indoor airflow. (a,b) 2D simulations and measurements by Nielsen (1976) (reproduced with permission from Peter V. Nielsen). (a) Test room with $H=89.3 \mathrm{~mm}$; other dimensions correspond to $L / H=3.0 ; W / H=1.0 ; h / H=0.056 ; t / H=$ $0.16 ; w / W=1.0$. (b) Comparison of simulations and measurements along vertical line in test room. (c,d) $2 \mathrm{D}$ simulations and measurements in a 4.2 by $2.8 \mathrm{~m}^{2}$ room by Awbi (1989): (c) comparison of air speed along vertical line in test room; (d) velocity vector field for isothermal case in vertical plane. (e-g) Measurements, 3D simulations (velocity vector field) and visualization of indoor airflow in a test room by Murakami and Kato (1989) (Figs. c-g: reproduced with permission (OElsevier) 
with Gosman to extend the calculation procedure to 3D and perform 3D isothermal ventilation simulations (Gosman et al. 1980). These pioneering research efforts were followed by many other RANS studies. Awbi (1989) performed 2D RANS simulations of airflow and heat transfer in heated or cooled rooms and 3D RANS simulations of a wall jet over surface-mounted obstructions with the standard $k$ - $\varepsilon$ model for closure (Figs. 9c,d). Murakami and Kato (1989) conducted 3D RANS simulations with the standard $k-\varepsilon$ model for a variety of room configurations including obstacles in the room (Figs. 9e-g). They also analyzed the spreading of a tracer gas inside the room and found favorable comparisons with dedicated experiments in 1/6 reduced-scale tests rooms. Other RANS CFD studies on indoor airflow were reported by Sakamoto and Matsuo (1980), Nomura et al. (1980), Timmons et al. (1980), Nielsen (1981), Holmes (1982), Broyd et al. (1983), Markatos and Pericleous (1984), Ishizu and Kaneki (1984), Reinartz and Renz (1984), Alamdari et al. (1984), Awbi and Setrak (1986), Waters (1986), Murakami et al. (1987), Whittle (1987), Jones (1990), Jones and O'Sullivan (1987), Jones and Reed (1988), Holmes and Whittle (1987), Lemaire (1989), Jones and Waters (1990, 1991), Holmes et al. (1990), Chen $(1995,1996)$ and others. Similar to early RANS studies for outdoor applications, also several early RANS studies for indoor airflow examined the influence of different computational parameters on the results (e.g. Nielsen et al. 1978; Murakami and Kato 1989; Chen 1995, 1996; Chen and Chao 1997; Nielsen 1998). These studies provided the basis for the best practice guideline documents for CFD for indoor airflow that would be compiled later.
Numerous CFD case studies were performed in the past decades using the 3D steady RANS equations, with applications focused on thermal comfort, ventilation efficiency and indoor air quality. These case studies employed a wide range of turbulence models.

\subsection{LES in building simulation-indoor}

To the best of our knowledge, the first LES simulation of room airflow was performed by Sakamoto and Matsuo (1980). They compared the simulation results in terms of mean velocity with measurements in a model room and found a good agreement both for the LES results but also for their RANS $k-\varepsilon$ results. This made them conclude that the RANS approach is more practical given its shorter computational time (Figs. 10a-d). Later, Hibi et al. (1985) and Murakami et al. (1986) further examined the accuracy of LES for 3D recirculating flow. Other efforts in LES simulation of indoor airflow were made by Murakami et al. (1995), Davidson and Nielsen (1996), Emmerich and McGrattan (1998), Zhang and Chen (2000a,b) (Figs. 10e-g), and others. In their extensive report on how to verify, validate and report indoor environment modeling CFD analyses, Chen and Srebric (2001) indicated that only very few LES simulations were performed for indoor environment modeling applications. After 2000, this number increased substantially, albeit often related to the modeling of the indoor dispersion of particles (e.g. Tian et al. 2007; Chang et al. 2007; Lai and Chan 2007; Abdalla et al. 2007; Wang et al. 2012; Liu and Novoselac 2014; Karadimou and Markatos 2016). a

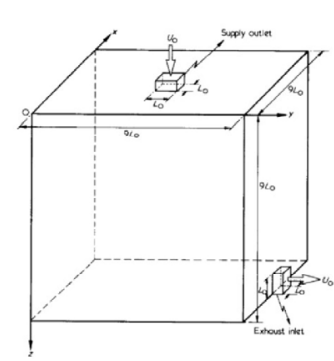

e

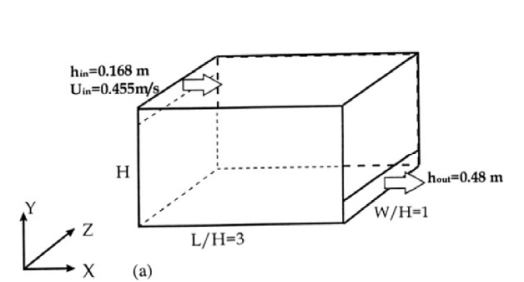

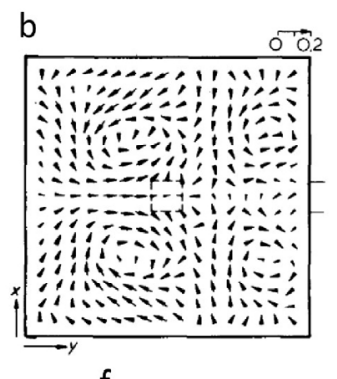

$\mathrm{f}$
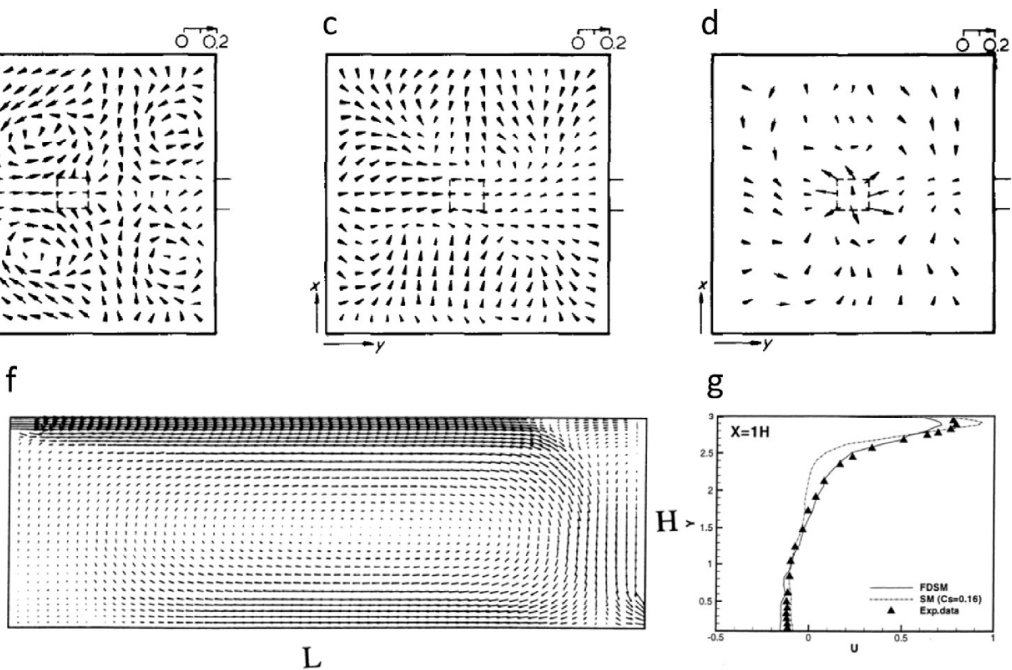

L

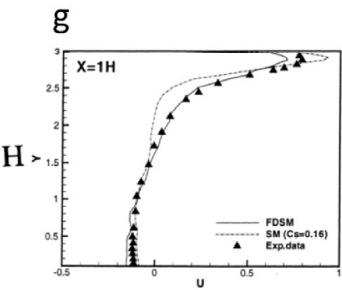

Fig. 10 Early LES studies of indoor airflow. (a-d) LES for $2 \mathrm{~m}$ cubic room by Sakamoto and Matsuo (1980): (a) room geometry; (b-d) velocity vectors in horizontal plane at midheight for (b) standard $k-\varepsilon$ model; (c) LES; (d) experiments. (e-g) LES for forced convection in rectangular room by Zhang and Chen (2000a): (e) room geometry; (f) mean velocity vectors in vertical centerplane by filtered dynamic SGS model (FDSM); (g) comparison of LES results by standard Smagorinsky SGS model, FDSM and experiments in vertical centerplane at $x / H=1$ (all figures: reproduced with permission @Elsevier) 


\section{Previous review and position papers on LES versus RANS}

"Great literature is simply language charged with meaning to the utmost possible degree." 3

This section provides relevant highlights from some previous position papers on LES versus RANS. The intention is neither to be complete, nor to be balanced. Several of these opinions will be revisited at the end of this paper, after having assessed the performance of LES and RANS in the five application areas in section 5 . The papers below are addressed in chronological order of appearance in their respective journals.

\subsection{CFD for outdoor applications}

In 1990, Joel H. Ferziger published the paper "Approaches to turbulent flow computation: applications to flow over obstacles" (Ferziger 1990), in which he specifically focused on RANS versus LES. A key argumentation in the paper is that the principal task of the wind engineer is to find a method that produces accurate values of the essential quantities at low cost. As a result, the method to be used may depend both on the required accuracy and on the problem. Indeed, Ferziger mentioned that while fields such as aerospace engineering will typically require a high accuracy (e.g. errors less than 5\%), others, such as wind engineering, are generally less demanding (e.g. errors of more than 25\% may be acceptable). Therefore he states that a model that is sufficiently accurate for one application may be totally unacceptable in another (Ferziger 1990).

Ferziger (1990) considered RANS and LES as two obviously imperfect approaches in view of practical engineering purposes. RANS models have the benefit of longer history and lower cost, but the existing turbulence models and wall models are often not sufficiently accurate for $3 \mathrm{D}$ separating and reattaching flows. LES on the other hand can address some of these issues, but the costs of LES are much higher and experience is limited. Ferziger (1990) reported that the fact that LES resolves more of the flow than RANS and the fact that therefore the calculation results can be rather insensitive to the quality of the SGS model has been advertised as one of the principal advantages of LES over RANS. However, he correctly argued that as the Reynolds number increases and/or the flow becomes more geometrically complex, more energy will be situated in the small scales of turbulence and the results will become more sensitive to the quality of the SGS model. This would

\footnotetext{
${ }^{3}$ Ezra Weston Loomis Pound (1885-1972): American poet, critic, translator, publisher and major figure in the early modernist movement.
}

require more accurate SGS models or the use of even finer computational grids. In this respect, Ferziger stated that "If it turns out that LES can be done on very coarse grids, it will be one of the few times that nature has been kind to us with regard to turbulent flows".

Although LES is potentially (sic) more accurate than RANS, Ferziger (1990) considered it to be too expensive to be a design tool. He concluded his paper by suggesting a research program that could lead to reliable methods in the next five to ten years. This program would employ high-quality experiments and carefully performed LES for producing accurate data and RANS for routine calculations.

In 1990, Shuzo Murakami published the paper "Computational wind engineering" (Murakami 1990a), in which he provided a detailed review of the state of the art in CFD for wind engineering applications. The range of CFD applications displayed in this early paper is impressive: from indoor turbulent flow fields over wind velocity patterns over isolated buildings and pressure coefficients on the surfaces of those buildings to the flow around an actual building complex including the flow details around individual balconies. Before outlining these applications, at the very start of the paper, Murakami stressed both the potential of the numerical approach but also the need for synergy between the numerical and the experimental approach in wind engineering. He considered it indispensable to examine the accuracy of the CFD simulations and to further develop the CFD approach by comparison with results from wind tunnel or field measurements. On the other hand, he expected that the increasing precision of CFD predictions would also increase the incentive for new research into experimental methods. Murakami (1990a) also correctly indicated that the graphical representation of the time-dependent flow fields by LES in the form of animations was a very useful tool in the analysis of the flows and that this provided information that in many cases was hard or even impossible to be obtained by experimental techniques.

In 1993, Michael A. Leschziner published the paper "Computational modelling of complex turbulent flowexpectations, reality and prospects" (Leschziner 1993). A key argument in this paper is that "CFD, whilst offering considerable predictive power and potential, is not yet sufficiently well established to be applied routinely to complex $3 \mathrm{D}$ flows, unless only a rough qualitative statement is being sought." This led him to several important statements. First, it is essential for a CFD user to possess considerable expertise, physical insight and experience, both to obtain meaningful solutions and to be able to appreciate the associated limitations. Second, CFD for general turbulent flow is unlikely ever to evolve to a "computational wind tunnel" or a "numerical wind tunnel". He referred to the rather radical view-expressed predominantly among the 
US aerodynamics fraternity-that the wind tunnel was destined to become a "convenient storage cabinet for computer output" (Leschziner 1993). He criticizes this rather narrow interpretation of CFD that could bear some truth for high-speed external aerodynamics and some turbomachinery applications, but not for wind engineering applications. Therefore he argued that wind tunnels are here to stay for many years to come and would continue to be the main vehicle for investigating realistic building design concepts (Leschziner 1993).

Concerning LES versus RANS, he stated that from the viewpoint of structural engineering, when peak wind pressures and peak wind loading need to be determined, LES is obviously the only alternative. For industrial applications in general, he expected that RANS methods would continue to play the main role for some years to come, but that there likely would be a continuous shift of focus towards LES. Nevertheless, he concluded that it is unlikely that LES will replace turbulence modeling (i.e. in the RANS framework) altogether and that "the need to arrive at acceptably accurate answers at minimum cost will probably secure at least a spacious niche within CFD for model-based algorithms", by which he again referred to the RANS framework (Leschziner 1993).

In 1997, Shuzo Murakami published the paper "Current status and future trends in computational wind engineering" (Murakami 1997). In this paper he outlined the specific difficulties pertaining to CFD in wind engineering, as well as the rapid growth of applications in this field, the new trends in RANS turbulence modeling and in LES SGS modeling. Based on a wide range of applications and comparisons with experimental data, he concluded that the different RANS turbulence models each have their advantages and disadvantages and that turbulence model selection should be based on the criteria of prediction accuracy and CPU time required. He indicated that selecting the best turbulence model for a given application is a knowledge-based learning process. Finally, he stated based on his many tests that LES with the dynamic SGS model provided the best results for many wind engineering applications, and that the rapid evolution of CPU hardware was expected to overcome the restriction of large CPU time, enabling wide application of LES to wind engineering problems in the near future.

In 1997, Shah and Ferziger (1997) published the paper “A fluid mechanician's view of wind engineering: Large eddy simulation of flow past a cubic obstacle" (Shah and Ferziger 1997). They provided results of LES simulations for the simple case of a surface-mounted cube in channel flow and stated that LES can accurately capture the effects of large-scale motions such as wind forces and their fluctuations. They correctly mentioned that the interest in LES had increased due to "the failure of RANS to do an adequate job, especially in cases in which information about the fluctuations is required". They indicated that the LES simulations they were presenting were expensive, and therefore, if high-quality results were required, it would not be possible at present to use LES as a design tool. They also argued that just the simple fact that one is using LES does not guarantee success. It is possible for LES to yield results that are incorrect qualitatively as well as quantitatively and that therefore, also in LES, the combination with experiments would remain necessary for a long time to come.

In 1997, Theodore Stathopoulos published the paper "Computational wind engineering: past achievements and future challenges" (Stathopoulos 1997). Because CFD in wind engineering involves complex $3 \mathrm{D}$ flows requiring solid knowledge of both turbulence theory and numerical analysis, he expressed his grave concern that "there are serious dangers inherent in the way that CFD is being increasingly used in industry often by people having little or no understanding of fluid dynamics or computational techniques." Concerning application areas, he indicated that where mean values of variables are involved such as mean wind speed and mean concentration, CFD approaches might be suitable "to provide some insight, valuable for preliminary design purposes", such as for the assessment of wind environmental conditions around buildings. For the prediction of pollutant concentrations however, the lack of success of several CFD exercises led him to conclude that "although CFD is definitely a good friend of wind engineering, it has not yet become a true ally". He concluded by arguing that "most practitioners are more concerned with obtaining results than with either the order of accuracy of their numerical schemes or the need to refine the grid until converged grid-independent solutions are obtained." And that the use of CFD in wind engineering was still in its infancy and had a very long way to go before it could become a design tool. His clear view was that it is unlikely that CFD for general turbulent flow would become a "computational wind tunnel", at least not in the foreseeable future, and that rather CFD and experiments should complement each other e.g. to reduce costs in the design process. These views were further addressed in a follow-up paper (Stathopoulos 2002).

In 1997, Wolfgang Rodi published the paper "Comparison of LES and RANS calculations of the flow around bluff bodies" (Rodi 1997). This paper provided very detailed comparisons of LES simulations with different SGS models and RANS simulations with different turbulence models versus high-quality experiments. Rodi (1997) also provided a clear view on the computational costs in terms of time: "on the SNI S600/20 vector computer the LES calculations (UKAHY4) took $160 \mathrm{~h}$ while the RANS two-layer model calculations took $6 \mathrm{~h}$ and the RANS calculations using wall functions only $15 \mathrm{~min}$." The detailed comparisons in terms 
of accuracy but also in terms of cost made him conclude that RANS simulations would remain needed and applied for many years to come in engineering simulations of flow around buildings. But because LES is intrinsically more suitable and had displayed great potential for better simulation of these complicated flows, he advocated further development and testing, expecting that "with the recent advances in computing power LES will soon be ready and feasible for practical applications." (Rodi 1997).

In 1999, David Gosman published the paper "Developments in CFD for industrial and environmental applications in wind engineering" (Gosman 1999). He acknowledged the limitations of RANS simulations especially for flows around building-like obstacles and the unresolved issues in LES such as economical near-wall modeling and the specification of inlet boundary conditions. But his overall conclusion was that the level of accuracy that could be achieved could be acceptable for some purposes, and that this had caused CFD to be applied in a range of applications, such as pedestrian-level wind comfort, traininduced wind speed, wind on off-shore structures and indoor HVAC applications. He also mentioned the important fact that CFD as a methodology but also the codes themselves had improved substantially in terms of versatility, ease of use and speed (thanks also to hardware developments), which should help accelerating the uptake of this technology by industrial users-however, not without the required level of knowledge of flow physics to properly interpret and exploit the results.

In 1999, Castro and Graham published the paper "Numerical wind engineering: the way ahead" (Castro and Graham 1999) in which they convincingly denounced the concept of the "numerical wind tunnel" in the design process, for example for the assessment of wind loads and pollutant dispersion. In line with Stathopoulos (1997) they pointed to the significant dangers of using CFD without a sound understanding of the fluid mechanics of the problem under study, without awareness of the validation of the code for similar problems and a clear understanding of the sources of errors and uncertainties and the levels of accuracy required. They also stated that inadequate turbulence modeling could lead to a highly accurate solution to the modelled equations that differs significantly from the actual flow. But that this difference "is often of secondary importance compared with those which arise because of 'bad' choices (or even plain user mistakes) in all the other areas." (Castro and Graham 1999).

In 1999, Shuzo Murakami et al. published the paper "CFD analysis of wind climate from human scale to urban scale" (Murakami et al. 1999) in which they extended the earlier published large number of examples (see Murakami 1990a) by covering a very wide range of spatial scales but also physical processes from human body convection over convective, conductive and radiative heat transfer in street canyons to the urban heat island effect. They mentioned that they compared their CFD results with measurements whenever available. This statement referred to their very important point that in some cases, measurement data could not be obtained or would be very difficult to obtain. In such cases, Murakami correctly argued that "we do think that the comprehensive assessment based on the CFD method combining various factors seems to be the only approach for clarifying such complicated phenomena."

In 2004, Robert N. Meroney published the paper "wind tunnel and numerical simulation of pollution dispersion: a hybrid approach" (Meroney 2004), in which he advocated an intensive hybrid approach. As an example, he mentioned that fluid modeling (by which he meant wind tunnel testing) could initially provide data from which CFD turbulence models can be created, the CFD simulations can use these models to rapidly survey alternate solution strategies using simplified domain scenarios, and then wind tunnel testing can investigate in great detail design consequences, finally followed by CFD to extend the initial conclusions to a broader set of similar cases. Meroney (2004) also stressed the very strong need for a critical attitude towards all CFD but also wind tunnel results: "Good mental health in a fluid or CFD modeler is always indicated by the presence of a suspicious nature, cynicism and a "show me" attitude. These are not necessarily the best traits for a life mate or a best friend, but they are essential if the integrity of the modeling process is to be maintained."

In 2005, Kemal Hanjalic published the paper "Will RANS survive LES? A view of perspectives" (Hanjalic 2005). He observed that despite all their disadvantages, RANS simulations with first-order closure had remained the workhorses in industrial CFD applications because they are easy to use, economical and therefore suitable for design and optimization. Although there was a consensus among CFD experts that RANS had not lived up to the earlier expectations, LES was also not without disadvantages. While LES had been shown to be a very powerful method, the very large demands on grid resolution were the reasons for Hanjalic (2005) why LES application "is and will for long be limited to low-to-moderate $\mathrm{Re}$ and $\mathrm{Ra}$ numbers and relatively simple geometries." He correctly mentioned that "conventional LES on a too-coarse grid of wall bounded flows, especially in attached flows regions, can be very erroneous and inferior to even simple conventional RANS." Based on all these reasons, Hanjalic (2005) argued that "RANS will further play an important role, especially in industrial and environmental computations, and the further increase in the computing power will be used more to utilize advanced RANS models to shorten the design and marketing cycle 
rather than to yield the way to LES." Although he foresaw also further efforts in the improvement of LES modeling. Similar expectations were expressed by Pope (1999).

Several later papers provided additional very valuable views, generally-but not always-in line with previously expressed opinions. Baker (2007) indicated that he expected the use of RANS simulations to decrease over time, "although their relative simplicity and economy will ensure their continued use for many applications." He anticipated that CFD applications will become widespread in those area where velocities rather than surface pressures are needed, such as pedestrian-level wind (PLW) comfort assessment. And that this increase in the use of CFD might even lead to a reduction of atmospheric boundary layer wind tunnel facilities over the next decades. Yoshie et al. (2007), focusing on the CFD prediction of PLW conditions, admitted that LES could improve the prediction of wind velocity especially in wake regions as well as provide information about gusts. But they mentioned that before LES could be used in general-purpose applications for PLW conditions around buildings, a dramatic increase in computational speed would be needed, and that until that time, "we must be content with RANS type models currently in use." Tominaga and Stathopoulos (2013), in reviewing CFD techniques for modeling near-field pollutant dispersion, addressed both the significant potential of CFD but also the many challenges involved in this very complex application area. Meroney (2016) recalls the common presumptions over the past 50 years that CFD and experimental fluid dynamics (EFD) were mutually exclusive and competitive, as well as the often asked question "When can we get rid of our physical modeling facilities?" He argued that this question ignored the tremendous synergy of combining the best qualities of both CFD and EFD both in research and design, as this hybrid CFD-EFD approach can "expedite results, improve understanding of flow phenomena, and often reduce research costs and time." Also Tominaga and Stathopoulos (2016) correctly highlighted the current important consensus that both approaches should be complementary and employed to reduce the inaccuracy in the results of a single-approach method.

\subsection{CFD for indoor applications}

In 1992, P.J. Jones and G.E. Whittle published the paper "Computational fluid dynamics for building air flow prediction-Current status and capabilities" (Jones and Whittle 1992). Given the status of CFD at the time, this paper did not yet consider LES. They stated that the standard $k-\varepsilon$ model is generally (but not universally) considered to be an appropriate turbulence model for (indoor) building simulation. But also that due to the limitations entailed by the assumption of isotropic turbulence, this model could prove inadequate, in which case an algebraic stress model or full RSM could be considered, however at the expense of increased computing time. As some major technical limitations and shortcoming in most CFD codes at that time, they listed the modeling of turbulence and the relative poor mesh generation methods and user interface. For the latter however they indicated that this was an area of fast development where substantial improvements were being made.

In 1997, Qingyan Chen published the paper "Computational Fluid Dynamics for HVAC: Successes and failures" (Chen 1997). He stressed the importance that CFD users should have a good knowledge of turbulent flows and numerical techniques to perform correct simulations. Based on his studies in turbulence model evaluation, he concluded that the predictions of first-order parameters such as mean velocities and temperatures by CFD are more accurate than those of second-order parameters such as turbulence intensities. He also mentioned that to date, LES had rarely been applied for actual engineering problems that involve high Reynolds number flow in complex geometries, because of the need for extensive computational power and the need for further development.

In 1998, Peter Nielsen published the paper "The selection of turbulence models for prediction of room airflow" (Nielsen 1998). From his comparison of turbulence modeling approaches, he concluded that a simple zero-equation model could be useful for provisional studies, a $k-\varepsilon$ model could be used for stratified flows, a low-Reynolds number $k-\varepsilon$ model was required for near-surface transport processes while LES could provide the most detailed information.

In 2001, Qingyan Chen and Jelena Srebric published the document "How to verify, validate and report indoor environment modeling CFD analysis" (Chen and Srebric 2001). In this extensive best practice document, they mentioned that only a few LES applications had been performed for indoor environment modeling because of the high computing costs but that it could become a powerful modeling tool in the near future.

Sørensen and Nielsen (2003) confirmed that LES can provide information beyond RANS models which allows for example a direct prediction of the turbulence intensity. However, they mentioned that the use of LES for predicting room airflow was very expensive and that the prediction accuracy of the average flow variables was not improved, at least not for fully developed flow, compared to results by a $k-\varepsilon$ model (Davidson and Nielsen 1996). This observation was clearly different from that in wind flow around buildings which indicates that outdoor and indoor applications in building simulation should correctly be considered as different subfields, as done in the present paper. Nevertheless, Sørensen and Nielsen (2003) mentioned that LES could provide 
advantages in cases of non-fully developed turbulent flow. While they argued that with increasing computational power, LES would most likely become a useful and practicable tool for room airflow simulations in the future, at the time they recommended using RANS turbulence models for practical purposes.

In 2007, John Zhai et al. published the paper "Evaluation of various turbulence models in predicting airflow and turbulence in enclosed environments by CFD: part 1 Summary of prevalent turbulence models" (Zhai et al. 2007) in which they provided a review of available methods including LES and RANS. They indicated that for the design and study of air distributions in enclosed environments, the mean air parameters were generally more useful than the instantaneous turbulent flow parameters which justified the stronger interest in RANS simulations that could provide quick predictions rather than the more detailed but also more time-consuming LES simulations. LES was indeed considered more a research than a design tool.

In 2009, Qingyan Chen published the review paper "Ventilation performance prediction for buildings: A method overview and recent applications" (Chen 2009). Based on this review, he concluded that RANS models could perform well for one flow but poorly in another, and that LES could yield good results provided that a sufficiently fine grid resolution was applied. He correctly documented that LES is more popular for predicting particle distributions in ventilated spaces, because in this case more detailed information on the turbulent nature of the flow is required, which is provided by the LES simulations. Chen (2009) finally indicated that at the time of his publication, LES was still mainly used as a research tool and that its penetration in design applications would still take quite some time.

In 2011, Yuguo Li and Peter Nielsen published the paper "Commemorating 20 years of Indoor Air" (Li and Nielsen 2011). While this paper did not focus on LES versus RANS, it is mentioned here because it- very much like several leading papers in wind engineering (see Section 4.1) - indicated the continuing importance of experiments. They indicated that in spite of the continuously increasing capabilities for CFD simulations, "CFD has not become a replacement for experiment and theoretical analysis in ventilation research, rather it has become an increasingly important partner." These authors "believe that an effective scientific approach for ventilation studies is still to combine experiments, theory, and CFD. We argue that CFD verification and validation are becoming more crucial than ever as more complex ventilation problems are solved."

In 2015, Peter Nielsen published the paper "Fifty years of CFD for room air distribution" (Nielsen 2015) in which he looks back on the very field he successfully initiated himself in 1973. He concluded that in these years, the indoor environment community had embraced CFD as a useful tool for the airflow prediction in ventilated spaces. While it had been used for many years in research, now it was also routinely used in civil engineering practice for the design of large or complicated air distribution systems. Concerning LES versus RANS, he mentioned that room airflow is not always fully developed turbulent flow. As a result, a typical EVM like the $k-\varepsilon$ model that is only valid for fully developed turbulent flow might not be a good option, and that indeed, for low-Reynolds number flow, LES simulations had shown a better agreement with experiments at specific locations. Nielsen (2015) also expected that the increasing computational resources would expand the use of LES in the future.

\section{Best practice guidelines}

\section{"Abeunt studia in mores" 4}

\subsection{General best practice guidelines}

As mentioned earlier, the results of most CFD approaches, including LES and RANS, can be very sensitive to the wide range of parameters that has to be set by the user. To remove or at least limit and assess errors and uncertainties, verification and validation are imperative. Best practice guidelines (BPG) have been developed in an attempt to guide the scientific and engineering community towards removing or limiting and assessing errors and uncertainties with the aim of obtaining more accurate and reliable simulation results. A number of these guidelines have a generic character and are applicable to LES, RANS and other approaches. Examples are the guidelines and standards concerning verification and validation, as outlined in e.g. Roache et al. (1986), Freitas (1993), Roache (1994, 1997), the guidelines by the American Institute of Aeronautics and Astronautics (AIAA 1998), Oberkampf et al. (2004), Roy (2005), Roy and Oberkampf (2010), the guidelines by the American Society of Mechanical Engineers (ASME 2009), and others. These guidelines and standards underlie more specific guideline documents, such as the extensive BPG by the European Research Community on Flow, Turbulence and Combustion (ERCOFTAC) published in 2000 by the Special Interest Group on Quality and Trust in Industrial CFD (Casey and Wintergerste 2000) and the ERCOFTAC BPG published in 2008 on CFD of dispersed multiphase flow (Sommerfeld et al. 2008). The former ERCOFTAC guidelines were focused on RANS simulations while the latter included a focus on DNS, LES and RANS. Although

\footnotetext{
4 "Practices passionately pursued become habits"; Ovidius in Heroides 15.83. Publius Ovidius Naso (43 BC - 17 AD), Roman poet, one of the three canonical poets of Latin literature together with Virgilius and Horatius.
} 
all of the aforementioned guidelines were not specifically intended for building simulation, almost all of them also apply to this field. Within the EC project ECORA, Menter et al. (2002) published BPG based on the ERCOFTAC guidelines but modified and extended specifically for CFD code validation. Generic best practice advice was also provided by Jakeman et al. (2006) in the article "Ten iterative steps in development and evaluation of environmental models", which were later on extended to development and evaluation of process-based biogeochemical models of estuaries by Robson et al. (2008) but also to CFD for environmental fluid mechanics (including building simulation) by Blocken and Gualtieri (2012). Although mainly focused on outdoor applications, they could also be applied to indoor applications.

\subsection{Best practice guidelines for outdoor applications}

Section 3.3 indicated that already since the start of the application of CFD for wind flow around bluff bodies in the late 70s and 80s, researchers had been testing the influence of different computational parameters on the results, which had provided a lot of valuable information. In addition, Schatzmann et al. (1997) provided an important contribution on validation with field and laboratory data. However, initially this information was dispersed over a large number of individual publications in different journals, conference proceedings and reports. Note that a part of this section is intentionally reproduced from (Blocken 2014).

Within the Network for Quality and Trust in the Industrial Application of CFD (QNET-CFD), the Thematic Area on Civil Construction and HVAC (Heating, Ventilating and Air-Conditioning) and the Thematic Area on the Environment presented some best practice advice for CFD simulations of wind flow and dispersion (Scaperdas and Gilham 2004; Bartzis et al. 2004).

In 2004, Franke et al. (2004) compiled a set of specific recommendations for the use of CFD in wind engineering from a detailed review of the literature, as part of the European COST Action C14: Impact of Wind and Storm on City Life and Built Environment (COST = European Cooperation in Science and Technology). Later, this contribution was extended into an extensive "Best Practice Guideline for the CFD simulation of flows in the urban environment" (Franke et al. 2007, 2011), in the framework of the COST Action 732: Quality Assurance and Improvement of Microscale Meteorological Models, managed by Schatzmann and Britter (http://www.mi.uni-hamburg.de/Home.484.0.html). Like the ERCOFTAC guidelines, also these BPG primarily focused on steady RANS simulations, although also some limited information on URANS, LES and hybrid URANS/ LES was provided. When using CFD tools, whether they are academic/open source or commercial codes, it is also important that the code is well documented, and that basic verification tests and validation studies have been successfully performed and reported. A good description of how a microscale airflow and dispersion model has to be documented can be found in the Model Evaluation Guidance Document published in the COST Action 732 by Britter and Schatzmann (2007).

In Japan, working groups of the Architectural Institute of Japan (AIJ) conducted extensive cross-comparisons between CFD simulation results and high-quality wind tunnel measurements to support the development of guidelines for practical CFD applications. Part of these efforts were reported by Yoshie et al. (2007). In 2008, Tominaga et al. (2008a) published the "AIJ guidelines for practical applications of CFD to pedestrian wind environment around buildings", and Tamura et al. (2008) provided the "AIJ guide for numerical prediction of wind loads on buildings". The guidelines by Tominaga et al. (2008a) focused on steady RANS simulations, while the guidelines by Tamura et al. (2008) also considered LES, given the importance of time-dependent analysis for wind loading of buildings and structures.

In addition to these general BPG, also some very specific guidelines were published. These include (1) consistent modeling of equilibrium atmospheric boundary layers in computational domains (e.g. Richards and Hoxey 1993; Blocken et al. 2007a,b; Hargreaves and Wright 2007; Franke et al. 2007; Di Sabatino et al. 2007; Gorlé et al. 2009; Yang et al. 2009; Parente et al. 2011; Richards and Norris 2011; Blocken 2015); (2) high-quality grid generation (e.g. Tucker and Mosquera 2001; van Hooff and Blocken 2010a) and (3) validation with field and laboratory data (e.g. Schatzmann et al. 1997; Schatzmann and Leitl 2011). Note that most of the efforts in the first two areas were focused on steady RANS simulations. In addition, Blocken et al. (2012) also provided a general decision framework for the analysis of PLW comfort and safety in urban areas.

The establishment of these guidelines has been an important step towards more accurate and reliable RANS CFD simulations for the outdoor built environment. Although several of the guideline documents mentioned above were developed with focus on PLW conditions (Franke et al. 2004; Tominaga et al. 2008a; Blocken et al. 2012), most of the information is also applicable to other topics in building simulation for the outdoor built environment.

In contrast to the fairly large number of efforts towards BPG for RANS for outdoor building simulation applications, such efforts for LES simulations are rather scarce. In the framework of the AIJ, Tamura et al. (2008) provided an initial guide for the numerical prediction of wind loads on buildings based on an earlier extensive cooperative project (Tamura et al. 1997). Gousseau et al. (2013) provided a detailed solution verification and validation study leading 
to guidelines for wind flow around an isolated high-rise building. Many studies compared LES and RANS simulation results, but more general or extensive BPG for LES in the field of outdoor building simulation are-to the best knowledge of the author-not yet available. However, LES entails a firmly increased simulation complexity compared to RANS and, as stated by Hanna (1989) “... as the model formulation increases in complexity, the likelihood of degrading the model's performance due to input data and model parameter uncertainty increases as well." The lack of such BPG for LES can be attributed to several reasons:

(1) The still rather limited use of LES for practical applications. The establishment of the RANS BPG has been an iterative process over several decades, incited and supported by successes and failures in a wide range of practical applications. Conversely, the lack of LES BPG is one of the reasons why LES is not applied more frequently-a vicious circle.

(2) The computational costs of LES are at least an order of magnitude larger than for RANS, and possibly at least two orders of magnitude larger when the necessary actions for solution verification and validation are to be included. But even without solution verification and validation, LES will often be too computationally demanding for many practical applications, even the less complicated ones such as PLW conditions (Yoshie et al. 2007). The establishment of BPG, which has to be based on many LES simulations in extensive sensitivity studies, will require a much higher computational cost and much more time and effort than the RANS BPG.

(3) Ironically, the lack of BPG in LES is undoubtedly delaying the development of further LES BPG. For RANS simulations, the establishment of the first series of BPG documents has incited continued efforts over the years and has led to the current situation in which the different outdoor applications in the field of building simulation are increasingly well covered by guidelines.

The lack of BPG for LES combined with the increased model complexity of LES can be held accountable, at least partly, for many poor quality LES simulations and can serve as background for the statements by Shah and Ferziger (1997) and Hanjalic (2005) mentioned in section 4. Shah and Ferziger (1997) indeed stated that it is possible for LES to yield results that are incorrect qualitatively as well as quantitatively, and Hanjalic (2005) mentioned that "conventional LES on a too-coarse grid of wall bounded flows, especially in attached flows regions, can be very erroneous and inferior to even simple conventional RANS."

\subsection{Best practice guidelines for indoor applications}

Section 3.4 indicated that already since the start of the application of CFD for indoor airflow in the 70s and 80s, researchers had been testing the influence of these parameters on the results, which had provided a lot of valuable information. Similar to the situation for outdoor building simulation applications, initially, this information was dispersed over a large number of individual publications in different journals, conference proceedings and reports. Later, several documents were compiled that serve as references on best practices in the field.

Chen (1997) described successes and failures in RANS CFD for HVAC applications. When testing eight popular eddy-viscosity and Reynolds-stress models for natural convection, forced and mixed convection and impinging jet flows in rooms, (Chen 1995, 1996) found that none of the models produces satisfactory results and that the difference between the computed turbulence level and the measured one can be more than $100 \%$.

Chen and Srebric (2001) provided a very extensive BPG report on how to verify, validate and report environment modeling CFD analysis. The report is focused on RANS simulations, and includes basic flow and heat transfer, turbulence modeling, numerical methods, assessment of the CFD results and drawing conclusions from the CFD simulation results. It illustrates the CFD process step-bystep for two representative indoor environmental modeling applications, an office with mechanical displacement ventilation and an apartment building with natural ventilation.

Sørensen and Nielsen (2003) provided a paper focused on quality control of CFD simulations for indoor environments, with two main targets: (1) performing simulations with sufficient accuracy; and (2) reporting the simulations results in sufficient detail to allow readers to judge the quality. They addressed issues in turbulence modeling, specification of boundary conditions, numerical errors, and choices of differencing schemes and computational grids. While their paper was primarily focused on RANS simulations, their philosophy and discussions equally apply to LES and DNS.

Nielsen (2004) discussed the quality level of CFD and the involved schemes by the use of the Smith and Hutton problem on the mass fraction transport equation. He discusses the different aspects of boundary conditions in the indoor environment as, e.g., the simulation of Air Terminal Devices and the simulation of furnishings and occupants.

The REHVA Guidebook 10 (Nielsen et al. 2007) also provides a very extensive set of guidelines for CFD calculations for the analysis of air and pollution distribution in various spaces. However, it explicitly focuses on the RANS approach with first-order closure. Important advice has also been documented in the books by Etheridge and Sandberg (1996), Heiselberg et al. (1998), Awbi (2003, 2008) and others. 


\section{LES and RANS in building simulation applications}

"The root of the matter is that the greatest stimulus of scientific discovery are its practical applications." 5

In the past decades, a very large number of valuable application studies have been performed by either LES or RANS, or both. Without wanting to detract from the importance of any of these studies, in the interest of brevity, only very few are mentioned in this section.

\subsection{Pedestrian-level wind conditions, wind comfort and wind safety}

Past studies on PLW conditions have revealed the interesting observation that steady RANS CFD simulations- when performed according to best practices-can accurately predict the mean wind speed in high wind speed regions around buildings, while their performance in the low wind speed regions can be very poor (Yoshie et al. 2007; Blocken and Carmeliet 2008; Blocken et al. 2008b, 2011; Blocken et al. 2016b). A few examples are provided below.

Yoshie et al. (2007) compared CFD simulations and wind tunnel measurements for an isolated building with ratio $L: W: H=1: 1: 2$ (Fig. 11a). The CFD simulations were
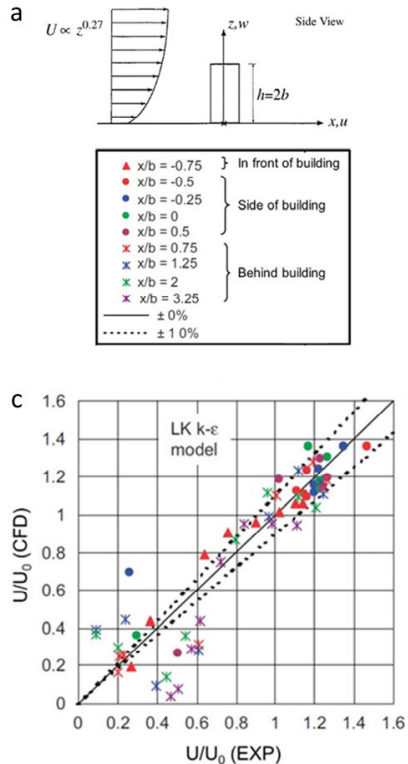

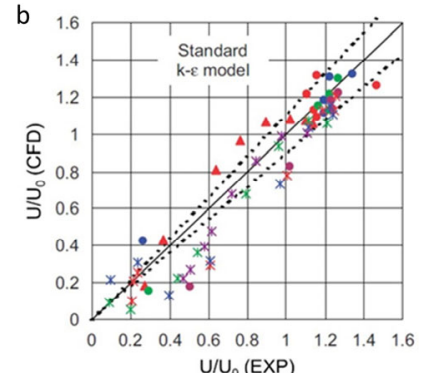

$\mathrm{U} / \mathrm{U}_{0}$ (EXP)

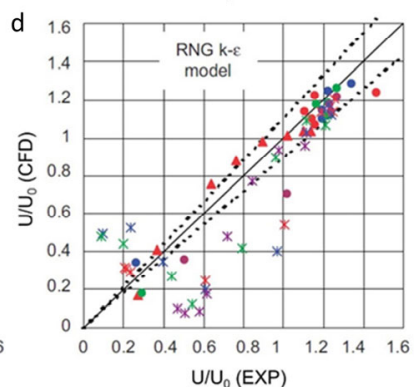

Fig. 11 (a) Isolated building configuration in the validation studies by Yoshie et al. (2007). (b-d) Comparison of CFD results and wind tunnel measurements of amplification factor $K=U / U_{0}$ around the building: (b) steady RANS with standard $k$ - $\varepsilon$ model; (c) steady RANS with LK $k-\varepsilon$ model; (d) steady RANS with RNG $k-\varepsilon$ model. The symbols refer to: $\Delta=$ front of building; $o=$ side of building; $\mathrm{x}=$ behind building. The different colors refer to a variety of positions in front, beside and behind the building (Yoshie et al. 2007; reproduced with permission @Elsevier)

${ }^{5}$ Lewis Fry Richardson (1908). performed with the steady RANS approach with the standard $k-\varepsilon$ model and two revised $k-\varepsilon$ models for closure: the Launder-Kato $k-\varepsilon$ model (Kato and Launder 1993) and the RNG $k-\varepsilon$ model (Yakhot and Orszag 1986). The comparison with the measurements in Figs. 11b-d shows that the amplification factor $K=U / U_{0}$ (ratio of local mean wind speed $U$ to the mean wind speed $U_{0}$ at the same position without buildings present) is generally predicted within $10 \%$ in the regions where $U / U_{0}>1$. However, in the wake region behind the building, where $U / U_{0}<1$, large underestimations are obtained, locally by a factor 5 or more (Figs. 11b-d). These underestimations are due to the underestimation of turbulent kinetic energy in the wake, because steady RANS evidently cannot capture the vortex shedding (Murakami 1993; Yoshie et al. 2007; Tominaga et al. 2008b).

Blocken and Carmeliet (2008) obtained very similar conclusions when performing steady RANS CFD simulations with the realizable $k-\varepsilon$ model (Shih et al. 1995) for groups of parallel shifted buildings. They compared the CFD results with the sand-erosion wind tunnel experiments by Beranek (1982). Figure 12 shows the very good agreement between CFD and wind tunnel results in the region of high $K$ (about

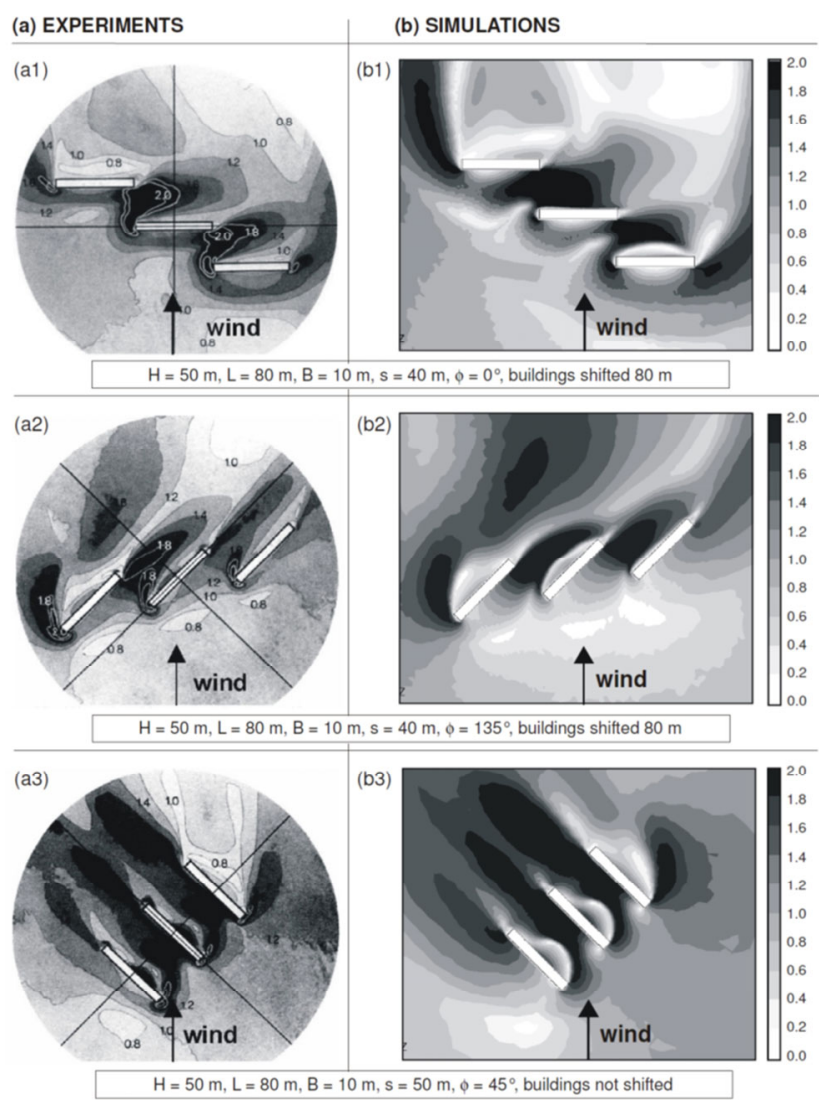

Fig. 12 Validation study for parallel building configurations by Blocken and Carmeliet (2008). (a) Top view of sand-erosion contour plots versus (b) top view of RANS CFD results of the amplification factor $K$. White contour lines in sand-erosion plots correspond to amplification factors of 1.8 and 2.0 
$10 \%$ accuracy) and significant underestimations in the regions of lower $K$. Later studies also consistently showed a close agreement between steady RANS predictions of mean wind speed in the regions of high $K$ (Yim et al. 2009; Blocken and Persoon 2009; Blocken et al. 2012; Janssen et al. 2013; An et al. 2013).

These observations that steady RANS CFD with first order-closure-when applied according to best practice can provide accurate results $(\sim 10 \%)$ of mean wind speed in regions of high $K(>1)$ but poor to very poor results in regions of low $K$ is very important towards the practical assessment of PLW comfort. Blocken et al. (2016b) hypothesized that the poor RANS performance in regions of low $K$ would not necessarily compromise the accuracy of PLW comfort assessment, because the higher amplification factors provide the largest contribution to the discomfort exceedance probability in the comfort criterion. To check this hypothesis, they executed a complete wind comfort assessment for a simple case: an isolated high-rise building tower $(L \times B \times H=$ $40 \mathrm{~m} \times 20 \mathrm{~m} \times 70 \mathrm{~m}$ ) on flat, level, uniformly rough terrain with aerodynamic roughness length $z_{0}=0.25 \mathrm{~m}$.

The wind comfort assessment study was performed according to the Dutch Wind Nuisance Standard NEN
8100 (NEN 2006a,b). A complete wind comfort assessment study involves a combination of three types of information/ data: (1) statistical meteorological data; (2) aerodynamic information; and (3) a comfort criterion. The aerodynamic information, i.e. the PLW speed around the building, was provided by the sand erosion tests by Beranek and van Koten (1979a,b). Figure 13 shows the results for different wind directions. We focus on two critical points $\mathrm{A}$ and $\mathrm{B}$ : for wind direction $0^{\circ}$, point $\mathrm{A}$ is situated in the corner stream and point $B$ in the standing vortex. The areas of the corner stream and the standing vortex exhibit the highest $K$ and represent the most problematic areas for wind comfort. Note however that as the wind direction changes, these points are located in areas of higher or lower $K$. The meteorological data are provided by the Royal Dutch Meteorological Institute and are the 30-year statistical meteorological data of potential wind speed $\left(U_{\text {pot }}\right)$ at Eindhoven airport. The potential wind speed is defined as the wind speed at $10 \mathrm{~m}$ height over a terrain with $z_{0}=$ $0.03 \mathrm{~m}$. We consider twelve wind directions: $0^{\circ}-330^{\circ}$ in intervals of $30^{\circ}$. The comfort criterion is that by NEN 8100 with a threshold wind speed $U_{\text {THR }}=5 \mathrm{~m} / \mathrm{s}$ and exceedance probabilities linked to different activities (Table 1). However,
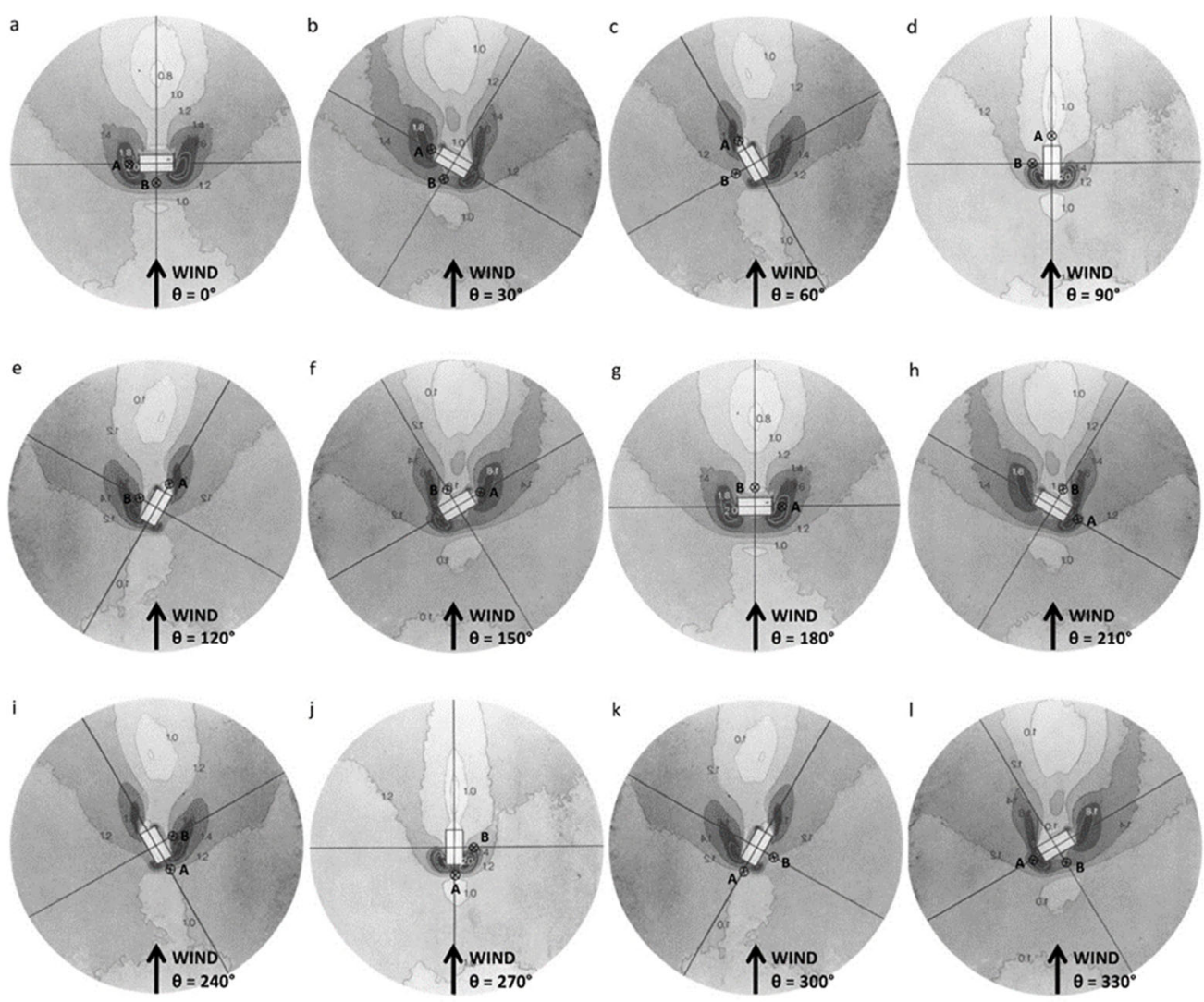

Fig. 13 Sand erosion contours of amplification factor $K$ for an isolated building with dimensions $L \times B \times H=40 \mathrm{~m} \times 20 \mathrm{~m} \times 70 \mathrm{~m}$ for 12 different wind directions. Indication of points A and B where wind comfort is evaluated (Blocken et al. 2016b; reproduced with permission (CElsevier) 
Table 1 Criteria for wind comfort according to NEN 8100 (2006a)

\begin{tabular}{|c|c|c|c|c|}
\hline \multirow{2}{*}{$\begin{array}{c}P\left(U_{\mathrm{THR}}>5 \mathrm{~m} / \mathrm{s}\right) \\
\text { (in } \% \text { hours per year) }\end{array}$} & \multirow[b]{2}{*}{ Grade } & \multicolumn{3}{|c|}{ Activity } \\
\hline & & Traversing & Strolling & Sitting \\
\hline$<2.5$ & A & Good & Good & Good \\
\hline $2.5-5.0$ & B & Good & Good & Moderate \\
\hline $5.0-10$ & $\mathrm{C}$ & Good & Moderate & Poor \\
\hline $10-20$ & $\mathrm{D}$ & Moderate & Poor & Poor \\
\hline$>20$ & $\mathrm{E}$ & Poor & Poor & Poor \\
\hline
\end{tabular}

also other threshold wind speed values are considered to extend the general character of this exercise. The exceedance probability $P_{\theta}$ of $U_{\text {pot }}$ in relation to a threshold wind speed $U_{\text {THR, } 10 \mathrm{~m}}$ at $10 \mathrm{~m}$ height can be expressed by a Weibull distribution where the Weibull parameters $A, c$ and $k$ are fitted based on the 30-year meteorological data:

$$
P_{\theta}=P_{\theta}\left(U_{\mathrm{pot}}>U_{\mathrm{THR}, 10 \mathrm{~m}}\right)=100 \cdot A(\theta) \cdot \exp \left[-\left(\frac{U_{\mathrm{THR}, 10 \mathrm{~m}}}{c(\theta)}\right)^{k(\theta)}\right]
$$

For simplicity we assume that every wind direction has the same frequency occurrence and the same contribution to the wind statistics, and that the exceedance probability for a given threshold value and a given wind direction is $1 / 12^{\text {th }}$ of the sum of the exceedance probabilities for all 12 wind directions:

$$
\begin{aligned}
P_{\theta}^{\prime} & =P_{\theta}^{\prime}\left(U_{\mathrm{pot}}>U_{\mathrm{THR}, 10 \mathrm{~m}}\right) \\
& =\frac{100}{12} \cdot \sum_{\theta=0^{\circ}}^{330^{\circ}}\left[A(\theta) \cdot \exp \left[-\left(\frac{U_{\mathrm{THR}, 10 \mathrm{~m}}}{c(\theta)}\right)^{k(\theta)}\right]\right]
\end{aligned}
$$

The aerodynamic information is the product of two contributions: a terrain-related contribution $\left(U_{0} / U_{\text {pot }}\right)$ and a design-related contribution $\left(K=U / U_{0}\right)$. The design-related contribution is given by the local amplification factor $K$ in Fig. 13. The terrain-related contribution is obtained by combining the expression of the vertical mean wind speed profile by the logarithmic law and the wind speed conversion using the blending height of $60 \mathrm{~m}$ (Verkaik 2006). Figure 14a shows the results in terms of the total exceedance probability
$P=\Sigma 12 P_{\theta}^{\prime}$ as a function of $K$ with $U_{\text {THR }}$ as a parameter. It indicates to which extent $K$ values contribute to the total exceedance probability. It clearly shows that larger $K$ values contribute more but that this is also governed by the choice of $U_{\text {THR. Figure }} 14 \mathrm{~b}$ shows the derivative of $P$ to $K$ with $U_{\text {THR }}$ as parameter. It indicates the sensitivity of $P$ to changes in $K$ and hence the extent to which errors in $K$ will propagate to errors in $P$.

To demonstrate the extent to which typically errors in $K$ as obtained by RANS first-order closure simulations propagate to errors in $P$, two different sets of $K$ values are considered. The first set corresponds to the values in Fig. 13. The second set is created from the first set by changes taking into account the error levels in Table 2. This yields the values of modified $K\left(K_{\bmod }\right)$ in Table 3 . The magnitude of the error levels is chosen based on Figs. 11b-d but assuming to some extent a worst-case scenario, i.e. all errors are underestimations, so there is no compensation of underestimations by overestimations as can be the case in reality as shown in Figs. 11b-d. Application of the total wind comfort procedure consists of combining Table 3 and Fig. 14a, which yields Fig. 15. The numerical values of the differences (i.e. errors) are given in Table 4. For all values of $U_{\mathrm{THR}}$ : In spite of the large errors imposed on especially the lower values of $K$, the errors in $P$ remain rather limited. In reality however it is likely that errors by overestimations and underestimations of $K$ will compensate each other, resulting in even lower total errors in $P$ than in the present study. One could argue that the $K$ errors will be larger in points other than $\mathrm{A}$ and $\mathrm{B}$ in less windy regions where $K$ is lower, however note that the points with the highest $K$ values are generally of most interest because they are the most important positions in terms of wind comfort.

Although LES is an intrinsically more accurate technique, this example study by Blocken et al. (2016b) supports the continued use of the faster and less expensive RANS approach for PLW studies. Extrapolating the statement by the late Joel H. Ferziger (Ferziger 1990), we argue that PLW comfort is one of the few topics in wind engineering where nature is kind to us concerning turbulent flows.
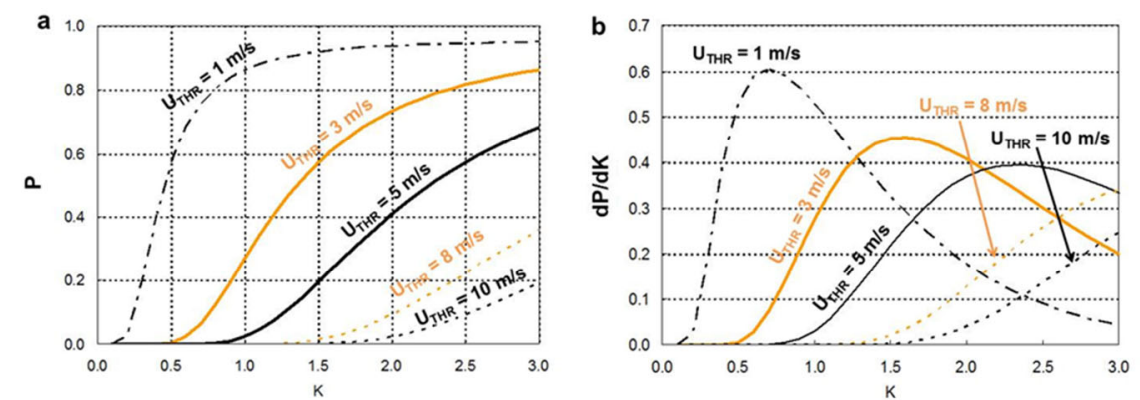

Fig. 14 (a) Exceedance probability $P$ as a function of local amplification factor $K$, with the threshold wind speed $U_{\text {THR }}$ as parameter. (b) Sensitivity $\mathrm{d} P / \mathrm{d} K$ as a function of $K$ with $U_{\mathrm{THR}}$ as a parameter (Blocken et al. 2016b; reproduced with permission $\odot$ Elsevier) 
Table 2 Errors imposed on amplification factor $K$, yielding modified values $K_{\text {mod }}$

\begin{tabular}{ccc}
\hline$K$ & Error & $K_{\text {mod }}$ \\
\hline 2.0 & $10 \%$ & 1.8 \\
1.9 & $10 \%$ & 1.71 \\
1.8 & $10 \%$ & 1.62 \\
1.7 & $10 \%$ & 1.53 \\
1.6 & $10 \%$ & 1.44 \\
1.5 & $10 \%$ & 1.35 \\
1.4 & $10 \%$ & 1.26 \\
1.3 & $10 \%$ & 1.17 \\
1.2 & $10 \%$ & 1.08 \\
1.1 & $10 \%$ & 0.99 \\
1.0 & $20 \%$ & 0.8 \\
0.9 & $20 \%$ & 0.72 \\
0.8 & $30 \%$ & 0.56 \\
0.7 & $30 \%$ & 0.49 \\
0.6 & $50 \%$ & 0.3 \\
0.5 & $50 \%$ & 0.25 \\
0.4 & $70 \%$ & 0.12 \\
0.3 & $70 \%$ & 0.09 \\
0.2 & $90 \%$ & 0.02 \\
0.1 & $90 \%$ & 0.01 \\
\hline & & \\
\hline
\end{tabular}

\subsection{Near-field pollutant dispersion around buildings}

Near-field dispersion is defined as the dispersion in the immediate range (horizontal distance downwind up to 10 times the building height) of the building under study. A distinction is made here concerning dispersion around an isolated building and dispersion in a high-density urban area, as both configurations lead to different conclusions in terms of RANS performance.

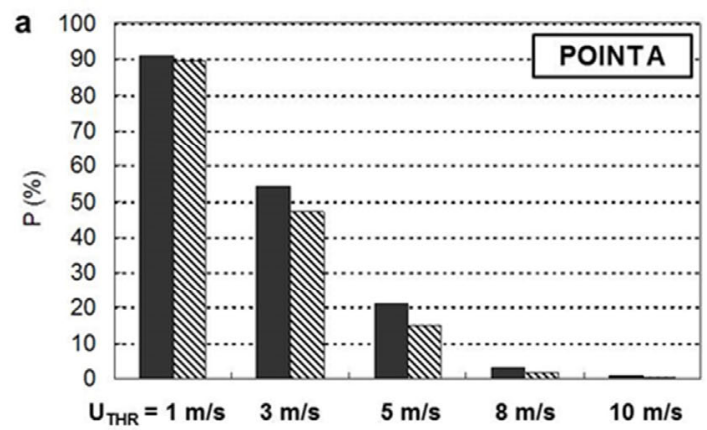

Table 3 Amplification factors $K$ and $K_{\text {mod }}$ for points A and B and all wind directions

\begin{tabular}{cccccc}
\hline & \multicolumn{2}{c}{ POINT A } & \multicolumn{2}{c}{ POINT B } \\
\cline { 2 - 5 } \cline { 4 - 5 } & $K$ & $K_{\text {mod }}$ & & $K$ & $K_{\text {mod }}$ \\
\hline $0^{\circ}$ & 2.00 & 1.80 & 1.50 & 1.35 \\
$30^{\circ}$ & 1.80 & 1.62 & 1.50 & 1.35 \\
$60^{\circ}$ & 1.50 & 1.35 & 1.20 & 1.08 \\
$90^{\circ}$ & 0.90 & 0.72 & 1.40 & 1.26 \\
$120^{\circ}$ & 1.20 & 1.08 & 1.40 & 1.26 \\
$150^{\circ}$ & 1.80 & 1.62 & 0.90 & 0.72 \\
$180^{\circ}$ & 2.00 & 1.80 & 1.00 & 0.80 \\
$210^{\circ}$ & 1.50 & 1.35 & 1.00 & 0.80 \\
$240^{\circ}$ & 1.20 & 1.08 & 1.50 & 1.35 \\
$270^{\circ}$ & 1.20 & 1.08 & 1.50 & 1.35 \\
$300^{\circ}$ & 1.20 & 1.08 & 1.20 & 1.08 \\
$330^{\circ}$ & 1.80 & 1.62 & 1.50 & 1.35 \\
\hline
\end{tabular}

Table 4 Total exceedance probabilities for amplification factors $K$ and $K_{\text {mod }}$ for points A and B and for different values of $U_{\text {THR }}$

\begin{tabular}{|c|c|c|c|c|c|c|c|c|c|c|}
\hline & \multicolumn{2}{|c|}{$\begin{array}{c}U_{\mathrm{THR}}= \\
1 \mathrm{~m} / \mathrm{s}\end{array}$} & \multicolumn{2}{|c|}{$\begin{array}{c}U_{\mathrm{THR}}= \\
3 \mathrm{~m} / \mathrm{s}\end{array}$} & \multicolumn{2}{|c|}{$\begin{array}{c}U_{\mathrm{THR}}= \\
5 \mathrm{~m} / \mathrm{s}\end{array}$} & \multicolumn{2}{|c|}{$\begin{array}{c}U_{\mathrm{THR}}= \\
8 \mathrm{~m} / \mathrm{s}\end{array}$} & \multicolumn{2}{|c|}{$\begin{array}{l}U_{\text {THR }}= \\
10 \mathrm{~m} / \mathrm{s}\end{array}$} \\
\hline & A & B & A & B & A & B & A & B & A & B \\
\hline$P(K)$ & 91.1 & 89.8 & 54.1 & 45.5 & 20.8 & 12.3 & 3.1 & 0.7 & 0.7 & 0.1 \\
\hline$P\left(K_{\mathrm{mod}}\right)$ & 89.5 & 87.3 & 47.1 & 36.2 & 15.2 & 7.6 & 1.6 & 0.3 & 0.2 & 0.0 \\
\hline Difference & 1.6 & 2.5 & 6.9 & 9.3 & 5.6 & 4.7 & 1.5 & 0.5 & 0.4 & 0.0 \\
\hline
\end{tabular}

\subsubsection{Generic isolated building}

Many CFD studies on pollutant dispersion for generic isolated buildings were based on the generic wind tunnel study of dispersion from a rooftop vent on an isolated cubic building by Li and Meroney (1983a,b) (Fig. 16a). CFD simulations for this configuration were reported by e.g. Li and Stathopoulos (1997), Blocken et al. (2008c), Tominaga and Stathopoulos (2009, 2010), Gousseau et al. (2011b,

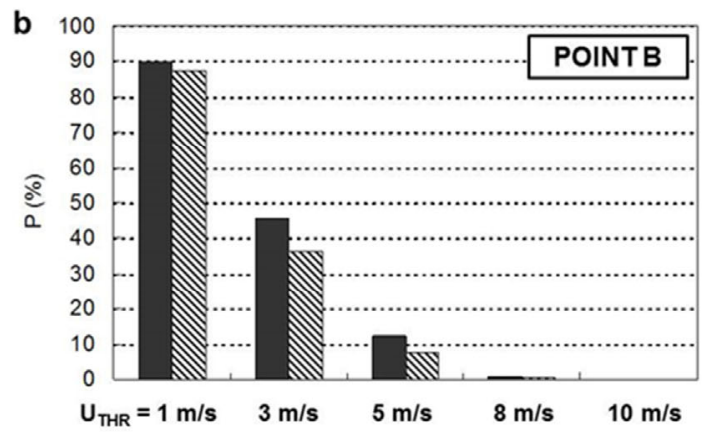

Fig. 15 Exceedance probability $P(\%)$ in (a) point A and (b) point B, for different values of the threshold wind speed $U_{\text {THR. The solid }}$ bars and the hashed bars represent results from the two sets of amplification factors (Blocken et al. 2016b; reproduced with permission (c) Elsevier) 
a

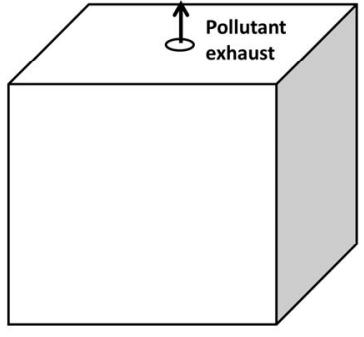

b
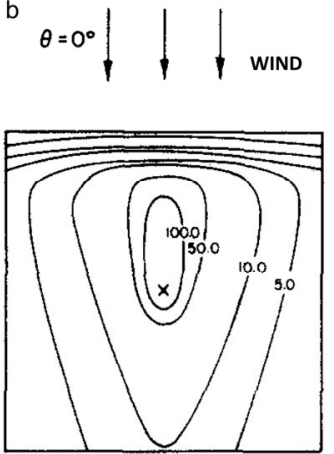

c

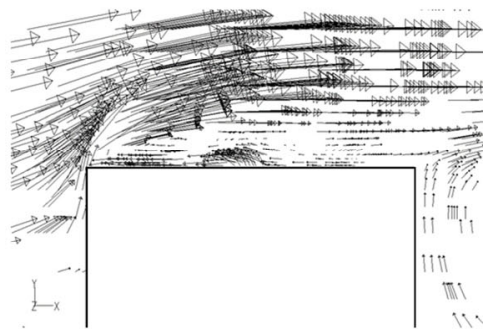

Fig. 16 (a) Isolated cubic building with rooftop vent; (b) contours of dimensionless concentration coefficient $C^{*}$ on the roof of the building (Li and Meroney 1983a; reproduced with permission (OElsevier); (c) mean velocity vector field in vertical centerplane through the cubic building (Blocken et al. 2008c)

2012) and Bazdidi-Tehrani et al. (2013). Below, the detailed simulations by Tominaga and Stathopoulos $(2009,2010)$ are provided in comparison to the wind tunnel experiments.

The reduced-scale building height is $0.05 \mathrm{~m}$ and the vent is located in the middle of the roof. The approach-flow is a neutrally stratified atmospheric boundary layer with power-law exponent 0.19 , reduced-scale height $0.3 \mathrm{~m}$, and mean wind speed $3.3 \mathrm{~m} / \mathrm{s}$ at roof height. The longitudinal turbulence intensity is about $12 \%$ at roof height. The momentum ratio; i.e. the ratio of vertical exhaust velocity from the vent to the approach-flow wind speed at roof height is 0.19 . Figure $16 \mathrm{~b}$ shows the measured contours of the dimensionless concentration coefficient $C^{*}$ on the roof.
$C^{*}$ is defined as:

$$
C^{*}=\frac{C U_{H} L H}{Q} \times 10^{-6}
$$

where $C$ is the mean concentration in $p p m, Q$ is the pollutant emission rate in $\mathrm{m}^{3} / \mathrm{s}, H$ and $L$ are obstacle height and length and $U_{H}$ the mean wind speed at height $H$. Here, $U_{H}$ is the approach-flow wind speed at roof height. Due to the low momentum ratio, the pollutant is trapped in the separation bubble above the roof and then transported inside this bubble towards the upwind roof edge, from which the pollutant is spread over the width of the roof and then convected downwind (Fig. 16c). Figure 17 displays the

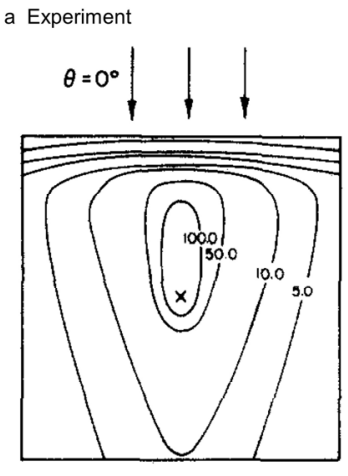

d LK K- $\varepsilon$ model

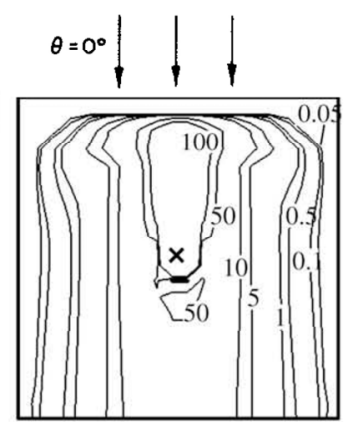

b Standard k- $\varepsilon$ model

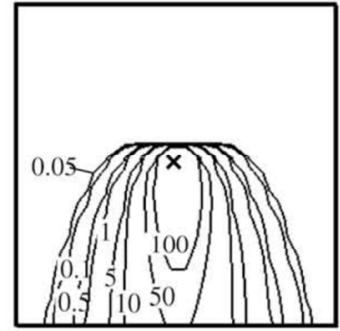

e RLZk- $\varepsilon$ model c RNG k- $\varepsilon$ model
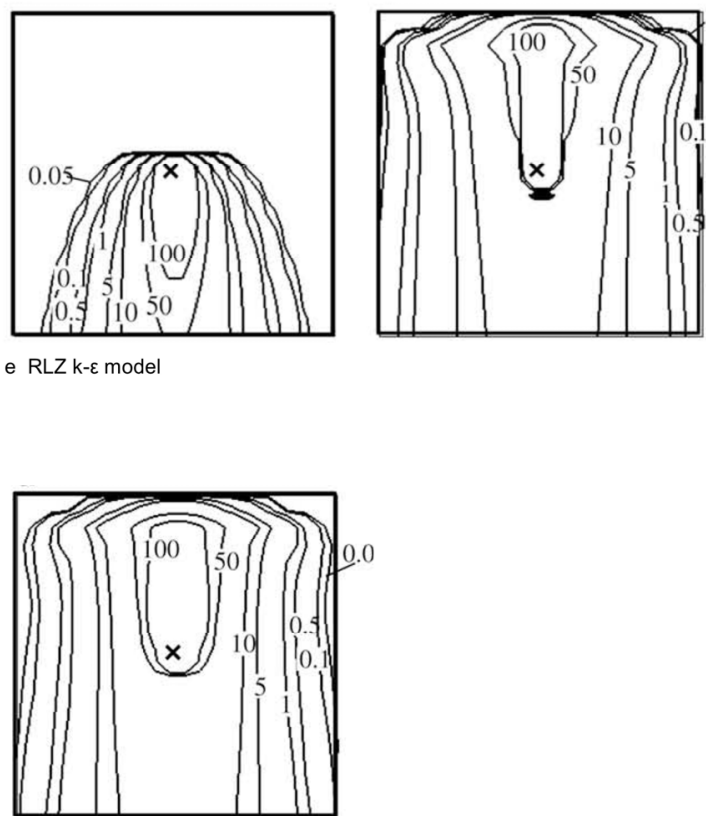

Fig. 17 Rooftop contours of dimensionless concentration coefficient $C^{*}$. (a) Experiment by Li and Meroney (1983a); (b-e) RANS CFD results by different turbulence models (Tominaga and Stathopoulos 2009) (all figures: reproduced with permission @Elsevier) 
RANS first-order closure simulations results by Tominaga and Stathopoulos (2009) on the building roof. While the standard $k-\varepsilon$ model provides a very poor agreement with the experiments, the modified $k-\varepsilon$ models provide a qualitatively better performance especially in terms of the upwind dispersion over the roof. However, deficiencies are noted for every simulation. Figures $17 \mathrm{c}$ and $\mathrm{d}$ show too much upwind dispersion and too low lateral dispersion. Figure $17 \mathrm{e}$ shows a somewhat better upwind dispersion but again a too low lateral dispersion.

A clearer view of the dispersion process that helps in understanding the deficiencies of the RANS modeling is shown in Fig. 18 as LES snapshots of contours of $C^{*}$ at different time steps. These contours show that the pollutant
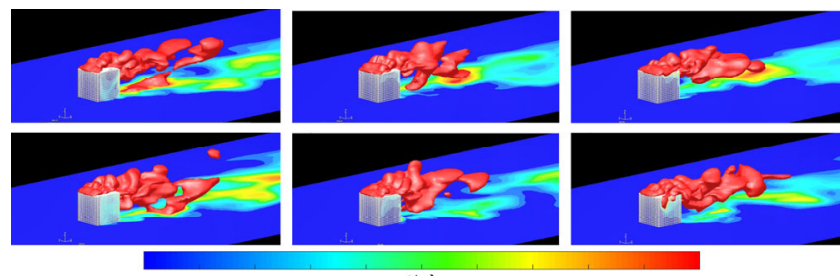

$C^{*} \rightarrow$

Fig. 18 LES simulation: snapshots of contours of dimensionless concentration coefficient $C^{*}$
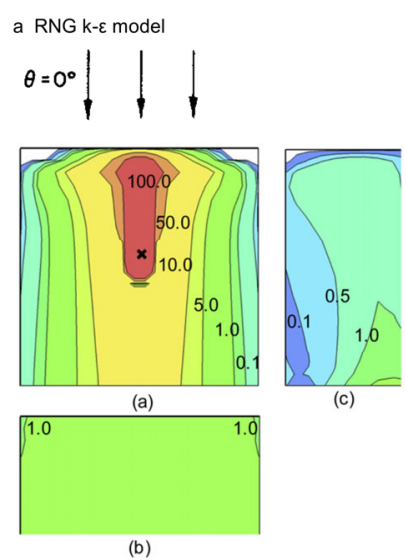

b Large Eddy Simulation
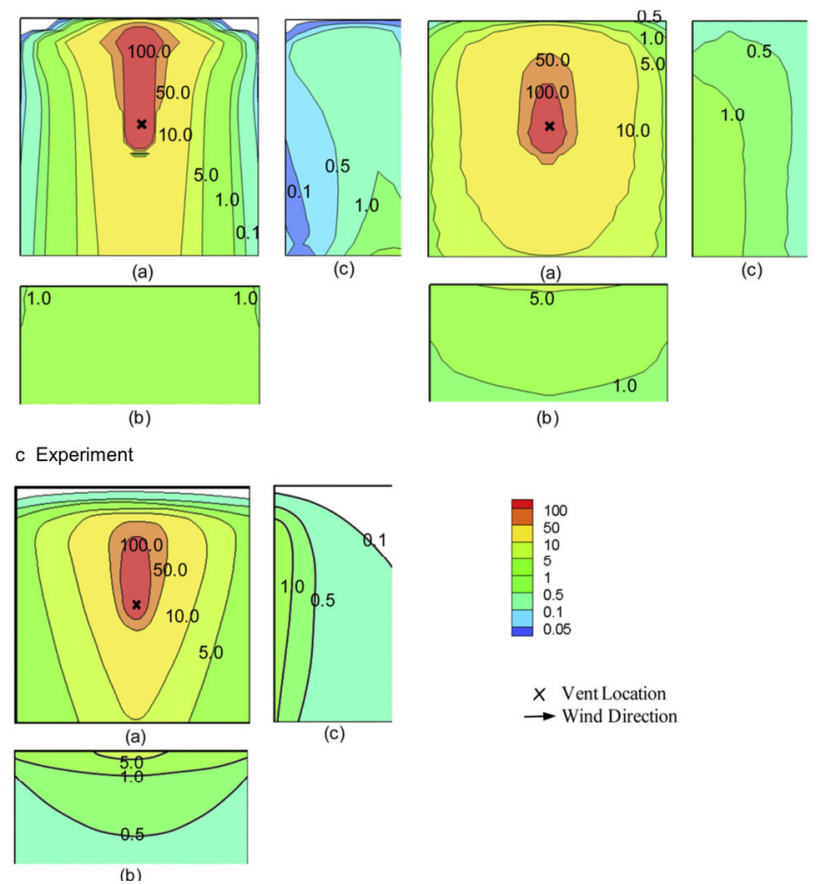

(b)
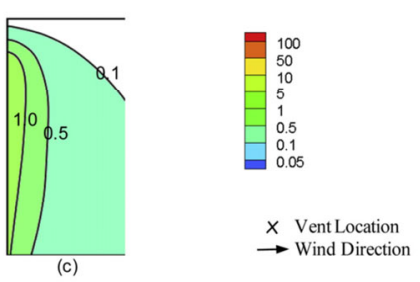

Fig. 19 Rooftop contours of dimensionless concentration coefficient $C^{*}$. (a) RANS CFD RNG $k-\varepsilon$ results by Tominaga and Stathopoulos (2010); (b) LES CFD results by Tominaga and Stathopoulos (2010); (c) experimental results by Li and Meroney (1983a) (all figures: reproduced with permission @Elsevier) exhausted from the rooftop vent is immediately convected upstream and the actually spread not along along part but along the entire upwind roof edge length, after which it is partly recirculated in the separation bubble and partly evacuated outside this bubble and moved into the wake region. As a result, indeed, the detailed LES simulations by Tominaga and Stathopoulos (2010) show a better agreement with the experiments, as shown in Fig. 19, not only for the roof top contours but also for the contours on the side and leeward facade. Figure 20 better highlights the different performance of the RANS RNG model versus LES by means of a semi-logarithmic diagram. Especially Fig. 20b that shows the lateral dispersion clearly illustrates the superior performance of LES compared to RANS RNG.

\subsubsection{Urban areas with high plan area density}

Two specific studies are addressed here: the study by Blocken et al. (2016a) on the generic urban area defined in the wind tunnel study by Garbero et al. (2010) and the study by Hanna et al. (2006) on the actual urban area of downtown Manhattan.

Garbero et al. (2010) reported wind tunnel experiments of the dispersion of passive tracer gas from a point source in regular arrays of rectangular building models (Fig. 21). Three different arrays were considered: array A with street width in both directions $S_{x}$ and $S_{y}$ equal to $H$; array B with $S_{x}=H$ and $S_{y}=2 H$; and array C with $S_{x}=2 H$ and $S_{y}=H$. The point source was positioned in the middle of the intersection between two perpendicular streets at height $z / H=0.5$ (Fig. 21). A neutrally stratified turbulent boundary layer was generated with a height of about $0.8 \mathrm{~m}$. The 1:400 reduced-scale building models had dimensions $L \times W \times H=$ $250 \mathrm{~mm} \times 250 \mathrm{~mm} \times 50 \mathrm{~mm}$, corresponding to $L \times W \times H=$ $100 \mathrm{~m} \times 100 \mathrm{~m} \times 20 \mathrm{~m}$ in full scale. The model roofs were each covered with 14 staggered "nuts" of $5 \mathrm{~mm}$ height representing roof-top structures. The reference wind speed at boundary-layer height was $5 \mathrm{~m} / \mathrm{s}$ resulting in an obstacle Reynolds number (based on obstacle height and wind speed at that height) of 6700. Concentration measurements were made at $z / H=0.5$ and $z / H=2$. The $3 \mathrm{D}$ steady RANS CFD simulations were performed with the realizable $k-\varepsilon$ model (Shih et al. 1995) and the Eulerian advectiondiffusion equation (Eq. 3d) with the standard gradientdiffusion hypothesis. Two different values of the turbulent Schmidt number $S c_{\mathrm{t}}$ are used (0.3 and 0.7) in accordance with previous overview and review studies on gas dispersion (Tominaga and Stathopoulos 2007, 2013). The results are shown as simulated versus measured profiles of $C^{*}$ at height $z / H=0.5$ along horizontal lines in the lateral streets and as simulated contours of $C^{*}$ (see insert figures) in a horizontal 


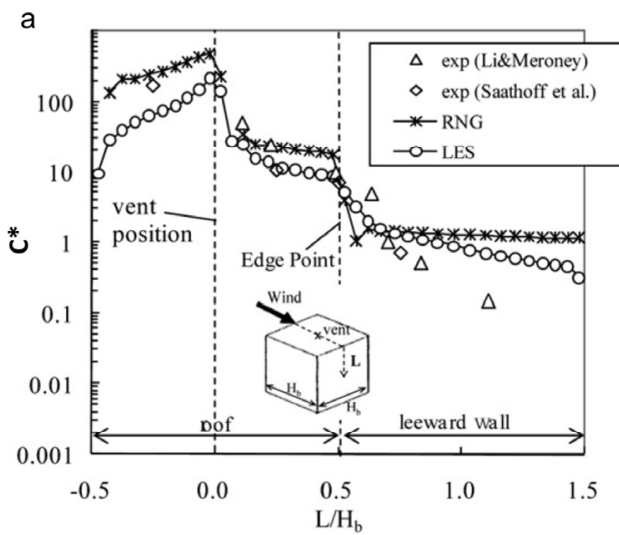

(1) Streamwise direction

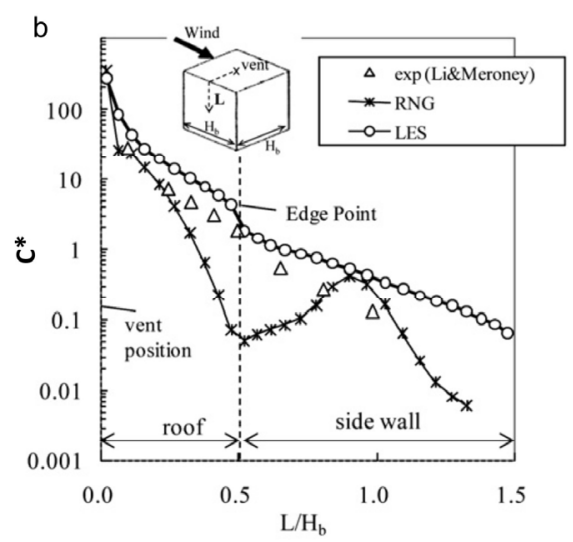

(2) Lateral direction

Fig. 20 Distribution of dimensionless concentration coefficient $C^{*}$ along lines on roof and leeward/side wall (Tominaga and Stathopoulos 2010; reproduced with permission (CElsevier)

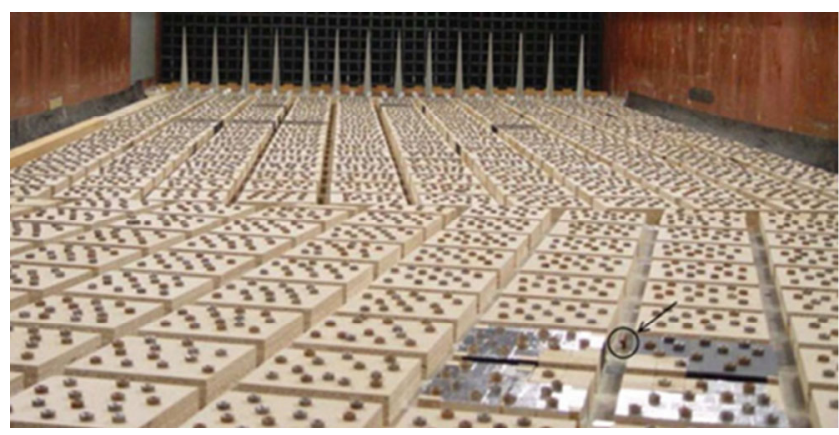

Fig. 21 Wind tunnel set-up of building array with indication of source position (Garbero et al. 2010; reproduced with permission (c) Springer)

plane at the same height (Figs. 22 to 24). The following main observations are made:

- Figure 22: the maximum concentrations are mostly reproduced within a factor 2 from the measurement values. The simulations with $S c_{\mathrm{t}}=0.3$ (more turbulent diffusion) underestimate the street concentrations while those with $S c_{\mathrm{t}}=0.7$ (less turbulent diffusion) overestimate the street concentrations, except in the first street downstream of the source. A higher turbulent diffusion causes more gas to leave the street canyons vertically and to be evacuated over the building array. For both $S c_{\mathrm{t}}$ values, plume spreading is underpredicted.

- Figure 23: The simulations with $S c_{\mathrm{t}}=0.3$ and 0.7 both underestimate the maximum concentrations. While for $S c_{\mathrm{t}}=0.7$, the deviations are less than a factor 2 , for $S c_{\mathrm{t}}=$ 0.3 , in the more downwind streets they can go up to a factor 4. Both $S c_{\mathrm{t}}$ values provide an accurate reproduction of the extent of the lateral spread.

- Figure 24: The larger street with in the streamwise direction provides a very different dispersion pattern as in the previous cases. $S c_{\mathrm{t}}=0.3$ underestimates the maximum
$C^{*}$ by a factor 2 up to 4 , while $S c_{\mathrm{t}}=0.7$ reproduces the maximum $C^{*}$ within a factor 0.25 . While both simulations cannot accurately reproduce the extent of the lateral spread, the predicted trend (skewness) in the $3^{\text {rd }}$ and $5^{\text {th }}$ street is good.

The fact that a variation in $S c_{\mathfrak{t}}$ sometimes yields a better accuracy is not surprising because the actual value of the $S c_{t}$ number depends on the type of flow pattern and on the location in this flow pattern. However, apart from the case with $S_{x}=50 \mathrm{~mm}, S_{y}=100 \mathrm{~mm}$ (Fig. 23), the measured

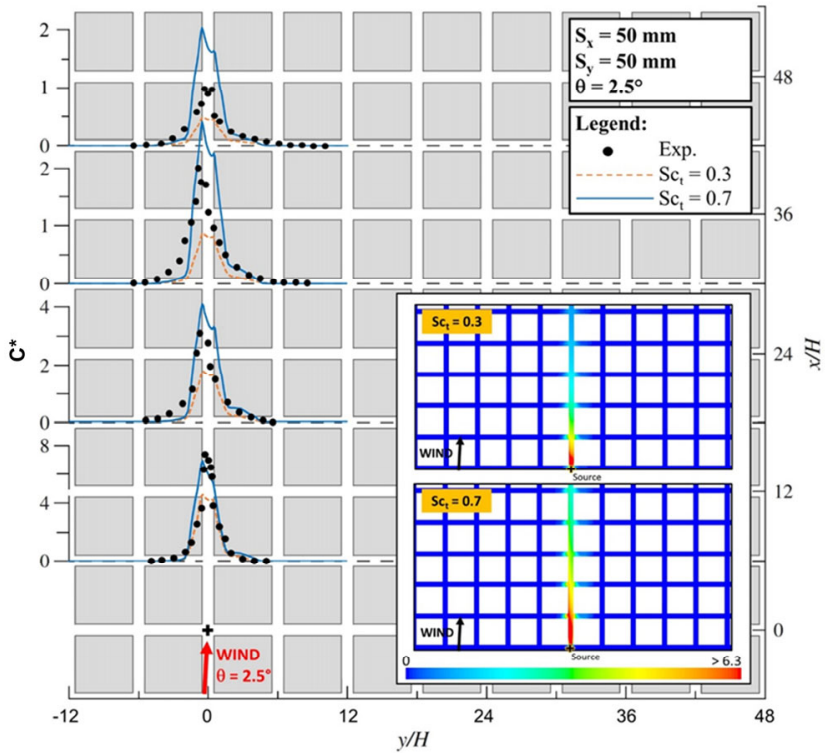

Fig. 22 Dimensionless concentration $C^{*}$ by CFD RANS realizable $k-\varepsilon$ simulations $\left(S c_{\mathrm{t}}=0.3\right.$ and 0.7$)$ and wind tunnel measurements at height $z / H=0.5$ for equally spaced buildings and wind direction $\theta=2.5^{\circ}$. Source is indicated by + . Inserts are contours of $C^{*}$ at height $z / H=0.5$ (Blocken et al. 2016a; reproduced with permission (CElsevier) 


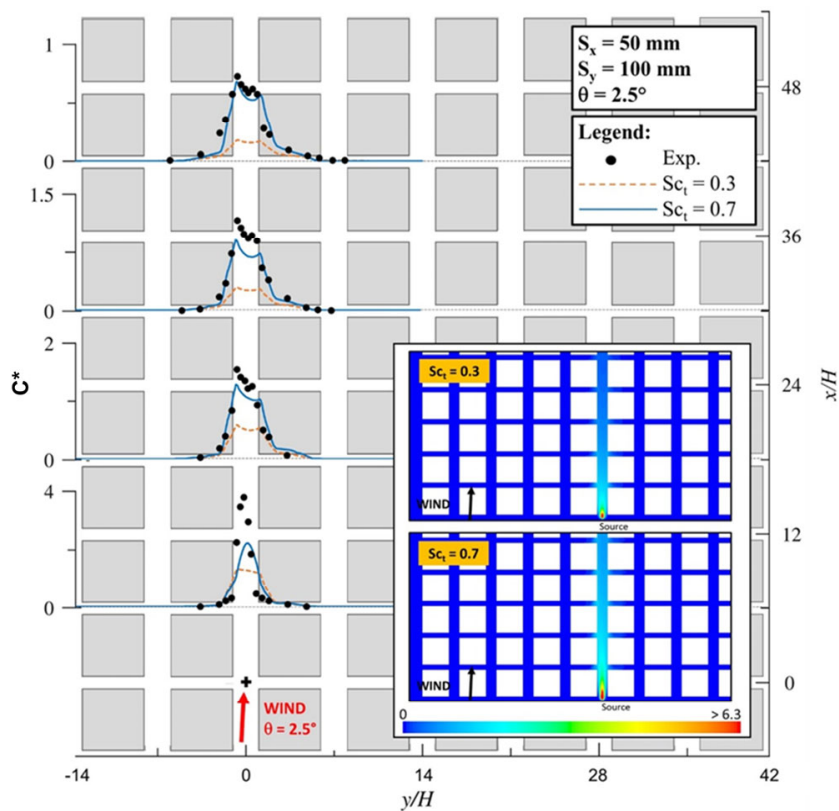

Fig. 23 Dimensionless concentration $C^{*}$ by CFD RANS realizable $k$ - $\varepsilon$ simulations $\left(S c_{\mathrm{t}}=0.3\right.$ and 0.7$)$ and wind tunnel measurements at height $z / H=0.5$ for unequally spaced buildings $\left(S_{x}=50 \mathrm{~mm}, S_{y}=\right.$ $100 \mathrm{~mm}$ ) and wind direction $\theta=2.5^{\circ}$. Source is indicated by + . Inserts are contours of $C^{*}$ at height $z / H=0.5$ (Blocken et al. 2016a; reproduced with permission (CElsevier)

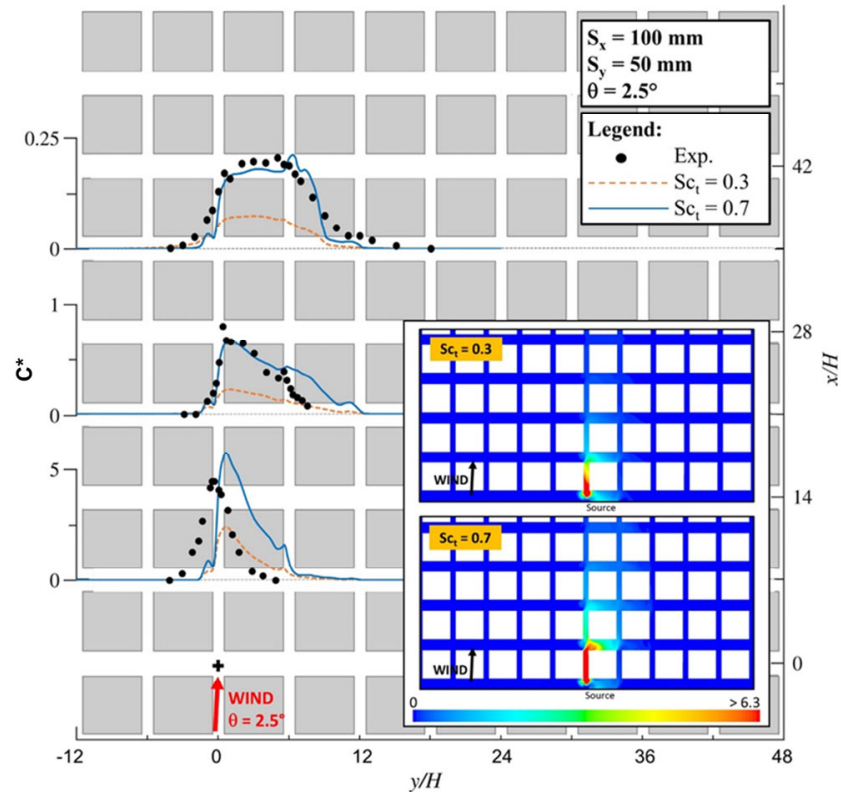

Fig. 24 Dimensionless concentration $C^{*}$ by CFD RANS realizable $k-\varepsilon$ simulations $\left(S c_{\mathrm{t}}=0.3\right.$ and 0.7$)$ and wind-tunnel measurements at height $z / H=0.5$ for unequally spaced buildings $\left(S_{x}=100 \mathrm{~mm}\right.$, $S_{y}=50 \mathrm{~mm}$ ) and wind direction $\theta=2.5^{\circ}$. Source is indicated by + . Inserts are contours of $C^{*}$ at height $z / H=0.5$ (Blocken et al. 2016a; reproduced with permission $\odot$ Elsevier)

concentrations are generally situated between the simulated concentrations by $S c_{\mathrm{t}}=0.3$ and $S c_{\mathrm{t}}=0.7$. Given the disagreements that are generally obtained between high- quality LES simulations and corresponding wind tunnel results, which can be much larger than a factor 2 , the abovementioned disagreements between RANS and experiments should be considered as acceptable.

The second study is near-field dispersion in the actual urban area of downtown Manhattan by Hanna et al. (2006). Figure 25 provides results of concentrations at pedestrian level at Madison Square Garden, obtained by two RANS $k$ - $\varepsilon$ models, one RANS non-linear eddy-viscosity model and an LES model with the Smagorinsky SGS model. While it is not clear whether the same colorbar range was used in every of these figures, the lack of which is attributed to security reasons, Hanna et al. (2006) do provide clear statements on the performance of the different models. They indicate that these tracer gas studies were not the main emphasis of the current paper, but that the results by the different models seem to agree quite well in that the tracer initially spreads a block or two upwind and laterally while it is still near street level, and then spreads downwind as a broad plume after mixing vertically to the building tops. Hanna et al. (2006) mention that their analysis of the time series of the modeled concentrations show the "hold up" of tracer material in the recirculating wake regions behind the buildings or in other areas with very low velocity. They state that the simulations by all applied models are qualitatively similar and that in fairly good agreement with the on-site observations at least concerning general patterns and flow magnitudes. Hanna et al. (2006) concluded that their preliminary CFD results show substantial promise for aiding in "increasing our understanding of wind flow and tracer dispersion in urban areas".

\subsection{Urban thermal environment}

To the best of our knowledge no information is yet available in the publicly available literature that allows a clear comparison between RANS and LES for a study of the urban thermal environment. Therefore, the case study by RANS by Toparlar et al. (2015) is selected here. This study is conducted according to CFD best practice and allows conclusions on the potential of RANS CFD to be made.

The case study is the Bergpolder Zuid region in Rotterdam, located in the Noord district of the city (Fig. 26a). Figures 26b and $c$ show the computational geometry and grid. The simulations are performed for five days during the July 2006 heat wave and the related meteorological input data are obtained from the Royal Dutch Meteorological Institute at the Rotterdam weather station. The 3D unsteady RANS equations were solved with the realizable $k$ - $\varepsilon$ turbulence model. Also conduction and radiation were modeled (see Toparlar et al. 2015 for details). The simulation results in 

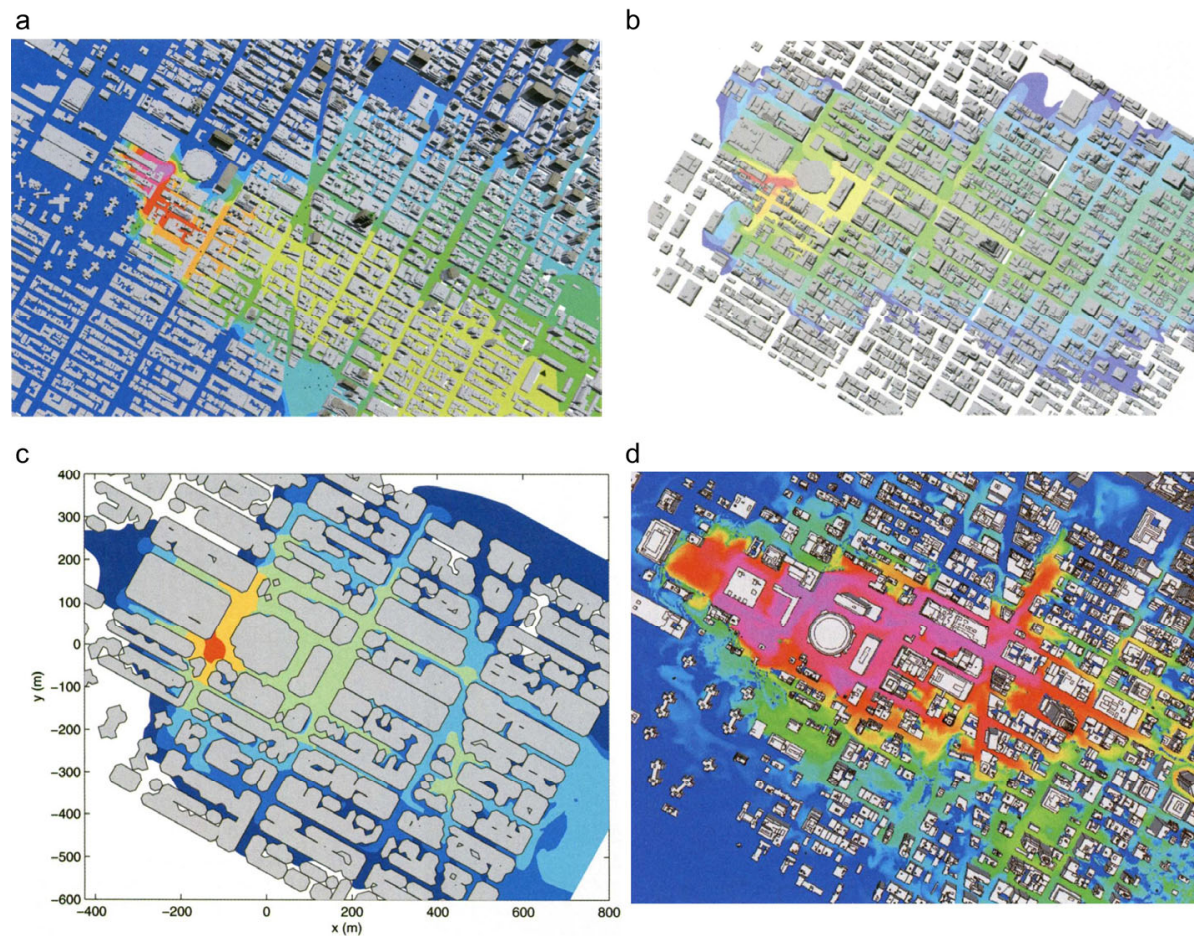

Fig. 25 Contours of simulated of tracer gas dispersion at pedestrian level for a point release near street level on the southwest side of Madison Square Garden, Manhattan, for WNW wind direction. This is one of the five source locations used during the MSG05 field experiment. (a,b) RANS $k$ - $\varepsilon$; (c) RANS non-linear eddy viscosity model; (d) LES Smagorinsky-Lilly model (colorbar not provided in original article, but purple/red is high concentration, green to blue is low concentration) (Hanna et al. 2006; reproduced with permission (c)American Meteorological Society (AMS))

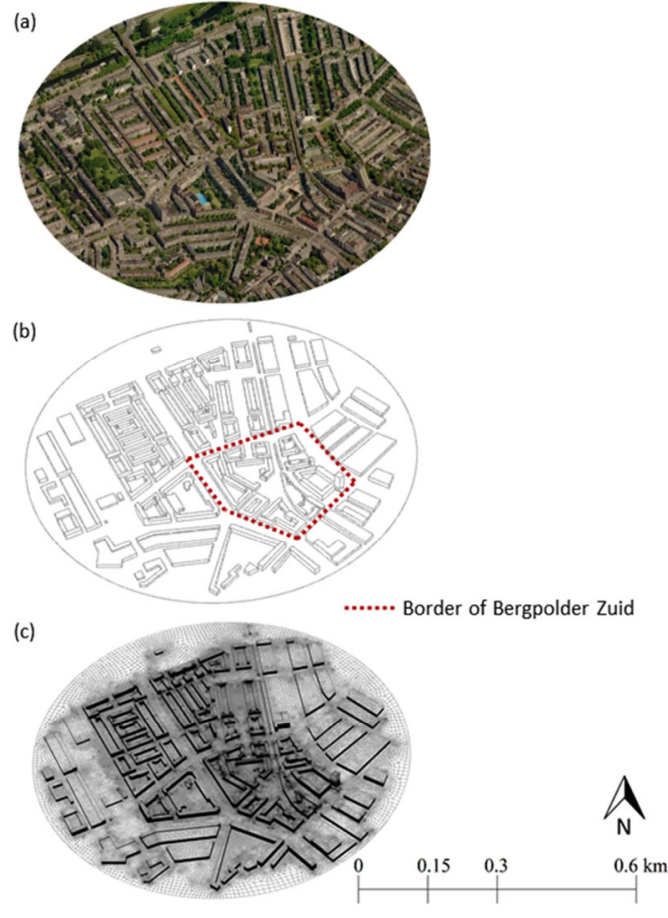

Fig. 26 (a) Aerial view of the Bergpolder region from south (source: Bing Maps); (b) corresponding computational geometry; (c) computational grid on the building surfaces and on part of the ground surface $(6,610,456$ cells) (Toparlar et al. 2015; reproduced with permission (CElsevier) terms of surface temperatures were compared with the experimental data by the NOAA-AVHHR satellite processed by Klok et al. (2012). Figure 27 shows a very good agreement, except during the hottest hours on day 4, which is likely to be attributed to the appearance of clouds that were not included in the CFD simulations. In general, the minimum, average and maximum deviations of surface temperature are $0.27 \%$ ( $19^{\text {th }}$ of July, $18: 38 \mathrm{~h}$ ), $7.9 \%$ and $24.2 \%$ ( $16^{\text {th }}$ of July, $8: 13 \mathrm{~h}$ ), respectively. The surface temperature amplitude is smaller in satellite imagery data than in the simulations. Overall, the agreement between the URANS simulations and the experiments is considered to be very good.

\subsection{Natural ventilation of buildings}

Most CFD research on natural ventilation focused on generic isolated buildings rather than on actual buildings or generic or actual building groups. Most of these studies were performed with the steady RANS approach and firstorder closure. Some exceptions are the studies by Kato et al. (1992), Kurabuchi et al. (2000), Jiang and Chen (2002), Hu et al. (2005, 2008), Meroney (2009), Chu and Chiang (2013) and van Hooff et al. (2017), who used LES, and the studies by Wright and Hargreaves (2006) and Meroney (2009) who used Detached Eddy Simulation (DES). 


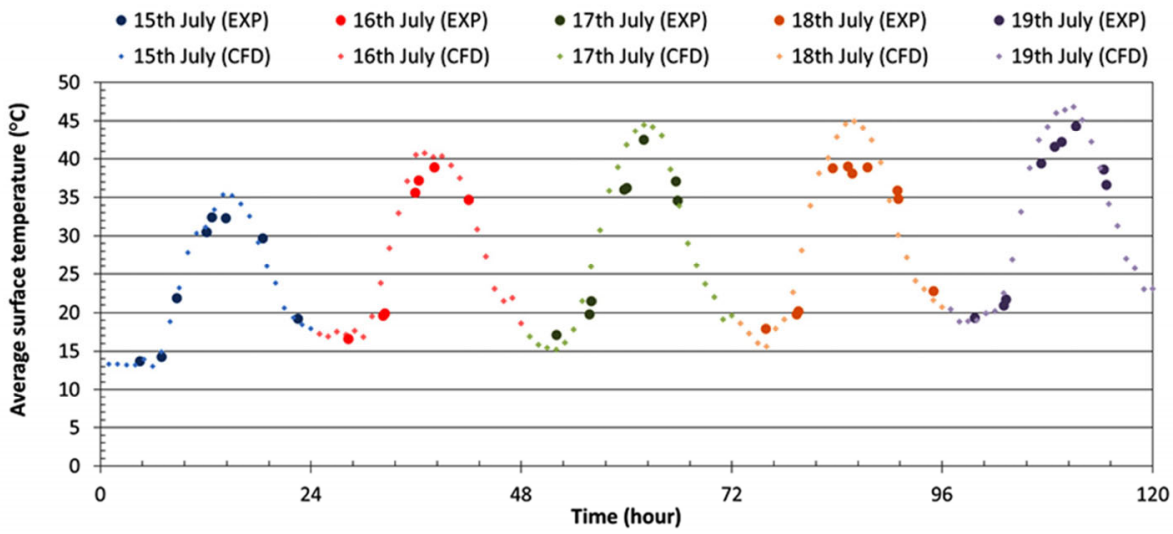

Fig. 27 Comparison of CFD simulation results and data from satellite images of average surface temperatures for five consecutive days (Toparlar et al. 2015; reproduced with permission @Elsevier)

Jiang and Chen (2002) compared results from LES with the Smagorinsky SGS model with experimental data from Katayama et al. (1992), who performed on-site measurements and wind tunnel tests for both outdoor and indoor airflows on a building site (Figs. 8a-f). Jiang and Chen (2002) focused on the influence of wind direction fluctuations on the

a

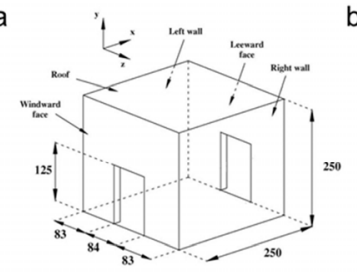

C

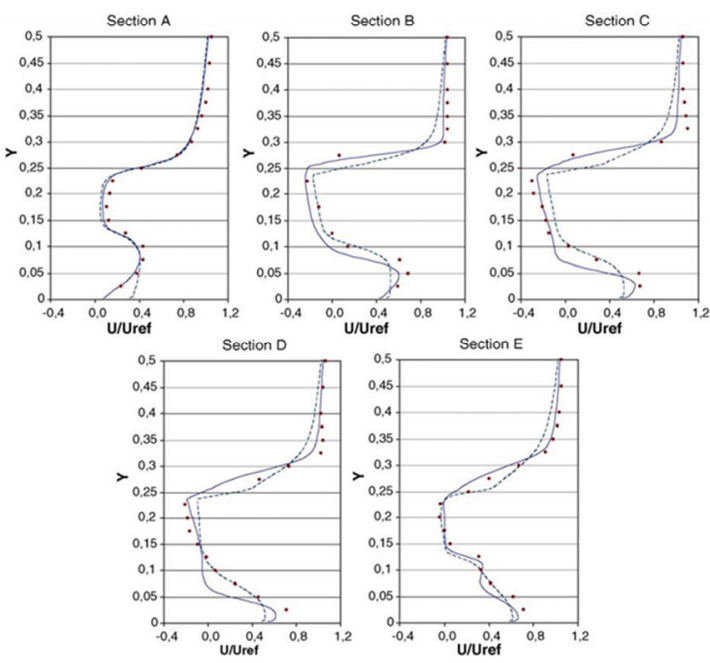

Fig. 28 (a) Building geometry with dimensions in mm (modified from Evola and Popov 2006); (b) sections A-E along which experimental and numerical results are compared; (c) vertical profiles of ratio of horizontal velocity component to reference wind speed: dots are wind tunnel results, solid lines are results from RNG $k-\varepsilon$ model, dashed lines results from standard $k-\varepsilon$ model. Dimensions on vertical axis in m (Evola and Popov 2006; reproduced with permission (CElsevier) outdoor and indoor wind velocity patterns. This recognizes the fact that natural wind is indeed highly variable in both speed and direction, even though this situation cannot easily be generated in a wind tunnel. In a conventional wind tunnel as well as in a conventional RANS or LES CFD simulation, the inlet wind direction is fixed, i.e. stationary, which could introduce considerable errors. Jiang and Chen (2002) demonstrated that both the wind tunnel results and the LES results with fixed wind direction showed a deep, thin and high velocity core in the north room (upper room) of building $\mathrm{A}$. On the other hand, the on-site measurements and the LES results with varied wind direction presented a shallower and wider high-speed region in both rooms, which was clearly more realistic. In both cases, a good agreement between LES and experiments was obtained.

Evola and Popov (2006) performed 3D steady RANS simulations with the standard and RNG $k-\varepsilon$ model for the analysis of cross-ventilation of the isolated cubic building model previously studied by Jiang et al. (2003) (Fig. 28a), with the wind direction perpendicular to the ventilation openings. The comparison between CFD and wind tunnel mean velocity was performed along 5 vertical lines (Fig. 28b). Figure $28 \mathrm{c}$ shows that the RNG $k-\varepsilon$ model outperformed the standard $k-\varepsilon$ model at some locations while the opposite occurred at some other locations. However, comparing the ventilation rates by both RANS models with the LES results by Jiang et al. (2003), the deviation by the standard $k-\varepsilon$ model and the RNG $k-\varepsilon$ model was only $9 \%$ and $3 \%$, respectively.

Meroney (2009) conducted an extensive turbulence model evaluation study for the generic isolated building that was experimentally analyzed by Karava et al. (2011) and Karava and Stathopoulos (2012). His study compared results from the steady RANS approach with the standard $k-\varepsilon$ model, the realizable $k-\varepsilon$ model, the RNG $k-\varepsilon$ model, the standard $k-\omega$ model and the Reynolds Stress Model 
(RSM), Detached-Eddy Simulation (DES) and Large-Eddy Simulation (LES). Meroney (2009) concluded that in spite of the clearly inherently transient nature of separation and reattachment, some of the steady RANS models showed a similar performance as the intrinsically superior LES or DES models.

Ramponi and Blocken (2012a,b) performed 3D steady RANS simulations for the same isolated building as studied by Karava et al. (2011), Karava and Stathopoulos (2012) and Meroney (2009) (Fig. 29a). The turbulence models included the standard $k-\varepsilon$ model, the realizable $k-\varepsilon$ model, the RNG $k-\varepsilon$ model, the standard $k-\omega$ model, the SST $k-\omega$ model and the RSM. Also the impact of other computational parameters was investigated. The best agreement with the PIV wind tunnel measurements by Karava et al. (2011) was obtained by the SST $k-\omega$ model (Figs. $29 \mathrm{~b}, \mathrm{c}$ ) followed by the RNG $k-\varepsilon$ model. Apart from the area close to the ventilation openings,
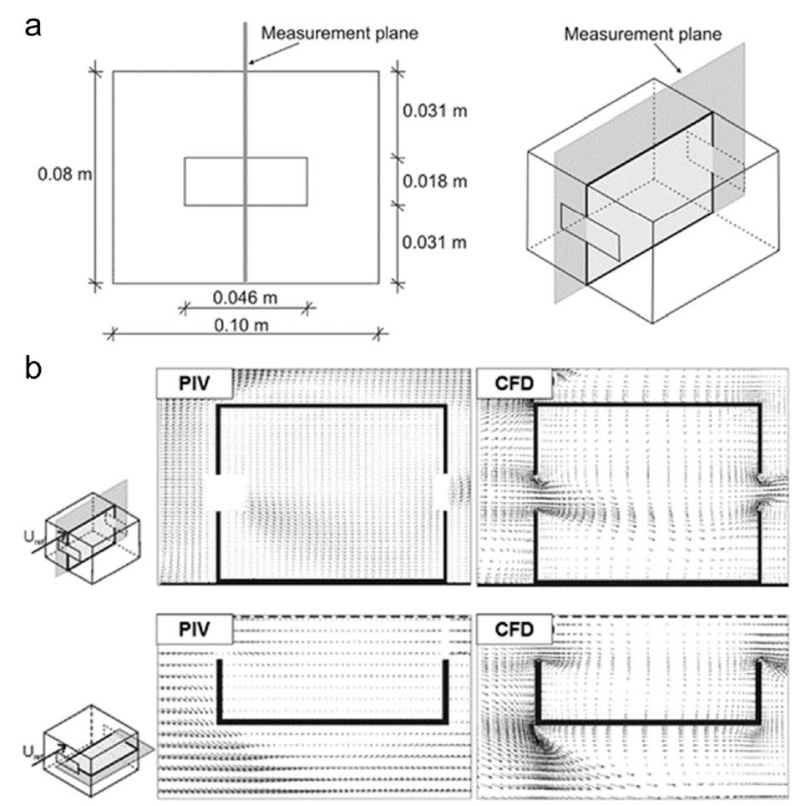

C
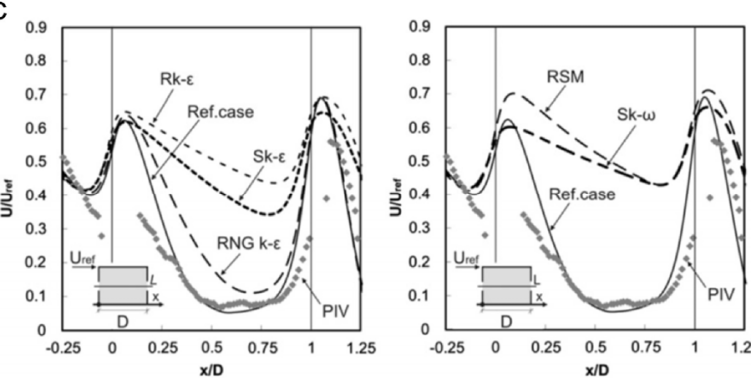

Fig. 29 (a) Building geometry and indication of vertical measurement plane; (b) comparison of PIV and CFD (SST $k$ - $\omega$ ) velocity vector fields in vertical centerplane and horizontal plane at midheight through the openings; (c) comparison of streamwise mean wind speed ratio $U / U_{\text {ref }}$ from PIV and RANS CFD with various turbulence models (note Ref.case $=$ SST $k-\omega$ ) along centerline through the openings (Ramponi and Blocken 2012a; reproduced with permission (C)lsevier) where the accuracy of the PIV measurements suffered from reflections, the differences between measurements and simulations by the SST $k-\omega$ model are generally less than $20 \%$, and less than $10 \%$ in the central part of the building.

The CFD study by van Hooff et al. (2017) based on the cross-ventilation wind tunnel experiments by Tominaga and Blocken $(2015,2016)$ indicated that the SST $k-\omega$ model, the RNG $k-\varepsilon$ model and the RSM reproduced the experimentally observed direction of the incoming jet, but that all RANS models failed in reproducing the turbulent kinetic energy, which was too low especially above and below the jet. They attributed this to the fact that steady RANS does not capture the vertical flapping of the jet. Because LES does capture this transient feature (Fig. 30), this resulted in a better reproduction of all three measured parameters (mean velocity, turbulent kinetic energy, volume flow rate). Van Hooff et al. (2017) therefore concluded that the choice RANS vs. LES actually depends on which parameter is the target parameter, but that the use of LES entails an increase in computational demand with a factor of $\approx 80-100$.

\subsection{Indoor airflow}

Many valuable studies on indoor airflow by either LES or RANS have been performed and these have contributed greatly to the present state of the art. A few selected studies that specifically focused on the performance of LES versus RANS are mentioned here.

Zhang et al. (2007) analyzed the capability of reproducing measured mean velocity, air temperature, Reynolds stresses and turbulent heat fluxes in a room by LES, DES and various RANS models: the indoor zero-equation model, three two-equation models (the RNG, low Reynolds $k$ - $\varepsilon$ number and $k$ - $\omega$ SST models), the $\mathrm{v}^{2}-\mathrm{f}$ model and a Reynolds-stress model (RSM). Four different cases were considered: natural convection in a tall cavity, forced convection in a model room with partitions, mixed convection in a square cavity, and strong buoyancy flow in a model fire room. They combined their results, including calculation time, in a clear overview table, reproduced here in Table 5, in which the performance of every approach/model to reproduce the experiments is given a label $A$ to $D$, based on the relative error between prediction and measurement at measured points as a major criterion. If this value was less than $10 \%$ or more than $50 \%$ at most measured points, the rating $\mathrm{A}$ or $\mathrm{D}$ was given, respectively. Hence these labels point to the extremes. Label $\mathrm{B}$ was awarded to predictions with a relative error less than $20 \%-30 \%$ at most measured points, and rating $\mathrm{C}$ to the remaining predictions. Zhang et al. (2007) concluded that LES provided the most detailed flow features, while the computing time was much higher 

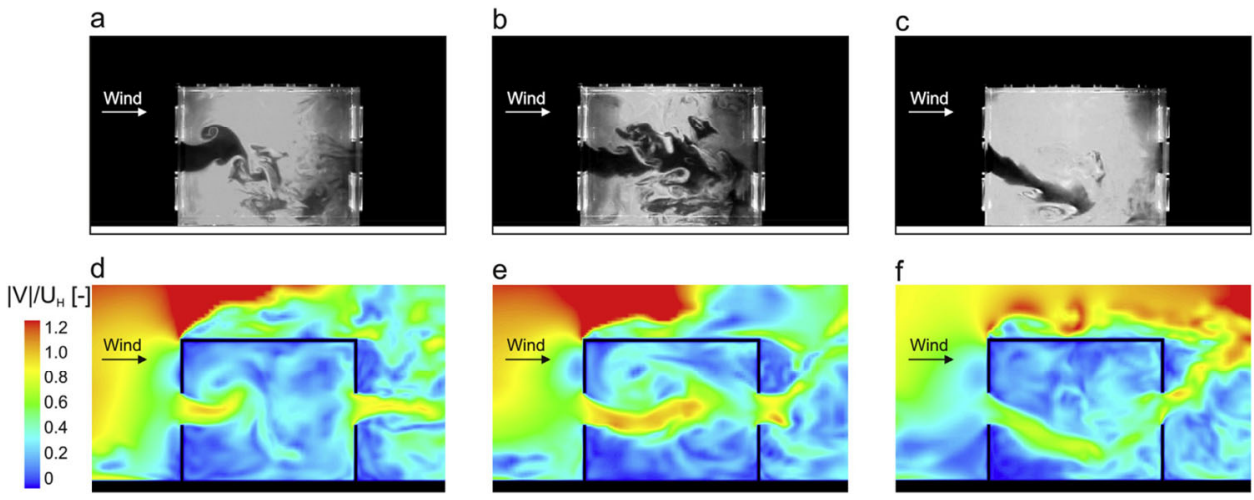

Fig. 30 Comparison of $(a-c)$ instantaneous images from flow visualization (Tominaga and Blocken 2015) with (d-f) instantaneous images from LES simulation (van Hooff et al. 2017). The figures indicate the observation and prediction of jet flapping inside the enclosure. (a,d) Upwards directed jet (bended jet). (b,e) Horizontally directed jet with small downward bend after jet entry. (c,f) Downward directed jet (all figures: reproduced with permission @Elsevier)

Table 5 Rated performance for the simulations for the four cases. $A=$ good, $B=$ acceptable, $C=$ marginal, $D=$ poor, $n / a=n o t$ applicable, and $\mathrm{n} / \mathrm{c}=$ not converged (Zhang et al. 2007)

\begin{tabular}{|c|c|c|c|c|c|c|c|c|c|}
\hline \multirow[b]{2}{*}{ Cases } & \multirow[b]{2}{*}{ Compared items } & \multicolumn{8}{|c|}{ Turbulence models } \\
\hline & & 0 -eq. & RNG $k-\varepsilon$ & SST $k-\omega$ & LRN-LS & $v^{2} f-d a v$ & RSM-IP & DES & LES \\
\hline \multirow{3}{*}{$\begin{array}{l}\text { Natural } \\
\text { convection }\end{array}$} & Mean temperature & B & $\mathrm{A}$ & $\mathrm{A}$ & $\mathrm{C}$ & A & A & $\mathrm{C}$ & A \\
\hline & Mean velocity & $\mathrm{D}$ & B & A & $\mathrm{B}$ & A & B & $\mathrm{D}$ & $\mathrm{B}$ \\
\hline & Turbulence & $\mathrm{n} / \mathrm{a}$ & $\mathrm{C}$ & $\mathrm{C}$ & $\mathrm{C}$ & A & $\mathrm{C}$ & $\mathrm{C}$ & A \\
\hline \multirow{2}{*}{$\begin{array}{c}\text { Forced } \\
\text { convection }\end{array}$} & Mean velocity & $\mathrm{C}$ & $\mathrm{A}$ & $\mathrm{C}$ & A & $\mathrm{A}$ & B & $\mathrm{C}$ & A \\
\hline & Turbulence & $\mathrm{n} / \mathrm{a}$ & B & $\mathrm{C}$ & B & B & B & $\mathrm{C}$ & B \\
\hline \multirow{3}{*}{$\begin{array}{c}\text { Mixed } \\
\text { convection }\end{array}$} & Mean temperature & A & A & A & A & A & B & B & A \\
\hline & Mean velocity & A & B & B & B & A & A & B & $\mathrm{B}$ \\
\hline & Turbulence & $\mathrm{n} / \mathrm{a}$ & $\mathrm{A}$ & $\mathrm{D}$ & B & A & A & B & B \\
\hline \multirow{3}{*}{$\begin{array}{c}\text { Strong } \\
\text { buoyancy } \\
\text { flow }\end{array}$} & Mean temperature & A & A & A & A & A & $\mathrm{n} / \mathrm{c}$ & $\mathrm{n} / \mathrm{a}$ & $\mathrm{B}$ \\
\hline & Mean velocity & B & $\mathrm{A}$ & A & A & A & $\mathrm{n} / \mathrm{c}$ & $\mathrm{n} / \mathrm{a}$ & A \\
\hline & Turbulence & $\mathrm{n} / \mathrm{a}$ & $\mathrm{C}$ & A & B & B & $\mathrm{n} / \mathrm{c}$ & $\mathrm{n} / \mathrm{a}$ & B \\
\hline Com & g time (unit) & 1 & \multicolumn{2}{|c|}{$2-4$} & \multicolumn{2}{|c|}{$4-8$} & \multicolumn{2}{|c|}{$10-20$} & $10^{2}-10^{3}$ \\
\hline
\end{tabular}

than the RANS models and the accuracy may not always be the highest. Among the RANS models, the $\mathrm{v}^{2} \mathrm{f}$-dav and RNG $k-\varepsilon$ models showed the best overall performance compared to the other models in terms of accuracy, computational efficiency and robustness. They recommended both models for indoor airflow simulations.

In a later study, Wang and Chen (2009) focused on reproducing specifically transitional flow regimes in an enclosure for three cases with gradually added flow features; jet, separations and thermal plumes. For these cases they analyzed the performance of the same models as Zhang et al. (2007). A test room of $2.44 \mathrm{~m} \times 2.44 \mathrm{~m} \times 2.44 \mathrm{~m}$ was used for this investigation with a linear (slot) diffuser located in the left wall near the ceiling along the whole width of the room and an exhaust slot along the whole width near the floor on the right wall. The slot Reynolds number was about
2,600 indicative of transitional flow. For these three cases and for the transitional flow, Wang and Chen (2009) again provided a clear overview table (Table 6) with ratings and concluded that some RANS models were good for the simple but not for the complicated flows, while LES was most accurate and stable.

\section{Discussion, conclusions and perspectives}

LES undeniably has the potential to provide more accurate and more reliable results than simulations based on the RANS approach. However, LES entails a higher simulation complexity and a much higher computational cost. In spite of some claims made in the past decades that LES would render RANS obsolete, RANS remains widely used in both research and engineering practice. This paper attempted to 
Table 6 Rated performance for the simulations for the three cases (Wang and Chen 2009)

\begin{tabular}{|c|c|c|c|c|c|c|c|c|c|}
\hline \multirow[b]{2}{*}{ Cases } & \multirow[b]{2}{*}{ Item } & \multicolumn{8}{|c|}{ Turbulence models } \\
\hline & & 0 -eq & LRN & RNG & SST & $v^{2} f$ & RSM & LES-DSL & DES-SA \\
\hline \multirow{2}{*}{1} & $U$ & B & A & A & A & $\mathrm{C}$ & A & B & B \\
\hline & TKE & N/A & A & A & $\mathrm{C}$ & B & A & B & B \\
\hline \multirow{2}{*}{2} & $U$ & A & B & B & $\mathrm{C}$ & A & A & A & B \\
\hline & TKE & N/A & $\mathrm{C}$ & B & B & B & B & A & B \\
\hline \multirow{3}{*}{3} & $U$ & $\mathrm{D}$ & $\mathrm{D}$ & B & $\mathrm{C}$ & A & $\mathrm{B}$ & A & A \\
\hline & TKE & N/A & $\mathrm{C}$ & B & B & B & B & A & B \\
\hline & $T$ & $\mathrm{C}$ & $\mathrm{C}$ & A & A & A & A & A & B \\
\hline \multicolumn{2}{|c|}{ Overall grade } & 2.5 & 2.6 & 3.4 & 2.9 & 3.3 & 3.6 & 3.7 & 3.1 \\
\hline
\end{tabular}

$U$ : mean air veloccity, TKE: turbulence kinetic energy, $T$ : mean air temperature.

A: good (4.0), B: acceptable (3.0), C: marginal (2.0), and D: unacceptable (1.0).

answer the questions why this is the case and whether this is justified, from the viewpoint of building simulation, for both outdoor and indoor applications. The answer to this and other questions is given in the following subsections.

\subsection{Potential accuracy}

LES is at least potentially more accurate and reliable than RANS because it resolves more of the flow. However, because of the higher simulation complexity it is easier to ruin a LES than a RANS simulation. As Hanna (1989) stated "as the model formulation increases in complexity, the likelihood of degrading the model's performance due to input data and model parameter uncertainty increases as well.” LES, for example, requires much more care for grid generation, certainly for complex geometries and even more when the grid size is used as the filter.

Concerning building simulation for outdoor applications, also the atmospheric inflow boundary conditions and rough wall boundary conditions are much more challenging in LES. Several related pertinent statements were made. Ferziger (1990) stated that RANS models have the benefit of longer history while experience in LES is limited. Shah and Ferziger (1997) stated that just the simple fact that one is using LES does not guarantee success, as LES can yield results that are both qualitatively and quantitatively incorrect. Hanjalic (2005) stated that "conventional LES on a too-coarse grid of wall bounded flows, especially in attached flows regions, can be very erroneous and inferior to even simple conventional RANS." Although these views were expressed quite a long time ago, all of them are still equally valid today.

Sørensen and Nielsen (2003) and Nielsen (2015) confirmed that LES could provide a direct prediction of the turbulence intensity but that for fully developed flow, the prediction accuracy of the average flow variables was not improved, while LES could provide advantages for non-fully developed turbulent flow. Chen (2009) concluded that RANS models could perform well for one flow but poorly in another but that LES could yield good results at sufficiently high grid resolutions. He correctly documented that LES is more popular for predicting particle distributions in ventilated spaces, because in this case more detailed information on the turbulent nature of the flow is required.

The problems of potentially inaccurate and unreliable LES simulations are co-determined or even aggravated by the lack of best practice guidelines (BPG) for LES, both for outdoor and indoor applications. And the fact that establishing such guidelines, in spite of the ever increasing computational power, is likely to take quite a lot longer for LES than RANS, given the much higher computational requirements for LES. So RANS models will keep having the benefit of more experience compared to LES for a long time - and it is not even certain that this will ever change.

\subsection{Computational requirements}

Even if LES would be performed according to best practice, still, the computational requirements remain much higher than for RANS. Concerning building simulation for outdoor applications, two groups of statements can be found in the literature, as clear from the overview of previous review and position papers in Section 4. The first group concerns positive statements that focus on the expectation that the rapid increase in computational resources would make LES more amenable for practical engineering problems. The second group of statements stresses the very large computational requirements by LES without expressing such positive expectation. Interestingly, these two different groups are not associated with clearly different periods in time.

In the first group, Ferziger (1990) considered LES too expensive to be a design tool. With the high grid requirements in mind, he stated "If it turns out that LES 
can be done on very coarse grids, it will be one of the few times that nature has been kind to us with regard to turbulent flows". Shah and Ferziger (1997) indicated that the LES simulations they were presenting were expensive, and therefore, if high-quality results were required, it would not be possible at present to use LES as a design tool. Hanjalic (2005) provided the rather uncommonly expressed view that "the further increase in the computing power will be used more to utilize advanced RANS models to shorten the design and marketing cycle rather than to yield the way to LES." Yoshie et al. (2007), focusing on PLW conditions, mentioned that the use of LES would require a dramatic increase in computational speed and that for now "we must be content with RANS type models currently in use."

In the second group, Leschziner (1993) expected there would likely be a continuous shift of focus towards LES. Murakami (1997) indicated that the rapid evolution of CPU hardware was expected to overcome the restriction of large CPU time, enabling wide application of LES to wind engineering problems in the near future. Rodi (1997) expected that "with the recent advances in computing power LES will soon be ready and feasible for practical applications."

As often in discussions between two prominent groups about complicated topics, these is some truth in both. Some of the above-cited authors, but not all, distinguish between research and design. Another distinction is that between the different application areas. While in research, indeed, the increasing computational resources have incited more focus on LES including applications, this is hardly the case in design. There are undoubtedly some exceptions but the vast majority of design and consultancy companies, when dealing with outdoor applications, resort to RANS simulation or to wind tunnel testing. Or both, but not to LES. At this moment, there are no clear indications that this is going to change drastically in the near future. Even for an application area such as wind pressures on building surfaces where peaks are important and for which RANS is generally considered not an option, LES is still very far from becoming standard practice in consultancy and design.

Concerning building simulation for indoor applications, Chen (1997) and Chen and Srebric (2001) correctly indicated that until that time, LES had rarely been applied for actual engineering problems because of the need to extensive computational power and the need for further development. In view of the increased computational power in the future, Sørensen and Nielsen (2003) stated LES would most likely become a useful and practicable tool for room airflow simulations in the future, but at the time they recommended using RANS turbulence models for practical purposes. Zhai et al. (2007) expressed a stronger interest in RANS simulations because of quick predictions rather than the more detailed but also more time-consuming LES simulations that were more considered as research than a design tool. Lately, Nielsen (2015) expressed his expectation that the increasing computational resources would expand the use of LES in the future.

\subsection{Required accuracy}

A criterion rather entangled with the two foregoing criteria is the required accuracy. Concerning building simulation for outdoor applications, Ferziger (1990) stated that the principal task of the wind engineer-by which he undoubtedly meant designer or consultant, not researcher-is to find a method that produces accurate values of the essential quantities at low cost. As a result, the method to be used may depend both on the required accuracy and on the problem. Indeed, for many practical applications, the accuracy presented by RANS-when applied according to best practice-can be considered as sufficient. It was demonstrated in Section 5 that this can be the case for PLW comfort where the areas of high wind speed are indeed of most importance, for near-field dispersion in urban areas with high plan area density, where the pollutant dispersion is largely governed by channeling in the narrow streets, for urban thermal environment at least when focusing on surface temperatures averaged over a sufficiently large area, and for building cross-ventilation (as single-sided ventilation is a much more challenging case). This view that RANS could provide "sufficiently accurate" results was also implicitly expressed by Leschziner (1993) stating that for industrial applications in general, RANS methods would continue to play the main role for some years to come and by Murakami (1997), indicating that RANS turbulence model selection should be based on the criteria of prediction accuracy (and CPU time) required. Hanjalic (2005) also confirmed the important role of RANS "especially in industrial and environmental computations". Gosman (1999), Yoshie et al. (2007) and Baker (2007) also referred to PLW comfort assessment as a suitable CFD (RANS) application.

Concerning building simulation for indoor applications, Chen (1997) found that the predictions of first-order parameters such as mean velocities and temperatures by RANS CFD were more accurate than those of second-order parameters such as turbulence intensities. Zhai et al. (2007) indicated that for the design and study of air distributions in enclosed environments, the mean air parameters were generally more useful than the instantaneous turbulent flow parameters which justified the stronger interest in RANS simulations. Nielsen (2015) indicated the superior performance of LES for non-fully developed turbulent flow.

\subsection{The numerical wind tunnel}

Although the analogy of the "numerical wind tunnel" appeals 
to the imagination, CFD experts in building simulation for the outdoor environment have consistently denounced this label, either explicitly or implicitly. Leschziner (1993) stated that CFD for general turbulent flow is unlikely ever to evolve to a "computational wind tunnel". He argued that wind tunnels are here to stay for many years to come and would continue to be the main vehicle for investigating realistic building design concepts. The clear view of Stathopoulos (1997) was that it is unlikely that CFD for general turbulent flow would become a "computational wind tunnel", at least not in the foreseeable future, and that rather CFD and experiments should complement each other. These views were further addressed in a follow-up paper (Stathopoulos 2002). Also Castro and Graham (1999) denounced the concept of the "numerical wind tunnel" in the design process, for example for the assessment of wind loads and pollutant dispersion. The same was done by Blocken (2014) in a more recent review paper. Indeed, while strictly atmospheric boundary layer wind tunnel testing could do without CFD, the opposite does not hold true, as validation remains needed. Also concerning CFD for the indoor environment, $\mathrm{Li}$ and Nielsen (2011) indicated that in spite of the continuously increasing capabilities for CFD simulations, "CFD has not become a replacement for experiment and theoretical analysis in ventilation research, rather it has become an increasingly important partner."

\subsection{The hybrid approach: experiments-CFD}

While it is well-known that CFD needs experiments for validation, the benefits of CFD for experimental testing might be less well-known. Nevertheless, this view was already present in the community since the very beginning.

Concerning building simulation for outdoor applications, in the 1970s, Deardorff advocated the combination of LES with laboratory (water tank) experiments and field measurements because of the large potential synergy of these three approaches. Murakami (1990a) stressed the synergy between CFD and experiments. He expected that the increasing precision of CFD predictions would also give rise to new research in experimental methods. Stathopoulos (1997) advocated using CFD and experiments to complement each other, for example for reducing costs in the design process. When Murakami et al. (1999) published an impressive range of practical applications in CFD from human scale to urban scale, they mentioned that they compared their CFD results with measurements whenever available. This statement referred to their very important point that in some cases, measurement data cannot be obtained or will be very difficult to obtain. In such cases, Murakami correctly argued that "we do think that the comprehensive assessment based on the CFD method combining various factors seems to be the only approach for clarifying such complicated phenomena." Indeed, a true synergy does not entail that both approaches are always equally important, but that, depending on the situation or application, one approach will be more applicable and hence leading, while the other one will provide support from the background. An example where CFD is more applicable and leading is the study of the urban heat island effect (Murakami et al. 1999), or, returning to the very origin of LES, numerical weather prediction as defined by Richardson (1922) and applied intensively and successfully up to the present day. Blocken (2014) listed some other applications where wind tunnel experiments would be very difficult or even impossible and where CFD could be used, such as natural ventilation through relatively small openings, where scaling down could change the nature of the flow in these openings from turbulent to laminar, wind flow and related processes in atmospheric boundary layers with stable and unstable stratification, multiphase flow problems such as the transport and deposition of sand, dust, rain, hail and snow, and meteorological phenomena such as tornadoes and downbursts. Meroney (2004) provided a compelling set of arguments for the hybrid approach between wind tunnel and CFD for pollution dispersion. In 2016, in the same hybrid framework, Meroney (2016) recalled the often asked question "When can we get rid of our physical modeling facilities?" He correctly stated that this question ignored the tremendous potential synergy of CFD and EFD both in research and design, as it can "expedite results, improve understanding of flow phenomena, and often reduce research costs and time." The same critical point was convincingly outlined by Tominaga and Stathopoulos (2016).

Concerning building simulation for indoor applications, Li and Nielsen (2011) compellingly argued that CFD had become a partner for experiment and theoretical analysis in ventilation research. They believed that "an effective scientific approach for ventilation studies is still to combine experiments, theory, and CFD."

In conclusion of this subsection, I provide this quote by Murakami (1990a) from the section of his paper where he focuses on the prediction of time-dependent flowfields by LES and visual animations of these results:

"Time-dependent flowfields given by LES and the techniques of visual animation based on them are very useful tools in turbulent flow analysis concerned with wind engineering and provide information hardly given by experimental techniques." This quote provided by one of the pioneers in the field provides a much better, more constructive and more appropriate view of the field of CFD - at least when applied according to best practice as done by many of us-than the rather tiresome and washed-out claims of non-CFD practitioners that CFD would stand for "Cheats, Frauds and Deceivers", or for other often-heard three-word combinations 
that I do not wish to repeat here. This quote correctly indicates that in some cases, in terms of gaining understanding of the flow physics, there is no better way than high-quality LES and its visual animation. While techniques such as Particle Image Velocimetry (PIV) claim to have similar capabilities, the costs of time-resolved stereo PIV are much higher than those of LES, the time expense at least equally high and probably much higher, and for urban applications the views will easily be obstructed by laser-light shielding by the obstacles constituting the urban model.

\subsection{No applications without basics}

Although this should be self-evident, many submissions of papers to international journals, many presentations at conferences but also many consultancy CFD simulations and reports still display a major lack of basic understanding of fluid mechanics and numerical techniques, let alone knowledge of the CFD literature and the best practice guidelines in the field. This problem was apparently already present in the early 1990s, as authors explicitly mentioned and warned for these situations. Leschziner (1993) stated that first and foremost, it is essential for a CFD user to possess considerable expertise, physical insight and experience, both to obtain meaningful solutions and to be able to appreciate the associated limitations. Stathopoulos (1997) expressed his grave concern that "there are serious dangers inherent in the way that CFD is being increasingly used in industry often by people having little or no understanding of fluid dynamics or computational techniques." And that "most practitioners are more concerned with obtaining results than with either the order of accuracy of their numerical schemes or the need to refine the grid until converged grid-independent solutions are obtained." In line with Stathopoulos (1997), Castro and Graham (1999) pointed to the significant dangers of using CFD without a sound understanding of the fluid mechanics of the problem under study, without awareness of the validation of the code for similar problems and a clear understanding of the sources of errors and uncertainties and the levels of accuracy required. In addition, Meroney (2004) also stressed the very strong need for a critical attitude towards all CFD but also wind tunnel results with the vivid quote: "Good mental health in a fluid or CFD modeler is always indicated by the presence of a suspicious nature, cynicism and a 'show me' attitude. These are not necessarily the best traits for a life mate or a best friend, but they are essential if the integrity of the modeling process is to be maintained." The same critical concerns were expressed very clearly and repeatedly in the indoor airflow community. Chen (1997) and Chen and Srebric (2001) stressed the importance that CFD users should have a good knowledge of turbulent flows and numerical techniques to perform correct simulations.

\subsection{User-friendly is good, but not too user-friendly}

Regrettably progress in a field often raises new problems. Progress refers to - as stated by Gosman (1999) - the improvement of CFD codes in terms of versatility, ease of use and speed, which helps accelerating the uptake of this technology by industrial users. However, Gosman also correctly added that this should not occur "without the required level of knowledge of flow physics to properly interpret and exploit the results." Unfortunately, that is exactly what is occurring in many occasions these days, and this points directly to the problem in subsection 7.6. All the valid statements in subsection 7.6 constitute a warning against using CFD as a "black box". Nevertheless, several commercial software developers, not expert in CFD, have recently engaged in extending their design software with a so-called "very user-friendly" CFD module that can be "used" by even non-experienced CFD users. In other words: by users without the required level of knowledge of fluid mechanics and numerical techniques, the CFD literature in the field and the BPG documents. Other CFD software developers have made their code freely available however without a proper manual that provides insight on the numerical techniques embedded in it. This very practice shows that the alarming statements made 20 of 30 years ago (see subsection 7.6 ) are probably even more pertinent today than they were at that time.

\subsection{Back to key question: why has LES not made RANS obsolete?}

The key question in this paper was why LES has not rendered RANS obsolete as RANS remains widely used in both research and engineering practice and whether this is justified. The answers have been provided above: although LES is intrinsically superior, it entails a higher simulation complexity and a much larger computational cost, and because of that and the lack of BPG it can even yield results that are less accurate and less reliable that those by RANS. In addition, for several practical applications, it has been shown that RANS results can be sufficiently accurate. Paraphrasing the late prof. Joel H. Ferziger: "It turns out that in terms of practical applications in building simulation, there are quite a few application areas where nature is kind to us with regard to turbulent flows". Furthermore, switching from RANS to LES will not bring the fantasy of the "numerical wind tunnel" any closer to reality. Validation with wind tunnel or field experiments remains imperative. 
Nevertheless, indeed, LES is intrinsically superior, and this is the reason why in research environments, the past decades have seen a gradually larger focus on LES. However, in design and consultancy, such a systematic shift in focus has not been observed. Even in research, RANS remains very popular for application areas such as PLW wind comfort, near-field pollutant dispersion in urban areas with high plan area density, urban thermal environment, natural ventilation of buildings and indoor airflow. The very many examples of RANS case studies that have appeared in the scientific literature in the past 20 years versus only relatively few by LES demonstrate that in many aspects of building simulation for outdoor and indoor applications, researchers and practicing engineers have employed the increasingly available computational power to perform RANS simulations for larger and more complex problems, rather than to make the switch from RANS to LES for less extensive problems.

\section{Acknowledgements}

"Cum omnibus virtutibus me adfectum esse cupio, tum nihil est quod malim quam me et esse gratum et videri. Haec enim est una virtus non solum maxima sed etiam mater virtutum omnium reliquarum" 1

The author expresses his large appreciation to the many pioneers in Building Simulation, both for outdoor and indoor applications, who have built this field to the very successful research and engineering arena it is today, with worldwide networks, journals, conferences, projects and other activities. While only few of them could be cited in this incomplete paper, certainly all are implicitly included in this paragraph of this acknowledgment.

The author is greatly indebted to his four mentors in Building Physics and Building Simulation, in alphabetical order of last name: Prof. dr. ir. Jan Carmeliet, previously full professor at KU Leuven in Leuven, Flanders, Belgium and now Chair of Building Physics at ETH Zurich, Switzerland, Prof. dr. ir. Hugo Hens, emeritus full professor at KU Leuven, Leuven, Flanders, Belgium, Prof. dr. ir. Jan Hensen, full professor at Eindhoven University of Technology in Eindhoven, the Netherlands and Prof. dr. Ted Stathopoulos, full professor at Concordia University in Montreal, Canada. The author is also deeply indebted to his mentor in Applied Physics/Fluid Mechanics, Prof. dr. ir. GertJan van Heijst, full professor at the Department of Applied Physics at Eindhoven

\footnotetext{
1 "While I wish to be adorned with every virtue, yet there is nothing which I can esteem more highly than being and appearing grateful. For this one virtue is not only the greatest, but is also the mother of all the other virtues". Source: Pro Plancio. Rome, 54 BC. Marcus Tullius Cicero (106 BC - 43 BC), Roman philosopher, politician, lawyer, orator, political theorist, consul and constitutionalist.
}

University of Technology.

The author is most grateful to Prof. dr. Xudong Yang, Editor-in-Chief of Building Simulation. The journal was inaugurated in 2008. The author was invited to join the editorial board in 2014. This special volume of the journal celebrates the 10-year anniversary of this journal. It takes a lot of patience, persistence, dedication and determination to start up a new journal and one could have wondered whether there was a need for yet another journal in the field of building engineering. The current success of this journal and the many excellent papers published in it show that the Editorin-Chief and the publisher were very right to establish and consolidate this journal. In the past 10 years, Prof. Yang has made the journal what it is today: an indispensable and excellent key medium to disseminate the latest and most important findings in the wide field of building simulation that is respected and appreciated by all colleagues working in the field.

The author thanks the anonymous reviewers for their very valuable and constructive comments that have improved this paper.

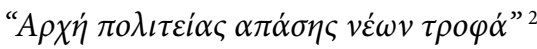

The author expresses his gratitude to the senior researchers, $\mathrm{PhD}$ students and MSc students in his group in Urban Physics, Wind Engineering and Sports Aerodynamics at Eindhoven University of Technology in the Netherlands and at KU Leuven in Flanders, Belgium. The most rewarding and most enjoyable aspect of the job is the opportunity to work with and educate excellent young individuals. Special thanks therefore go to current senior researchers dr.ir. Twan van Hooff, dr.ir. Hamid Montazeri, dr. Alessio Ricci and dr. Yigit Can Altan. Special thanks also go to the $\mathrm{PhD}$ students Adelya Khayrullina, Katarina Kosutova, Raffaele Vasaturo, Samy Iousef, Fabio Malizia, Feiyu Geng, Olga Palusci, Antoniou Nestoras, Rahim Rezaeiha, Andreas Pfahl, Zhiyun Wang, Jo-Hendrik Thysen, Anto Moediartianto, Giacomo Alessi, Thijs van Druenen, Xing Zheng, Gerson Fernandes, Paul Mannion, Lili Xia, Yu-Hsuan Juan and Mutmainnah Sudirman. The same warm acknowledgment is given to PDEng students Rob Vervoort, Claudio Alanis Ruiz and Marlies Verbruggen. And to all previous postdocs and $\mathrm{PhD}$ students in the team.

Elsevier is acknowledged for the permission to reproduce a large number of figures from previous publications. The American Meteorological Society is acknowledged for the permission to reproduce a few figures from previous publications. We thank Peter Nielsen for the permission to reproduce some figures from his pioneering $\mathrm{PhD}$ thesis

\footnotetext{
2 "The base of every state is the education of the youth". Pythagoras of Samos (c. 570 BC - c. 495 BC), Greek philosopher and mathematician.
} 
(Figs. 9a-b). We thank the Belgian artist François Schuiten for the permission to reproduce his drawing of the Forecast Factory (Fig. 3).

Open Access: This article is distributed under the terms of the Creative Commons Attribution 4.0 International License (http://creativecommons.org/licenses/by/4.0/), which permits unrestricted use, distribution, and reproduction in any medium, provided you give appropriate credit to the original author(s) and the source, provide a link to the Creative Commons license, and indicate if changes were made.

\section{References}

Abdalla IE, Cook MJ, Rees SJ, Yang Z (2007). Large-eddy simulation of buoyancy-driven natural ventilation in an enclosure with a point heat source. International Journal of Computational Fluid Dynamics, 21: 231-245.

Adamek K, Vasan N, Elshaer A, English E, Bitsuamlak G (2017). Pedestrian level wind assessment through city development: A study of the financial district in Toronto. Sustainable Cities and Society, 35: 178-190.

AIAA (1998). Guide for the verification and validation of computational fluid dynamics simulations. AIAA-G-077-1998. Reston, VA. USA: American Institute of Aeronautics and Astronautics.

Alamdari F, Hammond GP, Melo C (1984). 'Appropriate' calculation methods for convective heat transfer from building surfaces. In: Proceedings of the 1st National Conference on Heat Transfer, Leed, UK. Published in 1ChemE Syrup. series no. 86(2): 1201-1211.

Allegrini J, Kubilay A (2017). Wind sheltering effect of a small railway station shelter and its impact on wind comfort for passengers. Journal of Wind Engineering and Industrial Aerodynamics, 164: 82-95.

Allegrini J, Carmeliet J (2018). Simulations of local heat islands in Zürich with coupled CFD and building energy models. Urban Climate, 24: 340-359.

An K, Fung JCH, Yim SHL (2013). Sensitivity of inflow boundary conditions on downstream wind and turbulence profiles through building obstacles using a CFD approach. Journal of Wind Engineering and Industrial Aerodynamics, 115: 137-149.

Anderson JD Jr (1995). Computational Fluid Dynamics: The Basics with Applications. New York: Mc Graw-Hill.

Antoniou N, Montazeri H, Wigo H, Neophytou M, Blocken B, Sandberg $M$ (2017). CFD and wind-tunnel analysis of outdoor ventilation in a real compact heterogeneous urban area: Evaluation using "air delay". Building and Environment, 126: 355-372.

Ashford OM (1985). Prophet or Professor? The Life and Work of L.F. Richardson. Bristol, UK: Adam Hilger.

Ashie Y, Kono T (2011). Urban-scale CFD analysis in support of a climate-sensitive design for the Tokyo Bay area. International Journal of Climatology, 31: 174-188.

ASME (2009). Standard for verification and validation in Computational Fluid Dynamics and heat transfer. ASME VandV 20-2009, The American Society of Mechanical Engineers.
Awbi HB, Setrak AA (1986). Numerical solution of ventilation air jet. In: Proceedings of the 5th Symposium on the Use of Computers for Environmental Engineering Related to Buildings, CIBSE, Bath, UK.

Awbi HB (1989). Application of computational fluid dynamics in room ventilation. Building and Environment, 24: 73-84.

Awbi HB (2003). Ventilation of Buildings. London: Spon Press.

Awbi HB (2008). Ventilation Systems: Design and Performance. London: Taylor \& Francis.

Aydin YC, Mirzaei PA (2017). Wind-driven ventilation improvement with plan typology alteration: A CFD case study of traditional Turkish architecture. Building Simulation, 10: 239-254.

Baetke F, Werner H, Wengle H (1990). Numerical simulation of turbulent flow over surface-mounted obstacles with sharp edges and corners. Journal of Wind Engineering and Industrial Aerodynamics, 35: 129-147.

Baik JJ, Park SB (2009). Urban flow and dispersion simulation using a CFD model coupled to a mesoscale model. Journal of Applied Meteorology and Climatology, 48: 1667-1681.

Baker CJ (2007). Wind engineering-Past, present and future. Journal of Wind Engineering and Industrial Aerodynamics, 95: 843-870.

Bartzis JG, Vlachogiannis D, Sfetsos A (2004). Thematic area 5: Best practice advice for environmental flows. The QNET-CFD Network Newsletter, 2(4): 34-39.

Baskaran A, Stathopoulos T (1989). Computational evaluation of wind effects on buildings. Building and Environment, 24: 325-333.

Baskaran A, Stathopoulos T (1992). Influence of computational parameters on the evaluation of wind effects on the building envelope. Building and Environment, 27: 39-49.

Bazdidi-Tehrani F, Ghafouri A, Jadidi M (2013). Grid resolution assessment in large eddy simulation of dispersion around an isolated cubic building. Journal of Wind Engineering and Industrial Aerodynamics, 121: 1-15.

Beranek WJ, van Koten H (1979a). Visual techniques for the determination of wind environment. Journal of Wind Engineering and Industrial Aerodynamics, 4: 295-306.

Beranek WJ, van Koten H (1979b). Beperken van windhinder om gebouwen, deel 1, Stichting Bouwresearch no. 65. Kluwer Technische Boeken BV, Deventer. (in Dutch)

Beranek WJ (1982). Beperken van windhinder om gebouwen, deel 2, Stichting Bouwresearch no. 90. Kluwer Technische Boeken BV, Deventer. (in Dutch)

Blocken B, Roels S, Carmeliet J (2004). Modification of pedestrian wind comfort in the Silvertop Tower passages by an automatic control system. Journal of Wind Engineering and Industrial Aerodynamics, 92: 849-873.

Blocken B, Stathopoulos T, Carmeliet J (2007a). CFD simulation of the atmospheric boundary layer: Wall function problems. Atmospheric Environment, 41: 238-252.

Blocken B, Carmeliet J, Stathopoulos T (2007b). CFD evaluation of wind speed conditions in passages between parallel buildingsEffect of wall-function roughness modifications for the atmospheric boundary layer flow. Journal of Wind Engineering and Industrial Aerodynamics, 95: 941-962. 
Blocken B, Carmeliet J (2008). Pedestrian wind conditions at outdoor platforms in a high-rise apartment building: Generic subconfiguration validation, wind comfort assessment and uncertainty issues. Wind and Structures, 11: 51-70.

Blocken B, Stathopoulos T, Carmeliet J (2008a). Wind environmental conditions in passages between two long narrow perpendicular buildings. Journal of Aerospace Engineering, 21: 280-287.

Blocken B, Moonen P, Stathopoulos T, Carmeliet J (2008b). A numerical study on the existence of the Venturi effect in passages between perpendicular buildings. Journal of Engineering Mechanics, 134: 1021-1028.

Blocken B, Stathopoulos T, Saathoff P, Wang X (2008c). Numerical evaluation of pollutant dispersion in the built environment: Comparisons between models and experiments. Journal of Wind Engineering and Industrial Aerodynamics, 96: 1817-1831.

Blocken B, Persoon J (2009). Pedestrian wind comfort around a large football stadium in an urban environment: CFD simulation, validation and application of the new Dutch wind nuisance standard. Journal of Wind Engineering and Industrial Aerodynamics, 97: 255-270.

Blocken B, Stathopoulos T, Carmeliet J, Hensen JLM (2011). Application of computational fluid dynamics in building performance simulation for the outdoor environment: an overview. Journal of Building Performance Simulation, 4: 157-184.

Blocken B, Janssen WD, van Hooff T (2012). CFD simulation for pedestrian wind comfort and wind safety in urban areas: General decision framework and case study for the Eindhoven University campus. Environmental Modelling and Software, 30: $15-34$.

Blocken B, Gualtieri C (2012). Ten iterative steps for model development and evaluation applied to Computational Fluid Dynamics for Environmental Fluid Mechanics. Environmental Modelling and Software, 33: 1-22.

Blocken B (2014). 50 years of Computational Wind Engineering: Past, present and future. Journal of Wind Engineering and Industrial Aerodynamics, 129: 69-102.

Blocken B (2015). Computational Fluid Dynamics for urban physics: Importance, scales, possibilities, limitations and ten tips and tricks towards accurate and reliable simulations. Building and Environment, 91: 219-245.

Blocken B, Vervoort R, van Hooff T (2016a). Reduction of outdoor particulate matter concentrations by local removal in semi-enclosed parking garages: A preliminary case study for Eindhoven city center. Journal of Wind Engineering and Industrial Aerodynamics, 159: 80-98.

Blocken B, Stathopoulos T, van Beeck JPAJ (2016b). Pedestrian-level wind conditions around buildings: Review of wind-tunnel and CFD techniques and their accuracy for wind comfort assessment. Building and Environment, 100: 50-81.

Bolster DT, Linden PF (2007). Contaminants in ventilated filling boxes. Journal of Fluid Mechanics, 591: 97-116.

Bottema M (1993). Wind climate and urban geometry. PhD Thesis, Eindhoven University of Technology, the Netherlands.
Boussinesq J (1877). Essai sur la théorie des eaux courantes. Mémoires présentés par divers savants à l'Académie des Sciences, 23 (1): $1-680$.

Britter RE, Hunt JCR (1979). Velocity measurements and order of magnitude estimates of the flow between two buildings in a simulated atmospheric boundary layer. Journal of Wind Engineering and Industrial Aerodynamics, 4: 165-182.

Britter R, Schatzmann M (2007). Model Evaluation Guidance and Protocol Document COST Action 732. COST Office Brussels.

Broyd TW, Dean RB, Oldfield SG, Moult A (1983). The use of a computational method to assess the safety and quality of ventilation in industrial buildings. In: Proceedings of Conference on Heat and Fluid Flow in Nuclear and Process Plant Safety, London, UK.

Buccolieri R, Jeanjean APR, Gatto E, Leigh RJ (2018). The impact of trees on street ventilation, $\mathrm{NO}_{x}$ and $\mathrm{PM}_{2.5}$ concentrations across heights in Marylebone Rd street canyon, central London. Sustainable Cities and Society, 41: 227-241.

Casey M, Wintergerste T (2000). Best Practice Guidelines, ERCOFTAC Special Interest Group on Quality and Trust in Industrial CFD, ERCOFTAC, Brussels.

Castro IP, Robins AG (1977). The flow around a surface-mounted cube in uniform and turbulent streams. Journal of Fluid Mechanics, 79: 307-335.

Castro IP, Graham JMR (1999). Numerical wind engineering: The way ahead? Proceedings of the Institution of Civil EngineersStructures and Buildings, 134: 275-277.

Chang T-J, Kao H-M, Hsieh Y-F (2007). Numerical study of the effect of ventilation pattern on coarse, fine, and very fine particulate matter removal in partitioned indoor environment. Journal of the Air and Waste Management Association, 57: 179-189.

Charney JG, Fjörtoft R, von Neumann J (1950). Numerical integration of the barotropic vorticity equation. Tellus, 2: 237-254.

Chen Q (1995). Comparison of different $k-\varepsilon$ models for indoor air flow computations. Numerical Heat Transfer, Part B: Fundamentals, 28: 353-369.

Chen Q (1996). Prediction of room air motion by Reynolds-stress models. Building and Environment, 31: 233-244.

Chen Q (1997). Computational fluid dynamics for HVAC: Successes and failures. ASHRAE Transactions, 103(1): 11-10.

Chen Q, Chao NT (1997). Comparing turbulence models for buoyant plume and displacement ventilation simulation. Indoor and Built Environment, 6: 140-149.

Chen Q, Srebric J (2001). How to verify, validate and report indoor environment modeling CFD analysis. ASHRAE RP-1133. Final Report, ASHRAE TC 4.10, Indoor Environmental Modeling.

Chen Q (2009). Ventilation performance prediction for buildings: A method overview and recent applications. Building and Environment, 44: 848-858.

Chu CR, Chiang BF (2013). Wind-driven cross ventilation with internal obstacles. Energy and Buildings, 67: 201-209.

Conan B, van Beeck J, Aubrun S (2012). Sand erosion technique applied to wind resource assessment. Journal of Wind Engineering and Industrial Aerodynamics, 104-106: 322-329. 
Cook NJ (1975). A boundary layer wind tunnel for building aerodynamics. Journal of Wind Engineering and Industrial Aerodynamics, 1: 3-12.

Davidson L, Nielsen PV (1996). Large eddy simulation of the flow in a three-dimensional ventilation room. In: Proceedings of the 5th International Conference on Air Distribution in Rooms, ROOMVENT'96, pp. 161-168.

Deardorff JW (1970a). A numerical study of three-dimensional turbulent channel flow at large Reynolds numbers. Journal of Fluid Mechanics, 41: 453-480.

Deardorff JW (1970b). A three-dimensional numerical investigation of the idealized planetary boundary layer. Geophysical Fluid Dynamics, 1: 377-410.

Deardorff JW (1970c). Preliminary results from numerical integrations of the unstable planetary boundary layer. Journal of the Atmospheric Sciences, 27: 1209-1211.

Deardorff JW (1970d). Convective velocity and temperature scales for the unstable planetary boundary layer and for Rayleigh convection. Journal of the Atmospheric Sciences, 27: 1211-1213.

Deardorff JW (1972). Numerical investigation of neutral and unstable planetary boundary layers. Journal of the Atmospheric Sciences, 29: 91-115.

Dhunny AZ, Samkhaniani N, Lollchund MR, Rughooputh SDDV (2018). Investigation of multi-level wind flow characteristics and pedestrian comfort in a tropical city. Urban Climate, 24: 185-204.

Di Sabatino S, Buccolieri R, Pulvirtenti B, Britter R (2007). Simulations of pollutant dispersion within idealised urban-type geometries with CFD and integral models. Atmospheric Environment, 41: 8316-8329.

Du Y, Mak CM, Ai Z (2018). Modelling of pedestrian level wind environment on a high-quality mesh: A case study for the HKPolyU campus. Environmental Modelling \& Software, 103: 105-119.

Efthimiou GC, Adronopoulos S, Tavares R, Bartzis JG (2017). CFD-RANS prediction of the dispersion of a hazardous airborne material released during a real accident in an industrial environment. Journal of Loss Prevention in the Process Industries, 46: 23-36.

Emmerich SJ, McGrattan KB (1998). Application of a Large Eddy Simulation model to study room airflow. ASHRAE Transactions, 104(1): 1128-1137.

Etheridge DW, Sandberg M (1996). Building Ventilation: Theory and Measurement. Chichester, UK: John Wiley \& Sons.

Etheridge D (2011). Natural Ventilation of Buildings: Theory, Measurement and Design. Chichester, UK: John Wiley \& Sons.

Evola G, Popov V (2006). Computational analysis of wind driven natural ventilation in buildings. Energy and Buildings, 38: 491-501.

Ferziger JH (1990). Approaches to turbulent flow computation: applications to flow over obstacles. Journal of Wind Engineering and Industrial Aerodynamics, 35: 1-19.

Ferziger JH (1993). Simulation of complex turbulent flows: recent advances and prospects in wind engineering. Journal of Wind Engineering and Industrial Aerodynamics, 46-47: 195-212.
Ferziger JH, Peric M (1996). Computational Methods for Fluid Dynamics. Berlin: Springer.

Flaherty JE, Stock D, Lamb B (2007). Computational fluid dynamic simulations of plume dispersion in urban Oklahoma city. Journal of Applied Meteorology and Climatology, 46: 2110-2126.

Franke J, Hellsten A, Schlünzen H, Carissimo B (2007). Best practice guideline for the CFD simulation of flows in the urban environment. COST Office Brussels.

Franke J, Hellsten A, Schlünzen KH, Carissimo B (2011). The COST 732 Best Practice Guideline for CFD simulation of flows in the urban environment: A summary. International Journal of Environment and Pollution, 44: 419-427.

Franke J, Hirsch C, Jensen AG, Krüs HW, Schatzmann M, Westbury PS, Miles SD, Wisse JA, Wright NG (2004). Recommendations on the use of CFD in wind engineering. In: van Beeck JPAJ (Ed), Proceedings of the International Conference on Urban Wind Engineering and Building Aerodynamics. COST Action C14, Impact of Wind and Storm on City Life Built Environment, Sint-Genesius-Rode, Belgium.

Fraser SM, Carey C, Moustafa AAA (1990). Numerical and experimental analysis of flow around isolated and shielded cubes. Applied Mathematical Modelling, 14: 588-597.

Freitas CJ (1993). Journal of Fluids Engineering editorial policy statement on the control of numerical accuracy. Journal of Fluids Engineering, 115: 339-340.

Frost W, Maus JR, Fichtl GH (1974). A boundary-layer analysis of atmospheric motion over a semi-elliptical surface obstruction. Boundary-Layer Meteorology, 7: 165-184.

Gadilhe A, Janvier L, Barnaud G (1993). Numerical and experimental modelling of the three-dimensional turbulent wind flow through an urban square. Journal of Wind Engineering and Industrial Aerodynamics, 46-47: 755-763.

Gao Z, Bresson R, Qu Y, Milliez M, de Munck C, Carissimo B (2018). High resolution unsteady RANS simulation of wind, thermal effects and pollution dispersion for studying urban renewal scenarios in a neighborhood of Toulouse. Urban Climate, 23: 114-130.

Garbero V, Salizzoni P, Soulhac L (2010). Experimental study of pollutant dispersion within a network of streets. Boundary-Layer Meteorology, 136: 457-487.

Garcia-Sánchez C, Van Tendeloo G, Gorlé C (2017). Quantifying inflow uncertainties in RANS simulations of urban pollutant dispersion. Atmospheric Environment, 161: 263-273.

Germano M, Piomelli U, Moin P, Cabot WH (1991). A dynamic subgrid-scale eddy viscosity model. Physics of Fluids A: Fluid Dynamics, 3: 1760-1765.

Gorlé C, van Beeck J, Rambaud P, Van Tendeloo G (2009). CFD modelling of small particle dispersion: The influence of the turbulence kinetic energy in the atmospheric boundary layer. Atmospheric Environment, 43: 673-681.

Gosman AD, Nielsen PV, Restivo A, Whitelaw JH (1980). The flow properties of rooms with small ventilation openings. Journal of Fluids Engineering, 102: 316-323. 
Gosman AD (1999). Developments in CFD for industrial and environmental applications in wind engineering. Journal of Wind Engineering and Industrial Aerodynamics, 81: 21-39.

Gousseau P, Blocken B, Stathopoulos T, van Heijst GJF (2011a). CFD simulation of near-field pollutant dispersion on a highresolution grid: A case study by LES and RANS for a building group in downtown Montreal. Atmospheric Environment, 45: 428-438.

Gousseau P, Blocken B, van Heijst GJF (2011b). CFD simulation of pollutant dispersion around isolated buildings: On the role of convective and turbulent mass fluxes in the prediction accuracy. Journal of Hazardous Materials, 194: 422-434.

Gousseau P, Blocken B, van Heijst GJF (2012). Large-Eddy Simulation of pollutant dispersion around a cubical building: analysis of the turbulent mass transport mechanism by unsteady concentration and velocity statistics. Environmental Pollution, 167: 47-57.

Gousseau P, Blocken B, van Heijst GJF (2013). Quality assessment of Large-Eddy Simulation of wind flow around a high-rise building: Validation and solution verification. Computers \& Fluids, 79: 120-133.

Gousseau P, Blocken B, Stathopoulos T, van Heijst GJF (2015). Near-field pollutant dispersion in an actual urban area: Analysis of the mass transport mechanism by high-resolution Large Eddy Simulations. Computers \& Fluids, 114: 151-162.

Gromke C, Blocken B (2015). Influence of avenue-trees on air quality at the urban neighborhood scale. Part II: Traffic pollutant concentrations at pedestrian level. Environmental Pollution, 196: 176-184.

Gromke C, Blocken B, Janssen WD, Merema B, van Hooff T, Timmermans HJP (2015). CFD analysis of transpirational cooling by vegetation: Case study for specific meteorological conditions during a heat wave in Arnhem, Netherlands. Building and Environment, 83: 11-26.

Hanjalic K (2005). Will RANS survive LES? A view of perspectives. Journal of Fluids Engineering, 127: 831-839.

Hanna SR (1989). Plume dispersion and concentration fluctuations in the atmosphere. Encyclopedia of environmental control technology. In: Cheremisinoff PN (Ed), Encyclopedia of Environmental Control Technology, Vol. 2, Air Pollution Control, Chapter 14. Houston, TX, USA: Gulf Publishing Company. pp. 547-582.

Hanna SR, Brown MJ, Camell FE, Chan ST, Coirier WJ, Hansen OR, Huber AH, Kim S, Reynolds RM (2006). Detailed simulations of atmospheric flow and dispersion in downtown Manhattan: An application of five computational fluid dynamics models. Bulletin of the American Meteorological Society, 87: 1713-1726.

Hargreaves DM, Wright NG (2007). On the use of the $k-\varepsilon$ model in commercial CFD software to model the neutral atmospheric boundary layer. Journal of Wind Engineering and Industrial Aerodynamics, 95: 355-369.

He J, Song CCS (1999). Evaluation of pedestrian winds in urban area by numerical approach. Journal of Wind Engineering and Industrial Aerodynamics, 81: 295-309.
Heiselberg P, Murakami S, Roulet CA (1998). Ventilation of large spaces in buildings. Analysis and prediction techniques. IEA Annex 26: Energy Efficient Ventilation of Large Enclosures. Aalborg University, Denmark.

Hibi K, Murakami S, Mochida A (1985). Prediction of room air flow by means of large eddy simulation. Summaries of Technical Papers of Annual Meeting, Architectural Institute of Japan.

Hibi K, Ueda H, Wakahara T, Shimada K (1993). Use of large eddy simulation to measure fluctuating pressure fields around buildings with wall openings. Journal of Wind Engineering and Industrial Aerodynamics, 46-47: 239-244.

Hirsch C, Bouffioux V, Wilquem F (2002). CFD simulation of the impact of new buildings on wind comfort in an urban area. In: Proceedings of Cost Action C14, Impact of Wind and Storm on City Life and Built Environment, Nantes, France.

Hirt CW, Cook JL (1972). Calculating three-dimensional flows around structures and over rough terrain. Journal of Computational Physics, 10: 324-340.

Holmes MJ (1982). The application of fluid mechanics simulation program PHOEN1CS to a few typical HVAC problems. London: Ove Arup Partnership.

Holmes MJ, Whittle GE (1987). How accurate are the predictions of complex air movement models? Building Services Engineering Research and Technology, 8(2): 29-31.

Holmes MJ, Lam JKW, Ruddick KG, Whittle GE (1990). Computation of conduction, convection and radiation in the perimeter zone of an office space. In: Proceedings of International Conference of ROOMVENT, Oslo, Norway.

Horan JM, Finn DP (2008). Sensitivity of air change rates in a naturally ventilated atrium space subject to variations in external wind speed and direction. Energy and Buildings, 40: 1577-1585.

$\mathrm{Hu} \mathrm{CH}$, Kurabuchi T, Ohba M (2005). Numerical study of crossventilation using two-equation RANS turbulence models. International Journal of Ventilation, 4: 123-131.

$\mathrm{Hu} \mathrm{CH}$, Ohba M, Yoshie R (2008). CFD modelling of unsteady cross ventilation flows using LES. Journal of Wind Engineering and Industrial Aerodynamics, 96: 1692-1706.

Huber AH, Snyder WH (1982). Wind tunnel investigation of the effects of a rectangular-shaped building on dispersion of effluents from short adjacent stacks. Atmospheric Environment, 16: 28372848.

Hunt GR, Linden PF (1999). The fluid mechanics of natural ventilation-Displacement ventilation by buoyancy-driven flows assisted by wind. Building and Environment, 34: 707-720.

Hunt JCR (1998). Lewis Fry Richardson and his contributions to mathematics, meteorology, and models of conflict. Annual Reviews of Fluid Mechanics, 30: xiii-xxxvi.

Iqbal QMZ, Chan ALS (2016). Pedestrian level wind environment assessment around group of high-rise cross-shaped buildings: Effect of building shape, separation and orientation. Building and Environment, 101: 45-63. 
Irwin HPAH (1981). A simple omnidirectional sensor for wind-tunnel studies of pedestrian-level winds. Journal of Wind Engineering and Industrial Aerodynamics, 7: 219-239.

Ishizu Y, Kaneki K (1984). Evaluation of ventilation systems through numerical computation and presentation of a new ventilation model. ASHRAE Transactions, 24: 47-57.

Isyumov N, Davenport AG (1975). Comparison of full-scale and wind tunnel wind speed measurements in the commerce court plaza. Journal of Wind Engineering and Industrial Aerodynamics, 1: 201-212.

Isyumov N (1978). Studies of the pedestrian level wind environment at the boundary layer wind tunnel laboratory of the University of Western Ontario. Journal of Wind Engineering and Industrial Aerodynamics, 3: 187-200.

Jacob J, Sagaut P (2018). Wind comfort assessment by means of large eddy simulation with lattice Boltzmann method in full scale city area. Building and Environment, 139: 110-124.

Jakeman AJ, Letcher RA, Norton JP (2006). Ten iterative steps in development and evaluation of environmental models. Environmental Modelling and Software, 21: 602-614.

Janssen WD, Blocken B, van Hooff T (2013). Pedestrian wind comfort around buildings: Comparison of wind comfort criteria based on whole-flow field data for a complex case study. Building and Environment, 59: 547-562.

Jeanjean APR, Gallagher J, Monks PS, Leigh RJ (2017). Ranking current and prospective $\mathrm{NO}_{2}$ pollution mitigation strategies: $\mathrm{An}$ environmental and economic modelling investigation in Oxford Street, London. Environmental Pollution, 225: 587-597.

Jiang Y, Chen Q (2002). Effect of fluctuating wind direction on cross natural ventilation in buildings from large eddy simulation. Building and Environment, 37: 379-386.

Jiang Y, Alexander D, Jenkins H, Arthur R, Chen Q (2003). Natural ventilation in buildings: Measurement in a wind tunnel and numerical simulation with large-eddy simulation. Journal of Wind Engineering and Industrial Aerodynamics, 91: 331-353.

Jones W, Launder BE (1972). The prediction of laminarization with a two-equation model of turbulence. International Journal of Heat and Mass Transfer, 15: 301-314.

Jones PJ, O'Sullivan PE (1987). Development of a model to predict air flow and heat distribution in factories. SERC Final report.

Jones PJ, Reed N (1988). Air flow in large spaces. PHOENICS Newsletter, No. 13, CHAM Ltd.

Jones PJ (1990). Room air distribution and ventilation effectiveness in air-conditioned offices. In: Proceedings of the 5th International Conference on Indoor Air Quality and Chinnock, Toronto, Canada, pp. 133-138.

Jones PJ, Waters RA (1990). Designing the environment in and around buildings. Construction, 76: 33-36.

Jones PJ, Waters RA (1991). Modelling the atrium environment. In: Proceedings of International Conference on Architecture and Engineering, Nottingham, UK.

Jones PJ, Whittle GE (1992). Computational fluid dynamics for building air flow prediction-Current status and capabilities. Building and Environment, 27: 321-338.
Juan YH, Yang AS, Wen CY, Lee YT, Wang PC (2017). Optimization procedures for enhancement of city breathability using arcade design in a realistic high-rise urban area. Building and Environment, 121: 247-261.

Kang G, Kim JJ, Kim DJ, Choi W, Park SJ (2017). Development of a computational fluid dynamics model with tree drag parameterizations: Application to pedestrian wind comfort in an urban area. Building and Environment, 124: 209-218.

Kang J-H, Lee S-J (2008). Improvement of natural ventilation in a large factory building using a louver ventilator. Building and Environment, 43: 2132-2141.

Kang L, Zhou X, van Hooff T, Blocken B, Gu M (2018). CFD simulation of snow transport over flat, uniformly rough, open terrain: Impact of physical and computational parameters. Journal of Wind Engineering and Industrial Aerodynamics, 177: 213-226.

Karadimou DP, Markatos NC (2016). Modelling of two-phase, transient airflow and particles distribution in the indoor environment by Large Eddy Simulation. Journal of Turbulence, 17: 216-236.

Karava P, Stathopoulos T, Athienitis AK (2011). Airflow assessment in cross-ventilated buildings with operable facade elements. Building and Environment, 46: 266-279.

Karava P, Stathopoulos T (2012). Wind-induced internal pressures in buildings with large façade openings. Journal of Engineering Mechanics, 138: 358-370.

Karra S, Malki-Epshtein L, Neophytou MKA (2017). Air flow and pollution in a real, heterogeneous urban street canyon: A field and laboratory study. Atmospheric Environment, 165: 370-384.

Katayama T, Tsutsumi J, Ishii A (1992). Full-scale measurements and wind tunnel tests on cross-ventilation. Journal of Wind Engineering and Industrial Aerodynamics, 44: 2553-2562.

Kato S, Murakami S, Mochida A, Akabayashi S, Tominaga Y (1992). Velocity-pressure field of cross-ventilation with open windows analyzed by wind tunnel and numerical simulation. Journal of Wind Engineering and Industrial Aerodynamics, 44: 2575-2586.

Kato M, Launder BE (1993). The modelling of turbulent flow around stationary and vibrating square cylinders. In: Proceedings of the 9th Symposium on Turbulent Shear Flows.

Kawamura S, Kimoto E, Fukushima T, Taniike Y (1988). Environmental wind characteristics around the base of a tall buildingA comparison between model test and full-scale experiment. Journal of Wind Engineering and Industrial Aerodynamics, 28: 149-158.

Khayrullina A, van Hooff T, Blocken B, van Heijst GJF (2017). PIV measurements of isothermal plane turbulent impinging jets at moderate Reynolds numbers. Experiments in Fluids, 58: Article 31.

Kimura R (2002). Numerical weather prediction. Journal of Wind Engineering and Industrial Aerodynamics, 90: 1403-1414.

Klok L, Zwart S, Verhagen H, Mauri E (2012). The surface heat island of Rotterdam and its relationship with urban surface characteristics. Resources, Conservation and Recycling, 64: 23-29.

Kolmogorov AN (1941). The local structure of turbulence in incompressible viscous fluid for very large Reynolds numbers. Proceedings of the USSR Academy of Sciences (C. R. Acad. Sci. URSS), 30: 301-305. 
Kurabuchi T, Ohba M, Arashiguchi A, Iwabuchi T (2000). Numerical study of airflow structure of a cross ventilated model building. In: Proceedings of Air Distribution in Rooms: Ventilation for Health and Sustainable Environment, pp. 313-318.

Lai MKK, Chan ATY (2007). Large-eddy simulations on indoor/ outdoor air quality relationship in an isolated urban building. Journal of Engineering Mechanics, 133: 887-898.

Lam KM (1992). Wind environment around the base of a tall building with a permeable intermediate floor. Journal of Wind Engineering and Industrial Aerodynamics, 44: 2313-2314.

Lateb M, Masson C, Stathopoulos T, Bédard C (2010). Numerical simulation of pollutant dispersion around a building complex. Building and Environment, 45: 1788-1798.

Lateb M, Masson C, Stathopoulos T, Bédard C (2011). Effect of stack height and exhaust velocity on pollutant dispersion in the wake of a building. Atmospheric Environment, 45: 5150-5163.

Launder BE, Reece GJ, Rodi W (1975). Progress in the development of a Reynolds-stress turbulence closure. Journal of Fluid Mechanics, 68: 537-566.

Lemaire AD (1989). The numerical simulation of the air movement and heat transfer in a heated room resp. a ventilated atrium. TNO Institute of Applied Physics.

Leonard A (1974). Energy cascade in large-eddy simulations of turbulent fluid flow. Advances in Geophysics, 18A: 237-248.

Leschziner MA (1990). Modelling engineering flows with Reynolds stress turbulence closure. Journal of Wind Engineering and Industrial Aerodynamics, 35: 21-47.

Leschziner MA (1993). Computational modelling of complex turbulent flow-Expectations, reality and prospects. Journal of Wind Engineering and Industrial Aerodynamics, 46-47: 37-51.

Li WW, Meroney RN (1983a). Gas dispersion near a cubical model building. Part II. Concentration fluctuation measurements. Journal of Wind Engineering and Industrial Aerodynamics, 12: 35-47.

Li WW, Meroney RN (1983b). Gas dispersion near a cubical model building. Part I. Mean concentration measurements. Journal of Wind Engineering and Industrial Aerodynamics, 12: 15-33.

Li Y, Stathopoulos T (1997). Numerical evaluation of wind-induced dispersion of pollutants around a building, Journal of Wind Engineering and Industrial Aerodynamics, 67-68: 757-766.

Li Y, Nielsen PV (2011). CFD and ventilation research. Indoor Air, 21: 442-453.

Li F, Liu J, Ren J, Cao X (2018). Predicting contaminant dispersion using modified turbulent Schmidt numbers from different vortex structures. Building and Environment, 130: 120-127.

Lilly DK (1962). On the numerical simulation of buoyant convection. Tellus, 14: 148-172.

Lilly DK (1964). Numerical solutions for the shape-preserving twodimensional thermal convection element. Journal of the Atmospheric Sciences, 21: 83-98.

Lilly DK (1991). A proposed modification of the Germano subgrid-scale closure method. Physics of Fluids A: Fluid Dynamics, 4: 633-635.

Lilly DK (2000). The meteorological development of large eddy simulation. In: Kerr RM, Kimura Y (Eds), IUTAM Symposium on Developments in Geophysical Turbulence. Fluid Mechanics and
Its Applications, vol 58. Dordrecht, the Netherlands: Springer.

Linden PF, Lane-Derff GF, Smeed DA (1990). Emptying filling boxes: The fluid-mechanics of natural ventilation. Journal of Fluid Mechanics, 212: 309-335.

Linden PF (1999). The fluid mechanics of natural ventilation. Annual Review of Fluid Mechanics, 31: 201-238.

Liu YS, Cui GX, Wang ZS, Zhang ZS (2011). Large eddy simulation of wind field and pollutant dispersion in downtown Macao. Atmospheric Environment, 45: 2849-2859.

Liu YS, Miao SG, Zhang CL, Cui GX, Zhang ZS (2012). Study on micro-atmospheric environment by coupling large eddy simulation with mesoscale model. Journal of Wind Engineering and Industrial Aerodynamics, 107-108: 106-117.

Liu SC, Novoselac A (2014). Lagrangian particle modeling in the indoor environment: A comparison of RANS and LES turbulence methods (RP-1512). HVAC\&R Research, 20: 480-495.

Liu S, Pan W, Zhang H, Cheng X, Long Z, Chen Q (2017). CFD simulations of wind distribution in an urban community with a full-scale geometrical model. Building and Environment, 117: 11-23.

Liu S, Pan W, Zhao X, Zhang H, Cheng X, Long Z, Chen Q (2018). Influence of surrounding buildings on wind flow around a building predicted by CFD simulations. Building and Environment, 140: $1-10$.

Livermore SR, Woods AW (2007). Natural ventilation of a building with heating at multiple levels. Building and Environment, 42: 1417-1430.

Livesey F, Inculet D, Isyumov N, Davenport AG (1990). A scour technique for evaluation of pedestrian winds, Journal of Wind Engineering and Industrial Aerodynamics, 36: 779-789.

Lynch P (2008). The origins of computer weather prediction and climate modeling. Journal of Computational Physics, 227: 34313444 .

Markatos NC, Pericleous KA (1984). Laminar and turbulent natural convection in an enclosed cavity. International Journal of Heat and Mass Transfer, 27: 755-772.

Martins NR, da Graça GC (2016). Validation of numerical simulation tools for wind-driven natural ventilation design. Building Simulation, 9: 75-87.

Menter F, Hemstrom B, Henrikkson M, Karlsson R, Latrobe A, Martin A, Muhlbauer P, Scheuerer M, Smith B, Takacs T, Willemsen S (2002). CFD Best Practice Guidelines for CFD Code Validation for Reactor-Safety Applications, Report EVOLECORAD01, Contract No. FIKS-CT-2001-00154.

Menter F (1997). Eddy viscosity transport equations and their relation to the $k-\varepsilon$ model. Journal of Fluids Engineering, 119: 876-884.

Meroney RN (2004). Wind tunnel and numerical simulation of pollution dispersion: A hybrid approach. Paper for Invited Lecture at the Croucher Advanced Study Institute, Hong Kong University of Science and Technology.

Meroney RN (2009). CFD prediction of airflow in buildings for natural ventilation. In: Proceedings of the11th Americas Conference on Wind Engineering, San Juan, Puerto Rico. 
Meroney RN, Leitl BM, Rafailidis S, Schatzmann M (1999). Windtunnel and numerical modeling of flow and dispersion about several building shapes. Journal of Wind Engineering and Industrial Aerodynamics, 81: 333-345.

Meroney RN (2016). Ten questions concerning hybrid computational/ physical model simulation of wind flow in the built environment. Building and Environment, 96: 12-21.

Mochida A, Murakami S, Shoji M, Ishida Y (1993). Numerical simulation of flowfield around Texas Tech Building by Large Eddy Simulation. Journal of Wind Engineering and Industrial Aerodynamics, 46-47: 455-460.

Mochida A, Tominaga Y, Murakami S, Yoshie R, Ishihara T, Ooka R (2002). Comparison of various $k-\varepsilon$ models and DSM applied to flow around a high-rise building-Report on AIJ cooperative project for CFD prediction of wind environment. Wind and Structures, 5: 227-244.

Mochida A, Yoshino H, Takeda T, Kakegawa T, Miyauchi S (2005). Methods for controlling airflow in and around a building under cross-ventilation to improve indoor thermal comfort. Journal of Wind Engineering and Industrial Aerodynamics, 93: 437-449.

Mochida A, Yoshino H, Miyauchi S, Mitamura T (2006). Total analysis of cooling effects of cross-ventilation affected by microclimate around a building. Solar Energy, 80: 371-382.

Mochida A, Lun IYF (2008). Prediction of wind environment and thermal comfort at pedestrian level in urban area. Journal of Wind Engineering and Industrial Aerodynamics, 96: 1498-1527.

Montazeri H, Blocken B, Janssen WD, van Hooff T (2013). CFD evaluation of new second-skin facade concept for wind comfort on building balconies: Case study for the Park Tower in Antwerp. Building and Environment, 68: 179-192.

Montazeri H, Toparlar Y, Blocken B, Hensen JLM (2017). Simulating the cooling effects of water spray systems in urban landscapes: A computational fluid dynamics study in Rotterdam, The Netherlands. Landscape and Urban Planning, 159: 85-100.

Morsing S, Strøm JS, Zhang G, Kai P (2008). Scale model experiments to determine the effects of internal airflow and floor design on gaseous emissions from animal houses. Biosystems Engineering, 99: 99-104.

Murakami S, Uehara K, Komine H (1979). Amplification of wind speed at ground level due to construction of high-rise building in urban area. Journal of Wind Engineering and Industrial Aerodynamics, 4: 343-370.

Murakami S, Mochida A, Hibi K (1986). 3-D numerical simulation of room convection by means of large eddy simulation. In: Proceedings of Technical Display for NBS/CBT Building Technology Symposium, Room Convection and Indoor Air Quality Simulation Modelling, NBS Administration Building, Gaithersburg, MD, USA.

Murakami S, Mochida A, Hibi K (1987). Three-dimensional numerical simulation of air flow around a cubic model by means of large eddy simulation. Journal of Wind Engineering and Industrial Aerodynamics, 25: 291-305.

Murakami S, Mochida A (1988). 3-D numerical simulation of airflow around a cubic model by means of the $k-\varepsilon$ model. Journal of
Wind Engineering and Industrial Aerodynamics, 31: 283-303.

Murakami S, Mochida A (1989). Three-dimensional numerical simulation of turbulent flow around buildings using the $k-\varepsilon$ turbulence model. Building and Environment, 24: 51-64.

Murakami S, Kato S (1989). Numerical and experimental study on room airflow-3-D predictions using the $k-\varepsilon$ turbulence model. Building and Environment, 24: 85-97.

Murakami S (1990a). Computational Wind Engineering. Journal of Wind Engineering and Industrial Aerodynamics, 36: 517-538.

Murakami S (1990b). Numerical simulation of turbulent flowfield around cubic model: Current status and applications of $k-\varepsilon$ model and LES. Journal of Wind Engineering and Industrial Aerodynamics, 33: 139-152.

Murakami S, Mochida A, Hayashi Y (1990a). Examining the $k-\varepsilon$ model by means of a wind tunnel test and large-eddy simulation of the turbulence structure around a cube. Journal of Wind Engineering and Industrial Aerodynamics, 35: 87-100.

Murakami S, Mochida A, Hayashi Y (1990b). Numerical simulation of velocity field and diffusion field in an urban area. Energy and Buildings, 15-16: 345-356.

Murakami S, Mochida A, Hayashi Y, Sakamoto S (1992). Numerical study on velocity-pressure field and wind forces for bluff bodies by $k-\varepsilon$, ASM and LES. Journal of Wind Engineering and Industrial Aerodynamics, 44: 2841-2852.

Murakami S (1993). Comparison of various turbulence models applied to a bluff body. Journal of Wind Engineering and Industrial Aerodynamics, 46-47: 21-36.

Murakami S, Mochida A, Matsui K (1995). Large Eddy Simulation of non-isothermal room airflow-Comparison between standard and dynamic type of Smagorinsky models. Journal of Institute of Industrial Science, 47(2): 7-12.

Murakami S (1997). Current status and future trends in computational wind engineering. Journal of Wind Engineering and Industrial Aerodynamics, 67-68: 3-34.

Murakami S (1998). Overview of turbulence models applied in CWE1997. Journal of Wind Engineering and Industrial Aerodynamics, 74-76: 1-24.

Murakami S, Ooka R, Mochida A, Yoshida S, Kim S (1999). CFD analysis of wind climate from human scale to urban scale. Journal of Wind Engineering and Industrial Aerodynamics, 81: 57-81.

NEN (2006a). Wind comfort and wind danger in the built environment, NEN 8100 Dutch Standard. (in Dutch)

NEN (2006b). Application of mean hourly wind speed statistics for the Netherlands, NPR 6097:2006. Dutch Practice Guideline. (in Dutch)

Neophytou MKA, Markides CN, Fokaides PA (2014). An experimental study of the flow through and over two dimensional rectangular roughness elements: Deductions for urban boundary layer parameterizations and exchange processes. Physics of Fluids, 26(8): 086603.

Nicholls M, Pielke R, Meroney R (1993). Large eddy simulation of microburst winds flowing around a building. Journal of Wind Engineering and Industrial Aerodynamics, 46-47: 229-237.

Nielsen PV (1973). Berechnung der Luftbewegung in einem zwangsbelüfteten Raum. Gesundheits-Ingenieur, 94: 299-302.

Nielsen PV (1974a). Flow in air conditioned rooms. PhD Thesis, Technical University of Denmark, Denmark. (in Danish) 
Nielsen PV (1974b). Moisture transfer in air conditioned rooms and cold stores. In: Proceedings of the 2nd International CIB/RILEM Symposium on Moisture Problems in Buildings, Rotterdam, the Netherlands, Paper 1.2.1.

Nielsen PV (1976). Flow in air conditioned rooms. English translation and revision of PhD Thesis, Technical University of Denmark, Copenhagen.

Nielsen PV, Restivo A, Whitelaw JH (1978). The velocity characteristics of ventilated rooms. Journal of Fluids Engineering, 100: 291-298.

Nielsen PV, Restivo A, Whitelaw JH (1979). Buoyancy-affected flows in ventilated rooms. Numerical Heat Transfer, 2: 115-127.

Nielsen PV (1981). Contaminant distribution in industrial areas with forced ventilation and two-dimensional flow. In: IIR-Joint Meeting, Institut for Bygningsteknik, Aalborg Universitet.

Nielsen PV (1998). The selection of turbulence models for prediction of room airflow. ASHRAE Transactions, 104(1B): 1119-1127.

Nielsen PV (2004). Computational fluid dynamics and room air movement. Indoor Air, 14(Suppl. 7): 134-143.

Nielsen PV, Allard F, Awbi HB, Davidson L, Schälin A (2007). Computational fluid dynamics in ventilation design. REHVA Guidebook No. 10.

Nielsen PV (2015). Fifty years of CFD for room air distribution. Building and Environment, 91: 78-90.

Niemann HJ (1993). The boundary layer wind tunnel: An experimental tool in building aerodynamics and environmental engineering Journal of Wind Engineering and Industrial Aerodynamics, 48: 145-161.

Nomura T, Murakami S, Kato S, Sato M (1980). Correspondence of the three-dimensional numerical analysis of turbulence flow to model experiment. Transactions of AIJ, 298: 69-80.

Norton T, Grant J, Fallon R, Sun DW (2009). Assessing the ventilation effectiveness of naturally ventilated livestock buildings under wind dominated conditions using computational fluid dynamics. Biosystems Engineering, 103: 78-99.

Nozu T, Tamura T (2012). LES of turbulent wind and gas dispersion in a city. Journal of Wind Engineering and Industrial Aerodynamics, 104-106: 492-499.

Oberkampf WL, Trucano TG, Hirsch C (2004). Verification, validation, and predictive capability in computational engineering and physics. Applied Mechanics Reviews, 57: 345-384.

Panagiotou I, Neophytou MK-A, Hamlyn D, Britter RE (2013). City breathability as quantified by the exchange velocity and its spatial variation in real inhomogeneous urban geometries: An example from central London urban area. Science of the Total Environment, 442: 466-477.

Parente A, Gorlé C, van Beeck J, Benocci C (2011). Improved $k$ - $\varepsilon$ model and wall function formulation for the RANS simulation of ABL flows. Journal of Wind Engineering and Industrial Aerodynamics, 99: 267-278.

Partridge JL, Linden PF (2013). Validity of thermally-driven smallscale ventilated filling box models. Experiments in Fluids, 54: 1613.

Paterson DA, Apelt CJ (1986). Computation of wind flows over three-dimensional buildings. Journal of Wind Engineering and Industrial Aerodynamics, 24: 192-213.

Paterson DA, Apelt CJ (1989). Simulation of wind flow around threedimensional buildings. Building and Environment, 24: 39-50.

Paterson DA, Apelt CJ (1990). Simulation of flow past a cube in a turbulent boundary layer. Journal of Wind Engineering and Industrial Aerodynamics, 35: 149-176.

Patnaik G, Boris JP, Young TR (2007). Large scale urban contaminant transport simulations with miles. Journal of Fluid Engineering, 129: 1524-1532.

Peng L, Liu JP, Wang Y, Chan P, Lee T, Peng F, Wong M, Li Y (2018). Wind weakening in a dense high-rise city due to over nearly five decades of urbanization. Building and Environment, 138: 207-220.

Penwarden AD, Wise AFE (1975). Wind environment around buildings, Building Research Establishment Report, Department of Environment, BRE, HMSO, London, UK.

Pope SB (1999). A perspective on turbulence modeling. In: Salas MD, Hefner JN, Sakell L (Eds), Modeling Complex Flows. Dordrecht, the Netherlands: Kluwer Academic Publisher. pp. 53-67.

Pournazeri S, Princevac M, Venkatram A (2012). Scaling of building affected plume rise and dispersion in water channels and wind tunnels-Revisit of an old problem. Journal of Wind Engineering and Industrial Aerodynamics, 103: 16-30.

Prandtl L (1904). Über Flüssigkeitsbewegung bei sehr kleiner Reibung. In: Verhandlungen des III Internationalen Mathematiker-Kongresses, Heidelberg. Leipzig, Germany: B G Teubner. pp. 484-491.

Princevac M, Baik JJ, Li X, Pan H, Park SB (2010). Lateral channeling within rectangular arrays of cubical obstacles. Journal of Wind Engineering and Industrial Aerodynamics, 98: 377-385.

Ramponi R, Blocken B (2012a). CFD simulation of cross-ventilation for a generic isolated building: Impact of computational parameters. Building and Environment, 53: 34-48.

Ramponi R, Blocken B (2012b). CFD simulation of cross-ventilation flow for different isolated building configurations: Validation with wind tunnel measurements and analysis of physical and numerical diffusion effects. Journal of Wind Engineering and Industrial Aerodynamics, 104-106: 408-418.

Reinartz A, Renz U (1984). Calculations of the temperature and flow field in a room ventilated by a radial air distributor. International Journal of Refrigeration, 7: 308-312.

Reynolds O (1895). On the dynamical theory of incompressible viscous fluids and the determination of the criterion. Philosophical Transactions of the Royal Society of London. A, 186: 123-164.

Ricci A, Burlando M, Freda A, Repetto MP (2017a). Wind tunnel measurements of the urban boundary layer development over a historical district in Italy. Building and Environment, 111: 192-206.

Ricci A, Kalkman I, Blocken B, Burlando M, Freda A, Repetto MP (2017b). Local-scale forcing effects on wind flows in an urban environment: Impact of geometrical simplifications. Journal of Wind Engineering and Industrial Aerodynamics, 170: 238-255.

Richards PJ, Hoxey RP (1992). Computational and wind tunnel modelling of mean wind loads on the Silsoe structures building. Journal of Wind Engineering and Industrial Aerodynamics, 43: 1641-1652. 
Richards PJ, Hoxey RP (1993). Appropriate boundary conditions for computational wind engineering models using the $k-\varepsilon$ turbulence model. Journal of Wind Engineering and Industrial Aerodynamics, 46-47: 145-153.

Richards PJ, Mallinson GD, McMillan D, Li YF (2002). Pedestrian level wind speeds in downtown Auckland. Wind and Structures, 5: 151-164.

Richards PJ, Norris SE (2011). Appropriate boundary conditions for computational wind engineering models revisited. Journal of Wind Engineering and Industrial Aerodynamics, 99: 257-266.

Richardson LF (1908). A freehand graphic way of determining stream lines and equipotentials. Proceedings of the Physical Society of London, 21: 88-124.

Richardson LF (1922). Weather Prediction by Numerical Process. Cambridge, UK: The University Press.

Richardson LF (1926). Atmospheric diffusion shown on a distanceneighbour graph. Proceedings of the Royal Society of London. Series A, 110: 709-737.

Richardson LF (1929). A search for the law of atmospheric diffusion. Beiträge zur Physik der freien Atmosphäre, 15: 24-29.

Roache PJ, Ghia KN, White F (1986). Editorial policy statement on the control of numerical accuracy. Journal of Fluids Engineering, 108: 2.

Roache PJ (1994). Perspective: A method for uniform reporting of grid refinement studies. Journal of Fluids Engineering, 116: 405-413.

Roache PJ (1997). Quantification of uncertainty in computational fluid dynamics. Annual Review of Fluid Mechanics, 29: 123-160.

Robins AG, Castro IP (1977a). A wind tunnel investigation of plume dispersion in the vicinity of a surface mounted Cube. 1 . The flow field. Atmospheric Environment, 11: 291-297.

Robins AG, Castro IP (1977b). A wind tunnel investigation of plume dispersion in the vicinity of a surface mounted Cube. 2 . The concentration field. Atmospheric Environment, 11: 299-311.

Robson BJ, Hamilton DP, Webster IT, Chan T (2008). Ten steps applied to development and evaluation of process-based biogeochemical models of estuaries. Environmental Modelling \& Software, 23: 369-384.

Rodi W (1997). Comparison of LES and RANS calculations of the flow around bluff bodies. Journal of Wind Engineering and Industrial Aerodynamics, 69-71: 55-75.

Rossi R, Iaccarino G (2013). Numerical analysis and modeling of plume meandering in passive scalar dispersion downstream of a wall-mounted cube. International Journal of Heat and Fluid Flow, 43: $137-148$.

Roy CJ (2005). Review of code and solution verification procedures for computational simulation. Journal of Computational Physics, 205: 131-156.

Roy CJ, Oberkampf WL (2010). A complete framework for verification, validation, and uncertainty quantification in scientific computing. In: Proceedings of the 48th AIAA Aerospace Sciences Meeting, Orlando, FL, USA.

Sakamoto Y, Matsuo Y (1980). Numerical predictions of threedimensional flow in a ventilated room. Applied Mathematical Modelling, 4: 67-72.

Salizzoni P, Soulhac L, Mejean P (2009). Street canyon ventilation and atmospheric turbulence. Atmospheric Environment, 43: 5056-5067.

Sasaki R, Uematsu Y, Yamada M, Saeki H (1997). Application of infrared thermography and a knowledge-based system to the evaluation of the pedestrian-level wind environment around buildings. Journal of Wind Engineering and Industrial Aerodynamics, 67-68: 873-883.

Scaperdas A, Gilham S (2004). Thematic Area 4: Best practice advice for civil construction and HVAC. The QNET-CFD Network Newsletter, 2(4): 28-33.

Schatzmann M, Lohmeyer A, Ortner G (1987). Flue gas discharge from cooling towers. Wind tunnel investigation of building downwash effects on ground-level concentrations. Atmospheric Environment, 21: $1713-1724$.

Schatzmann M, Rafailidis S, Pavageau M (1997). Some remarks on the validation of small-scale dispersion models with field and laboratory data. Journal of Wind Engineering and Industrial Aerodynamics, 67-68: 885-893.

Schatzmann M, Leitl B (2011). Issues with validation of urban flow and dispersion CFD models. Journal of Wind Engineering and Industrial Aerodynamics, 99: 169-186.

Selvam RP (1997). Computation of pressures on Texas Tech University building using large eddy simulation. Journal of Wind Engineering and Industrial Aerodynamics, 67-68: 647-657.

Shah KB, Ferziger JH (1997). A fluid mechanicians view of wind engineering: Large eddy simulation of flow past a cubic obstacle. Journal of Wind Engineering and Industrial Aerodynamics, 67-68: 211-224.

Shih TH, Liou WW, Shabbir A, Yang Z, Zhu J (1995). A new $k$ - $\varepsilon$ eddy viscosity model for high Reynolds number turbulent flows. Computers \& Fluids, 24: 227-238.

Simiu E, Scanlan RH (1986). Wind Effects on Structures. An introduction to Wind Engineering, 2nd edn. New York: John Wiley \& Sons.

Smagorinsky J (1963). General circulation experiments with the primitive equations I. The basic experiment. Monthly Weather Review, 91(3): 99-164.

Sommerfeld M, van Wachem B, Oliemans R (2008). Best practice guidelines for computational fluid dynamics of dispersed multiphase flows. ERFOCTAC (European Research Community on Flow, Turbulence and Combustion). Version 1.

Song CCS, He J (1993). Computation of wind flow around a tall building and the large-scale vortex structure. Journal of Wind Engineering and Industrial Aerodynamics, 46-47: 219-228.

Sørensen DN, Nielsen PV (2003). Quality control of computational fluid dynamics in indoor environments. Indoor Air, 13: 2-17.

Spalart P, Allmaras S (1992). A one-equation turbulence model for aerodynamic flows. In: Proceedings of the 30th Aerospace Sciences Meeting and Exhibit, Reno, NV, USA.

Stathopoulos T (1984). Design and fabrication of a wind tunnel for building aerodynamics. Journal of Wind Engineering and Industrial Aerodynamics, 16: 361-376.

Stathopoulos T, Storms R (1986). Wind environmental conditions in passages between buildings. Journal of Wind Engineering and Industrial Aerodynamics, 24: 19-31. 
Stathopoulos T, Zhou YS (1993). Numerical simulation of windinduced pressures on buildings of various geometries. Journal of Wind Engineering and Industrial Aerodynamics, 46-47: 419-430.

Stathopoulos T, Baskaran A (1990). Boundary treatment for the computation of three-dimensional turbulent conditions around a building. Journal of Wind Engineering and Industrial Aerodynamics, 35: 177-200.

Stathopoulos T, Baskaran A (1996). Computer simulation of wind environmental conditions around buildings. Engineering Structures, 18: 876-885.

Stathopoulos T (1997). Computational Wind Engineering: Past achievements and future challenges. Journal of Wind Engineering and Industrial Aerodynamics, 67-68: 509-532.

Stathopoulos $\mathrm{T}$ (2002). The numerical wind tunnel for industrial aerodynamics: Real or virtual in the new millennium? Wind and Structures, 5: 193-208.

Summers DM, Hanson T, Wilson CB (1986). Validation of a computer simulation of wind flow over a building model. Building and Environment, 21: 97-111.

Surry D (1991). Pressure measurements on the Texas Tech building: Wind tunnel measurements and comparisons with full scale. Journal of Wind Engineering and Industrial Aerodynamics, 38: 235-247.

Takakura S, Suyama Y, Aoyama M (1993). Numerical simulation of flowfield around buildings in an urban area. Journal of Wind Engineering and Industrial Aerodynamics, 46-47: 765-771.

Tamura T, Kawai H, Kawamoto S, Nozawa K, Sakamoto S, Ohkuma $\mathrm{T}$ (1997). Numerical prediction of wind loading on buildings and structures-Activities of AIJ cooperative project on CFD. Journal of Wind Engineering and Industrial Aerodynamics, 67-68: 671-685.

Tamura T, Nozawa K, Kondo K (2008). AIJ guide for numerical prediction of wind loads on buildings. Journal of Wind Engineering and Industrial Aerodynamics, 96: 1974-1984.

Tapsoba M, Moureh J, Flick D (2007). Airflow patterns in a slotventilated enclosure partially loaded with empty slotted boxes. International Journal of Heat and Fluid Flow, 28: 963-977.

Thomas LP, Marino BM, Tovar R, Castillo JA (2011). Flow generated by a thermal plume in a cooled-ceiling system. Energy and Buildings, 43: 2727-2736.

Tian ZF, Tu JY, Yeoh GH, Yuen RKK (2007). Numerical studies of indoor airflow and particle dispersion by large eddy simulation. Building and Environment, 42: 3483-3492.

Tieleman HW, Reinhold TA, Marshall RD (1978). Wind tunnel simulation of atmospheric surface layer for the study of wind loads on low-rise buildings. Journal of Wind Engineering and Industrial Aerodynamics, 3: 21-38.

Timmons MB, Albright LD, Furry RB, Torrance KE (1980). Experimental and numerical study of air movement in slot ventilated enclosures. ASHRAE Transactions, 86(1): 221-240.

To AP, Lam KM (1995). Evaluation of pedestrian-level wind environment around a row of tall buildings using a quartile-level wind speed descripter. Journal of Wind Engineering and Industrial Aerodynamics, 54-55: 527-541.
Toja-Silva F, Chen J, Hachinger S, Hase F (2017). CFD simulation of $\mathrm{CO}_{2}$ dispersion from urban thermal power plant: Analysis of turbulent Schmidt number and comparison with Gaussian plume model and measurements. Journal of Wind Engineering and Industrial Aerodynamics, 169: 177-193.

Tominaga Y, Murakami S, Mochida A (1997). CFD prediction of gaseous diffusion around a cubic model using a dynamic mixed SGS model based on composite grid technique. Journal of Wind Engineering and Industrial Aerodynamics, 67-68: 827-841.

Tominaga Y, Stathopoulos T (2007). Turbulent Schmidt numbers for CFD analysis with various types of flowfield. Atmospheric Environment, 41: 8091-8099.

Tominaga Y, Mochida A, Yoshie R, Kataoka H, Nozu T, Yoshikawa M, Shirasawa T (2008a). AIJ guidelines for practical applications of CFD to pedestrian wind environment around buildings. Journal of Wind Engineering and Industrial Aerodynamics, 96: 1749-1761.

Tominaga Y, Mochida A, Murakami S, Sawaki S (2008b). Comparison of various revised $k-\varepsilon$ models and LES applied to flow around a high-rise building model with 1:1:2 shape placed within the surface boundary layer. Journal of Wind Engineering and Industrial Aerodynamics, 96: 389-411.

Tominaga Y, Stathopoulos T (2009). Numerical simulation of dispersion around an isolated cubic building: Comparison of various types of $k$ - $\varepsilon$ models. Atmospheric Environment, 43: 3200-3210.

Tominaga Y, Stathopoulos T (2010). Numerical simulation of dispersion around an isolated cubic building: Model evaluation of RANS and LES. Building and Environment, 45: 2231-2239.

Tominaga Y, Stathopoulos T (2013). CFD simulation of near-field pollutant dispersion in the urban environment: A review of current modeling techniques. Atmospheric Environment, 79: 716-730.

Tominaga Y (2015). Flow around a high-rise building using steady and unsteady RANS CFD: Effect of large-scale fluctuations on the velocity statistics. Journal of Wind Engineering and Industrial Aerodynamics, 142: 93-103.

Tominaga Y, Sato Y, Sadohara S (2015). CFD simulations of the effect of evaporative cooling from water bodies in a micro-scale urban environment: Validation and application studies. Sustainable Cities and Society, 19: 259-270.

Tominaga Y, Blocken B (2015). Wind tunnel experiments on cross-ventilation flow of a generic building with contaminant dispersion in unsheltered and sheltered conditions. Building and Environment, 92: 452-461.

Tominaga Y, Blocken B (2016). Wind tunnel analysis of flow and dispersion in cross-ventilated isolated buildings: Impact of opening positions. Journal of Wind Engineering and Industrial Aerodynamics, 155: 74-88.

Tominaga Y, Stathopoulos T (2016). Ten questions concerning modeling of near-field pollutant dispersion in the built environment. Building and Environment, 105: 390-402.

Tominaga Y, Stathopoulos T (2017). Steady and unsteady RANS simulations of pollutant dispersion around isolated cubical buildings: Effect of large-scale fluctuations on the concentration field. Journal of Wind Engineering and Industrial Aerodynamics, 165: 23-33. 
Toparlar Y, Blocken B, Vos P, van Heijst GJF, Janssen WD, van Hooff T, Montazeri H, Timmermans HJP (2015). CFD simulation and validation of urban microclimate: A case study for Bergpolder Zuid, Rotterdam. Building and Environment, 83: 79-90.

Toparlar Y, Blocken B, Maiheu B, van Heijst GJF (2017). A review on the CFD analysis of urban microclimate. Renewable and Sustainable Energy Reviews, 80: 1613-1640.

Toparlar Y, Blocken B, Maiheu B, van Heijst GJF (2018). The effect of an urban park on the microclimate in its vicinity: A case study for Antwerp, Belgium. International Journal of Climatology, 38: e303-e322.

Tsang CW, Kwok KCS, Hitchcock PA (2012). Wind tunnel study of pedestrian level wind environment around tall buildings: Effects of building dimensions, separation and podium. Building and Environment, 49: 167-181.

Tucker PG, Mosquera A (2001). NAFEMS introduction to grid and mesh generation for CFD. NAFEMS CFD Working Group, R0079.

Uematsu Y, Yamada M, Higashiyama H, Orimo T (1992). Effects of the corner shape of high-rise buildings on the pedestrian-level wind environment with consideration for mean and fluctuating wind speeds. Journal of Wind Engineering and Industrial Aerodynamics, 44: 2289-2300.

van Hooff T, Blocken B (2010a). Coupled urban wind flow and indoor natural ventilation modelling on a high-resolution grid: A case study for the Amsterdam ArenA stadium. Environmental Modelling \& Software, 25: 51-65.

van Hooff T, Blocken B (2010b). On the effect of wind direction and urban surroundings on natural ventilation of a large semienclosed stadium. Computers \& Fluids, 39: 1146-1155.

van Hooff T, Blocken B, Defraeye T, Carmeliet J, van Heijst GJF (2012a). PIV measurements and analysis of transitional flow in a reduced-scale model: Ventilation by a free plane jet with Coanda effect. Building and Environment, 56: 301-313.

van Hooff T, Blocken B, Defraeye T, Carmeliet J, van Heijst GJF (2012b). PIV measurements of a plane wall jet in a confined space at transitional slot Reynolds numbers. Experiments in Fluids, 53: 499-517.

van Hooff T, Blocken B (2013). CFD evaluation of natural ventilation of indoor environments by the concentration decay method: $\mathrm{CO}_{2}$ gas dispersion from a semi-enclosed stadium. Building and Environment, 61: 1-17.

van Hooff T, Blocken B, Tominaga Y (2017). On the accuracy of CFD simulations of cross-ventilation flows for a generic isolated building: comparison of RANS, LES and experiments. Building and Environment, 114: 148-165.

Vasilic-Melling D (1977). Three dimensional turbulent flow past rectangular bluff bodies, $\mathrm{PhD}$ Thesis, Imperial College of Science and Technology, UK.

Verkaik JW (2006). On wind and roughness over land. PhD Thesis, Wageningen University, the Netherlands.

Visser GT, Cleijne JW (1994). Wind comfort predictions by wind tunnel tests: Comparison with full-scale data. Journal of Wind Engineering and Industrial Aerodynamics, 52: 385-402.
Wang M, Chen Q (2009). Assessment of various turbulence models for transitional flows in an enclosed environment. $H V A C \& R$ Research, 15: 1099-1119.

Wang M, Lin CH, Chen Q (2012). Advanced turbulence models for predicting particle transport in enclosed environments. Building and Environment, 47: 40-49.

Wang W, Xu Y, Ng E (2018a). Large-eddy simulations of pedestrianlevel ventilation for assessing a satellite-based approach to urban geometry generation. Graphical Models, 95: 29-41.

Wang W, Xu Y, Ng E, Raasch S (2018b). Evaluation of satellitederived building height extraction by CFD simulations: A case study of neighborhood-scale ventilation in Hong Kong. Landscape and Urban Planning, 170: 90-102.

Waters R (1986). Air movement studies. Clean Room Design Seminar, Institution of Mechanical Engineers (IMechE), London.

Westbury PS, Miles SD, Stathopoulos T (2002). CFD application on the evaluation of pedestrian-level winds. In: Proceedings of Cost Action C14, Impact of Wind and Storm on City Life and Built Environment, Nantes, France.

Whittle GE (1987). Numerical air flow modelling. BSRIA Technical Note TN 2/8, Bracknell, UK.

Wilcox DC (2004). Turbulence Modelling for CFD, 2nd edn. La Cañada, CA, USA: DCW Industries.

Wiren BG (1975). A wind tunnel study of wind velocities in passages between and through buildings, In: Proceedings of the 4th International Conference on Wind Effects on Buildings and Structures, Heathrow, UK, pp. 465-475.

Wright NG, Easom GJ, Hoxey RJ (2001). Development and validation of a non-linear $k-\varepsilon$ model for flow over a full-scale building. Wind and Structures, 4: 177-196.

Wright NG, Hargreaves DM (2006). Unsteady CFD Simulations for natural ventilation. International Journal of Ventilation, 5: 13-20.

$\mathrm{Wu} \mathrm{H}$, Stathopoulos T (1994). Further experiments on Irwin's surface wind sensor. Journal of Wind Engineering and Industrial Aerodynamics, 53: 441-452.

Wu H, Stathopoulos T (1997). Application of infrared thermography for pedestrian wind evaluation. Journal of Engineering Mechanics, 123: 978-985.

Wu W, Zhai J, Zhang G, Nielsen PV (2012). Evaluation of methods for determining air exchange rate in a naturally ventilated dairy cattle building with large openings using computational fluid dynamics (CFD). Atmospheric Environment, 63: 179-188.

Yakhot V, Orszag SA (1986). Renormalization group analysis of turbulence, I. Basic theory. Journal of Scientific Computing, 1: $3-51$.

Yamada T, Meroney RN (1972). Numerical and wind tunnel simulation of airflow over an obstacle. In: Proceedings of National Conference on Atmospheric Waves, Salt Lake City, USA.

Yang Y, Gu M, Chen S, Jin X (2009). New inflow boundary conditions for modelling the neutral equilibrium atmospheric boundary layer in computational wind engineering. Journal of Wind Engineering and Industrial Aerodynamics, 97: 88-95. 
Yang AS, Juan YH, Wen CY, Chang CJ (2017). Numerical simulation of cooling effect of vegetation enhancement in a subtropical urban park. Applied Energy, 192: 178-200.

Yasa E (2016). Computational evaluation of building physics-The effect of building form and settled area, microclimate on pedestrian level comfort around buildings. Building Simulation, 9: 489-499.

Yim SHL, Fung JCH, Lau AKH, Kot SC (2009). Air ventilation impacts of the "wall effect" resulting from the alignment of high-rise buildings. Atmospheric Environment, 43: 4982-4994.

Yoshie R, Mochida A, Tominaga Y, Kataoka H, Harimoto K, Nozu T, Shirasawa T (2007). Cooperative project for CFD prediction of pedestrian wind environment in the Architectural Institute of Japan. Journal of Wind Engineering and Industrial Aerodynamics, 95: 1551-1578.

Yu H, Liao C-M, Liang H-M, Chiang K-C (2007). Scale model study of airflow performance in a ceiling slot-ventilated enclosure: Non-isothermal condition. Building and Environment, 42: 1142-1150.
Yuan C, Ng E (2014). Practical application of CFD on environmentally sensitive architectural design at high density cities: A case study in Hong Kong. Urban Climate, 8: 57-77.

Zhai Z, Zhang Z, Zhang W, Chen Q (2007). Evaluation of various turbulence models in predicting airflow and turbulence in enclosed environments by CFD: part-1: Summary of prevalent turbulence models. HVAC\&R Research, 13: 853-870.

Zhang Z, Zhang W, Zhai Z, Chen Q (2007). Evaluation of various turbulence models in predicting airflow and turbulence in enclosed environments by CFD: part-2: Comparison with experimental data from literature. HVAC\&R Research, 13: 871-886.

Zhang W, Chen Q (2000a). Large eddy simulation of indoor airflow with a filtered dynamic subgrid scale model. International Journal of Heat and Mass Transfer, 43: 3219-3231.

Zhang W, Chen Q (2000b). Large eddy simulation of natural and mixed convection airflow indoors with two simple filtered dynamic subgrid scale models. Numerical Heat Transfer, Part A: Applications, 37: 447-463. 